\title{
Modigliani Meets Minsky: Inequality, Debt, and Financial Fragility in America, 1950-2016
}

\author{
Alina K. Bartscher ${ }^{\dagger}$, Moritz Kuhn", Moritz Schularick ${ }^{\S}$ \\ and Ulrike I. Steins
}

\section{Working Paper No. 124}

April 28, 2020

\begin{abstract}
This paper studies the secular increase in U.S. household debt and its relation to growing income inequality and financial fragility. We exploit a new household-level dataset that covers the joint distributions of debt, income, and wealth in the United States over the past seven decades. The data show that increased borrowing by middle-class families with low income growth played a central role in rising indebtedness. Debt-to-income ratios have risen most dramatically for households between the 50th and 90th percentiles of the income distribution. While their income growth was low, middle-class families borrowed against the sizable housing wealth gains from rising home prices. Home equity borrowing accounts for about half of the increase in U.S. household debt between the 1970s and 2007. The resulting debt increase made balance sheets more sensitive to income and house price fluctuations and turned the American middle class into the epicenter of growing financial fragility.

\footnotetext{
† University of Bonn, Adenauerallee 24-42, 53113 Bonn, Germany, alina.bartscher@uni-bonn.de

*University of Bonn, CEPR, and IZA, Adenauerallee 24-42, 53113 Bonn, Germany, mokuhn@uni- bonn.de

$\S$ Federal Reserve Bank of New York and University of Bonn, CEPR, Adenauerallee 24-42, 53113 Bonn, Germany, schularick@uni-bonn.de

I University of Bonn, Adenauerallee 24-42, 53113 Bonn, Germany, ulrike.steins@uni-bonn.de
} 
JEL Codes: E21, E44, D14, D31

Keywords: household debt, inequality, household portfolios, financial fragility

\section{https://doi.org/10.36687/inetwp124}

Acknowledgements: We thank participants of seminars at the University of Chicago Booth School of Business, Cambridge University, SciencesPo, the Wharton School at the University of Pennsylvania, and the Bundesbank, as well as Stefania Albanesi, Luis Bauluz, Christian Bayer, Tobias Berg, David Berger, Douglas W. Diamond, Karen Dynan, Eugene Fama, Olivier Godechot, Ethan Ilzetzki, Oscar Jorda, Anna Kovner, Dirk Krüger, Felix Kubler, Yueran Ma, Costas Meghir, Atif Mian, Stefan Nagel, Stijn van Nieuwerbergh, Filip Novokmet, Thomas Piketty, Raghuram Rajan, Morten Ravn, José-Víctor Ríos-Rull, Kenneth Snowden, Ludwig Straub, Amir Sufi, Alan Taylor, Sascha Steffen, Gianluca Violante, Joseph Vavra, Paul Wachtel, Nils Wehrhöfer, Eugene White, and Larry White. Lukas Gehring provided outstanding research assistance. Schularick is a Fellow of the Institute for New Economic Thinking. He acknowledges support from the European Research Council Grant (ERC-2017-COG 772332), and from the Deutsche Forschungsgemeinschaft (DFG) under Germany's Excellence Strategy - EXC 2126/1-39083886, as well as a Fellowship from the Initiative on Global Markets at the University of Chicago Booth School of Business. Kuhn thanks the Federal Reserve Bank of Minneapolis. The views expressed herein are solely the responsibility of the authors and should not be interpreted as reflecting the views of the Federal Reserve Bank of New York or the Board of Governors of the Federal Reserve System. 


\section{Introduction}

The rising indebtedness of U.S. households is a much-debated phenomenon. The numbers are eye-catching. Between 1950 and the 2008 financial crisis, American household debt has grown fourfold relative to income. In 2010, the household debt-to-income ratio peaked at close to $120 \%$, up from $30 \%$ on the eve of World War II. Figure 1 shows the trajectory of this secular increase over the past seven decades. The underlying drivers of the process, however, remain controversial.

Rising income inequality is frequently invoked as an important factor. The line with circles in Figure 1 shows that the share of the richest $10 \%$ of households in total household income increased from below 35\% to almost 50\% between 1950 and 2016. Rajan's (2011) influential book Fault Lines popularized the view that growing income inequality and indebtedness are two sides of the same coin. The idea is that households with stagnant incomes have increasingly relied on debt to finance consumption - whether out of sheer necessity to "get by" or to "keep up with the Joneses" at the top of the income distribution, whose incomes were growing nicely (cf. Fligstein, Hastings, and Goldstein 2017). A recent paper by Mian, Straub, and Sufi (2019) discusses how rising income concentration at the top brought about a "savings glut of the rich" that supplied the funds for increased borrowing by non-rich households.

But we still know surprisingly little about the borrowers and their financial situation. From the borrowers' perspective, the financial history of the growth of U.S. household debt and its distribution remains largely unwritten. This paper closes this gap. We study

Figure 1: Debt-to-income ratio and top 10\% income share, 1950-2016

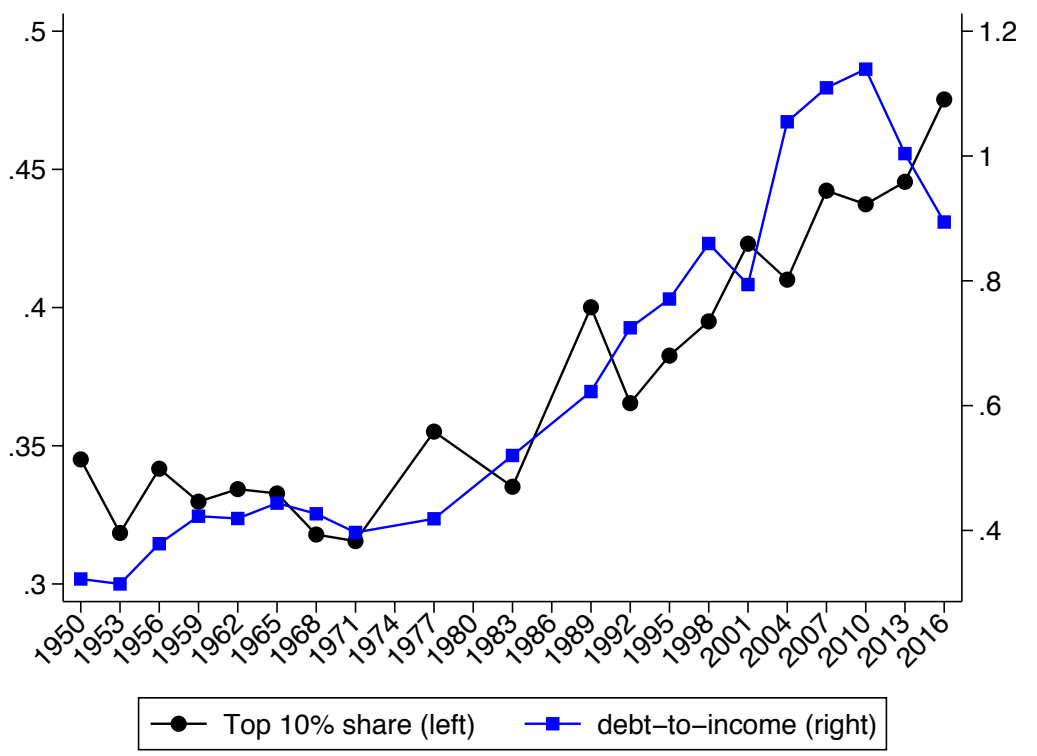

Notes: The graph shows the share of the top $10 \%$ of the income distribution (left axis) and the household debt-to-income ratio (right axis) over time. 
the dynamics of household debt over the entire postwar period, asking which households borrowed so much more, and why. Without long-run household-level data for the joint distributions of income, debt, and assets, this task would be daunting. However, we can rely on a new dataset that combines historical waves of the Survey of Consumer Finances (SCF), going back to 1949, with the modern SCF that the Federal Reserve Board has administered since 1983 (see Kuhn, Schularick, and Steins forthcoming). This long-run "SCF+" makes it possible to follow the evolution of household borrowing across the entire income distribution over seven decades. Where needed, we also combine information from the cross-sectional SCF + data with data from the Panel Study of Income Dynamics (PSID), which has provided panel data on housing wealth and mortgage since 1968.

The data support the much-discussed association between rising income inequality and increased borrowing. Debt growth was concentrated among households with low income growth. Debt-to-income ratios have risen most dramatically for households whose share in aggregate income has fallen. Middle-class households, defined here as households between the 50th and 90th percentiles of the income distribution, account for most of the debt growth. Higher borrowing by middle-class households accounts for $55 \%$ of the total increase in household debt since 1950. By contrast, households in the bottom $50 \%$ of the income distribution account for a relatively small share of the total debt increase (15\%). While their debt-to-income ratio has risen, too, their share in total debt has fallen. The American household debt boom of the past decades is first and foremost a middle-class affair.

The transformation of middle-class balance sheets in the past four decades was comprehensive. Adjusting by the consumer price index (CPI), the average incomes of households in the 50th to 90th percentiles of the income distribution have grown by about $25 \%$ since the 1970s, or less than half a percent per year. Over the same period, the amount of debt acquired by these households grew by $250 \%$ until the 2008 crisis, about ten times faster than their incomes. A similar picture emerges for households below the median of the income distribution. Here, income growth was barely positive in CPI-adjusted terms between 1971 and 2007, but debt grew by a factor of almost ten at the median. This association between low income growth and high borrowing is puzzling. In standard economic logic, households are typically expected to borrow against the expectation of higher, not lower or stagnant, future income.

How can one rationalize this behavior? Here the strength of the SCF + data with respect to its comprehensive coverage of the entire household balance sheet comes into play and leads to an important insight. A plausible suspicion would be that with rising debt, the net wealth of middle-class households decreased. After all, the liability side of the typical middle-class balance sheet grew substantially. Yet this is not the case. The net wealth position of middle-class households actually improved. Households borrowed more, but at the same time became (wealth-) richer. Simple balance sheet accounting dictates that this 
result is possible only if the value of household assets increased even faster than household debt. In the absence of a substantial increase in savings out of stagnant incomes, this can happen only if the value of existing assets rises. The explanation for the U.S. household debt boom that we put forward in this paper builds on this disconnect between income and asset growth that is evident in the $\mathrm{SCF}+$.

The housing market played the central role in this process. We will show that owing to their high exposure to house prices, middle-class American families made sizable wealth gains when their main asset, residential real estate, appreciated in price. In inflationadjusted terms, quality-adjusted house prices in the United States increased by $75 \%$ between the mid-1970s and the mid-2000s. Housing wealth-to-income ratios of middleclass households more than doubled from $140 \%$ of income to $300 \%$ in 2007, with price effects alone accounting for close to $50 \%$ of this increase. In other words, the income growth of middle-class households was low, but at the same time, their housing wealth grew strongly. Wealth-to-income ratios increased even more for these households relative to those at the top.

From here, our analysis essentially follows the logic of the canonical Modigliani life-cycle model (Modigliani and Brumberg 1954). When middle-class households racked up sizable gains in housing wealth, they used debt to turn higher lifetime wealth into additional expenditures. We show that the combined effects of home equity extraction through refinancing, HELOCs, and second mortgages were quantitatively large and explain a substantial share of the increase in household debt since the 1970s. Debt is key for the response to the wealth shock because housing is a peculiar asset. A key characteristic is that it is indivisible, meaning it cannot be sold in small increments, unlike, for instance, equities. When the stock market rises, households can sell some shares and use the proceeds for consumption. Turning housing wealth gains into additional expenditures (while continuing to live in the same house) is possible only by taking on debt.

The PSID contains data on housing wealth and mortgages that allow us to identify homeequity-extracting households and quantify the aggregate effects of home-equity-based borrowing since the 1980s. Using the PSID, we decompose the debt increase into additional debt incurred by extractors, new homeowners, and upgraders moving to larger homes. We find that home-equity-based borrowing against existing owner-occupied real estate accounts for around $50 \%$ of the increase in housing debt since the 1980s. From the early 1980 s to the 2008 crisis, equity extraction alone pushed the household debt-to-income ratio up by more than 30 percentage points.

Without equity extraction, the housing debt-to-income ratio would have stayed at around $50 \%$ of income until 2008. Home equity extraction averaged around $1.5 \%$ of annual income until the mid-1980s and rose to around $4.5 \%$ thereafter. Over a twenty-year period, the cumulative effects of additional equity extraction were substantial. Importantly, we find 
that home-equity-based borrowing was responsible for a significant fraction of the rise in U.S. household debt even before the extraction boom of the 2000s, which has been studied by Greenspan and Kennedy (2008), Klyuev and Mills (2007), and Mian and Sufi (2011), among others. This is consistent with the findings of Guren et al. (2018), who report substantial housing wealth effects even since the 1980s.

Stratifying equity extraction by income groups, we show that about half of total homeequity-based borrowing is accounted for by middle-class households (50\%-90\%). Local projections at the state level not only confirm a close association between house prices and equity extraction but also corroborate a higher elasticity of equity extraction to house prices for middle-class households whose portfolios are most concentrated in housing and more strongly leveraged.

A large share of the increase in household debt can be rationalized as a Modigliani-style response of middle-class households to capital gains they made in housing markets. We will show that the observed equity extraction is qualitatively and quantitatively in line with the predictions of recent models such as Berger et al. (2017). In their model, a consumption response to housing wealth gains arises as soon as the strict assumptions that underlie the model in Sinai and Souleles (2005) are relaxed. ${ }^{1}$

The intuition for the positive response is straightforward. When homeowners make capital gains in the housing market, they are richer than they expected when originally making their financial planning decisions. As housing is indivisible, households need to liquidate some of their home equity if they want to smooth consumption over time. In principle, households could also sell their house and buy a new one. However, this would involve substantial transaction, search, and potentially also emotional costs (see Aladangady 2017), and few households do this in practice, as the PSID shows. The remaining option is to engage in negative savings (equity extraction) after the deviation from the life-cycle wealth profile. Importantly, the reason for the house price increase is irrelevant, as long as it was unexpected when financial plans were being made, and is assumed to persist.

Empirical evidence for recent years supports the theoretical argument that housing wealth effects are substantial. Based on matched microdata, Aladangady (2017) estimates a causal effect of house prices on consumption of around 5 cents per dollar increase of home value. Mian and Sufi (2014) explicitly consider the response of household debt to

\footnotetext{
${ }^{1}$ Sinai and Souleles (2005) argue that if houses are handed from generation to generation, and there is no mobility and adjustment in housing size, then housing tenure becomes infinite and house price changes will not affect household consumption. Yet in the presence of life-cycle variation in housing size, contemporaneous ownership of housing of parent and children generations, or imperfectly correlated local housing markets and household mobility, rising housing wealth triggers consumption responses of homeowners also in their model. The positive net response in Berger et al. (2017) also results from an additional substitution effect that Sinai and Souleles (2005) rule out by construction. Berger et al. (2017) interpret the net effect as an endowment effect with income, substitution, and collateral effects canceling out. Campbell and Cocco (2007) also discuss the result from Sinai and Souleles (2005) and argue that changing life-cycle housing demand leads to an age-varying endowment effect from house price shocks.
} 
house price shocks. They exploit regional heterogeneity in the United States and also find substantial effects that can be rationalized in the context of recent models with liquidity-constrained consumers, such as Kaplan and Violante (2014).

Taken together, these findings lead us to a more nuanced interpretation of the postwar household debt boom. It is true that middle-class families with low average income growth were chiefly responsible for increased borrowing. It is also true that these households relied on debt to finance consumption in the face of stagnant incomes. But they could do so because they had become richer, at least for the time being. It is obviously possible that households, in particular during the later years of the boom of the 2000s, mistakenly treated house price increases as persistent when they were not.

Note that this history of household debt in America is compatible with the idea of a savings glut, arising either from global factors (Bernanke 2005) or from growing income concentration at the top (Mian, Straub, and Sufi 2019), which lowered interest rates, loosened borrowing constraints, and increased housing values. Our analysis does not speak to the initial trigger of this process. Rising income inequality might well have played a role as argued by Mian, Straub, and Sufi (2020). The argument we make is that once the house price increase was under way, home-owning middle-class households made large wealth gains and turned those wealth gains into spending via home-equitybased borrowing without a deterioration in net worth. Clearly, the fact that interest rates kept on falling despite rising borrowing volumes meshes nicely with the idea of a creditsupply-driven household debt boom. We discuss the importance of enabling factors such as financial deregulation and the 1986 tax reform, which maintained interest deductibility for mortgages and thereby created incentives to switch to home-equity-based products. Story (2008) describes how banks heavily advertised these new products in the 1980s with catchphrases such as "Now, when the value of your home goes up, you can take credit for it."

In the last part of the paper, we discuss how this rational response of Modigliani households leads to a more fragile macroeconomy. Home-equity-based borrowing may be optimal from an individual household's point of view, but in the process balance sheets are extended and become more sensitive to shocks. We document this "Minsky" aspect of the debt buildup by conducting a quantitative assessment of household balance sheets akin to stress test for banks, similar to Fuster, Guttman-Kenney, and Haughwout (2018). We trace the results of this stress test over seven decades of postwar history and show the increased vulnerability of households. This finding connects our paper to a lively research agenda concerned with the effects of shocks to household balance sheets on macroeconomic activity (see, e.g., Mian and Sufi 2009, Mian and Sufi 2017, and Jordà, Schularick, and Taylor 2013), as well as the interactions between housing and credit markets (Guerrieri and Uhlig 2016). 
In any given year, we "shock" households with an exogenous income decline based on estimates for earnings losses in recessions from Davis and von Wachter (2011). We then construct a measure for the total value of mortgage debt that is owed by "at risk" households whose liquidity is severely weakened after the shock. Following the literature, we define households as being at risk if their debt-service ratio crosses $40 \%$ of income.

Across the stress scenarios, the increase in financial fragility, measured by the value of loans at risk, turns out to be sizable, especially for middle-class households. From the 1950s to the 1970s, the value of outstanding mortgage debt that was at risk following an income shock increased fivefold in the aggregate but eightfold for the middle class. The middle class, we conclude, turned from being an anchor of financial stability to being the epicenter of financial risk in the U.S. economy.

Literature: The analysis of household balance sheets and their importance for the business cycle and financial fragility has become an active research field for macroeconomists (Mian and Sufi 2014, 2017, Zinman 2015, Jordà, Schularick, and Taylor 2013, Adelino, Schoar, and Severino (2018), Albanesi, De Giorgi, and Nosal 2017). A large empirical and theoretical literature has examined wealth effects due to house price increases and their consequences for household borrowing and consumption. ${ }^{2}$ Empirical trends in household indebtedness have been discussed in Dynan and Kohn (2007) and Wolff (2010). Dynan and Kohn (2007) provide an early analysis of the 1990s debt boom and discuss potential sources for the rise in indebtedness of U.S. households. They likewise point to the important role of mortgage debt and document its comovement with house prices. Wolff (2010) provides a broader perspective on the change in household finances, which emphasizes the rise in middle-class debt since 1983.

Regarding house prices and credit conditions, several important papers have traced house price increases to regulatory changes since the 1980s (e.g., Hoffmann and Stewen 2019, Favara and Imbs 2015, Di Maggio and Kermani 2017). Recent research has also emphasized the link between rising inequality and household borrowing (De Stefani 2018, Mian, Straub, and Sufi 2019). In their influential work, Mian and Sufi $(2009,2011)$ argue that household borrowing in low-income regions of the United States grew particularly strongly before the 2008 crisis and was then followed by severe output and employment losses. In a theoretical model, Kumhof, Rancière, and Winant (2015) show that higher savings of the rich may lead to a decline in interest rates, which leads to higher borrowing by low- and middle-income households and higher financial fragility. However, Coibion et al. (2020) find that low-income households face higher borrowing costs and reduced access to credit as inequality increases. Adelino, Schoar, and Severino (2016) and Albanesi, De Giorgi, and Nosal (2017) provide complementary evidence on the debt boom during the 2000s

\footnotetext{
${ }^{2}$ Iacoviello (2005), Hurst and Stafford (2004), Calomiris, Longhofer, and Miles (2013), Aladangady (2017), Cloyne et al. (2017), Guren et al. (2018), Andersen and Leth-Petersen (2019), Campbell and Cocco (2007), Berger et al. (2017), and Kaplan, Mitman, and Violante (2017) among others.
} 
and highlight the important role of the middle class for the debt boom during these years. Adelino, Schoar, and Severino (2016) also conclude that the growth of middle-class debt played an important role. Similarly, Foote, Loewenstein, and Willen (2016) study debt growth in the early 2000s across the income distribution and discuss the implications for theoretical models of the debt boom. Our study is also linked to work that discusses a policy option to limit the accumulation of excessive leverage when there are externalities on the macro level (Korinek and Simsek 2016, Schmitt-Grohé and Uribe 2016).

The structure of the paper is as follows. We first introduce and discuss the historical SCF data and show that the microdata closely match aggregate trends. Second, we show that the mortgage borrowing of households between the 50th and 90th percentiles of the income distribution accounts for the lion's share of the debt increase. Third, using PSID data, we show that equity extraction in response to higher housing wealth played a central role in the aggregate debt increase. Fourth, we rationalize our empirical findings in the context of a Modigliani life-cycle model. Finally, we turn to the Minsky side of the debt increase and show that, in particular, the financial fragility of middle-class households has risen substantially over time.

\section{Data}

Our paper relies on a new data source that allows us to track the financial history of debt in the United States since World War II along the income distribution. The "SCF+" combines historical waves of the Survey of Consumer Finances (SCF) going back to 1949 with the modern waves available since 1983. The historical files are kept at the InterUniversity Consortium for Political and Social Research (ICPSR).

Kuhn, Schularick, and Steins (forthcoming) give a detailed description of the construction of the SCF+, including demographic details, the coverage of rich households, and its strength in providing the joint distributions of income, assets, and debt. The early surveys were carried out annually between 1947 and 1971 and then again in 1977. We follow Kuhn, Schularick, and Steins (forthcoming) and use data since 1949, which is the first year in which all relevant variables are available, and pool the early waves into three-year bins.

In the following, we will briefly introduce the dataset and discuss how the data match trends from the National Income and Product Accounts (NIPA) and the Financial Accounts (FA). We will also briefly introduce our second main data source, the Panel Study of Income Dynamics (PSID), that we rely on to complement the cross-sectional information from the $\mathrm{SCF}+$ with data that provide a panel dimension.

We complement the microdata with data from the Macrohistory Database (Jordà, Schularick, and Taylor 2017), in particular house prices and the consumer price index (CPI). 
The house price index in the Macrohistory Database is based on the index of Shiller (2009) until 1974 and the repeat sales index of the Federal Housing Finance Agency (FHFA, former OFHEO) since 1975. These indices are designed to filter out changes in the average quality and size of homes (cf. Rappaport 2007). If not explicitly stated otherwise, all presented results are in real terms, converted to 2016 dollars using the CPI.

\subsection{Household debt in the SCF+}

The SCF is a key resource for research on household finances. Data for the modern survey waves after 1983 are readily available from the website of the Board of Governors of the Federal Reserve System. The surveys are conducted every three years by the Federal Reserve Board (see Bricker et al. 2017 for more details). The comprehensiveness and quality of the SCF data explain its popularity among researchers (see Kuhn and RiosRull 2016 and the references therein).

Adding data from the historical surveys results in a dataset that contains household-level information over the entire postwar period and provides detailed demographic information in addition to financial variables. Important for the current analysis, the $\mathrm{SCF}+$ data contain all variables needed to construct long-run series for the evolution of household debt including its sub-components. The SCF + data are weighted with post-stratified cross-sectional weights that ensure representativeness along several socioeconomic characteristics, in particular race, education, age, and homeownership.

Total debt consists of housing and non-housing debt. Several recent papers have stressed the importance of real estate investors for the debt boom prior to 2007 (Haughwout et al. 2011, Bhutta 2015, Mian and Sufi 2018, Albanesi, De Giorgi, and Nosal 2017, DeFusco, Nathanson, and Zwick 2017). Real estate investors are defined as borrowers with multiple first-lien mortgages. While they accounted for a disproportionately large share of mortgage growth before 2007 compared to their relatively small population share, mortgage debt on the principal residence is on average eight times larger than mortgage debt on other real estate (see Appendix Figure A.1). When it comes to housing debt, in this paper we focus only on debt incurred for owner-occupied housing. We treat investment in non-owner-occupied housing like business investment and use the net position only when calculating wealth.

Non-housing debt includes car loans, education loans, and loans for the purchase of other consumer durables. Data on credit card balances become available after 1970 with the introduction and proliferation of credit cards. Note that the appearance of new financial products like credit cards does not impair the construction of consistent data over time. Implicitly, these products are counted as zero for years before their appearance.

The core of our analysis studies the dynamics of debt along the income distribution. 
For this, we calculate total income as the sum of wages and salaries plus income from professional practice and self-employment, rental income, interest, dividends, and transfer payments, as well as business and farm income.

We abstain from any sample selection for most of our analysis. One exception is the decomposition of changes in debt-to-income ratios in Section 3.3. Here we use householdlevel ratios and drop observations with extreme debt-to-income ratios larger than 50 in absolute value. Moreover, we use household-level loan-to-value ratios and debt-serviceto-income ratios in Section 6, after trimming the largest percentage. Our analysis in this part explicitly relies on individual ratios. Otherwise, we use ratios of averages instead of averages of ratios because of their greater robustness to outliers.

\subsection{Panel data from the PSID}

The key strength of the SCF + is that it allows us to study the joint distribution of income and wealth over seven decades. However, the data are in the form of repeated cross sections and thus do not allow us to track individual households over time. As the analysis in Section 4.2 requires a panel dimension, we use data from the PSID. While the $\mathrm{SCF}+$ is at the household level, the PSID is at the family level. Therefore, PSID families living together were aggregated into one household for better comparability (cf. Pfeffer et al. 2016). Additional details are given in Appendix B.

Following Kaplan, Violante, and Weidner (2014), we only use data from the PSID's "Survey Research Center (SRC) sample." Post-stratified cross-sectional survey weights are provided on the PSID web page only for the waves between 1997 and 2003. Therefore, we use the longitudinal family weights provided on the PSID homepage and post-stratify them to match the same Census variables that we targeted in the post-stratification of the historical SCF waves. We verified that all reported results are similar when using the unweighted PSID data or the original longitudinal PSID weights without post-stratification. Figure B.1 in the appendix compares the PSID data to the SCF+. Overall, the two datasets align very well. ${ }^{3}$

\subsection{Aggregate trends in SCF+ and NIPA}

Aggregated household surveys are not always easy to match to data for the macroeconomy. Measurement concepts can differ, such that even high-quality microdata may not match aggregate data one-to-one. To judge the reliability of the $\mathrm{SCF}+$ data, we start by

\footnotetext{
${ }^{3}$ The particular strength of the SCF data is the representation of the top tail of the wealth distribution at the 99th percentile and above. While we do not study these households in detail, we always rely on SCF data for the top tail of the income and wealth distribution.
} 
comparing the aggregate trends in income and household debt in the SCF + to data from the National Income and Product Accounts (NIPA) and the Financial Accounts (FA).

We index the series to 100 in 1983-1989 to abstract from level differences that can be attributed to different measurement concepts and focus on comparing growth trends over time. During the base period 1983-1989, the SCF+ data correspond to $89 \%$ of NIPA income and $78 \%$ of FA debt in levels. ${ }^{4}$

Figure 2 shows the comparison of growth trends between the $\mathrm{SCF}+$ and aggregate data for 1950 to 2016. Overall, the aggregate data and the aggregated microdata show very similar trends. With respect to housing debt, the SCF + data and the FA match almost

Figure 2: Income and debt in the SCF+ versus NIPA and FA

(a) Income

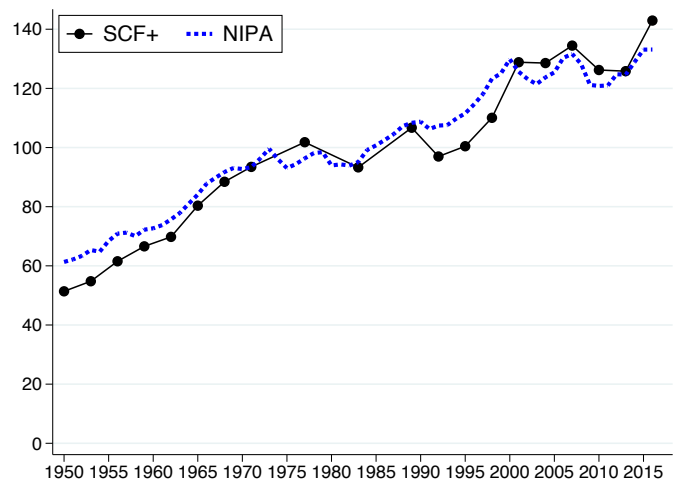

(c) Housing debt

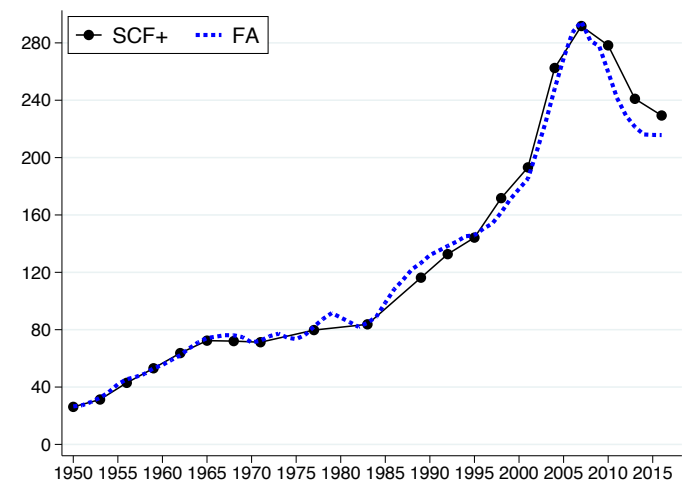

(b) Total debt

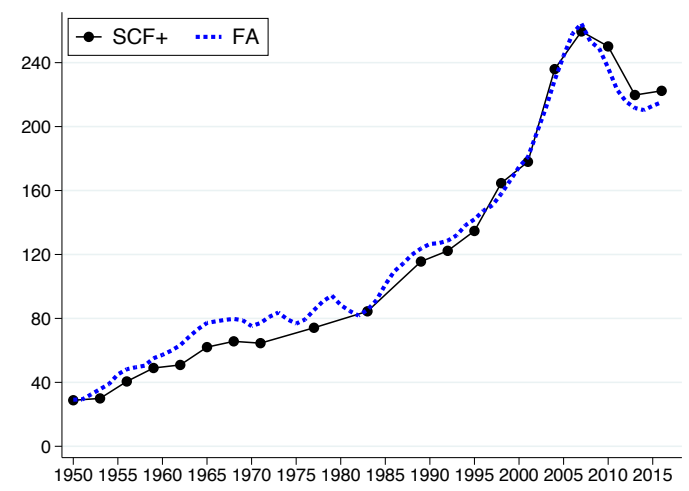

(d) Non-housing debt

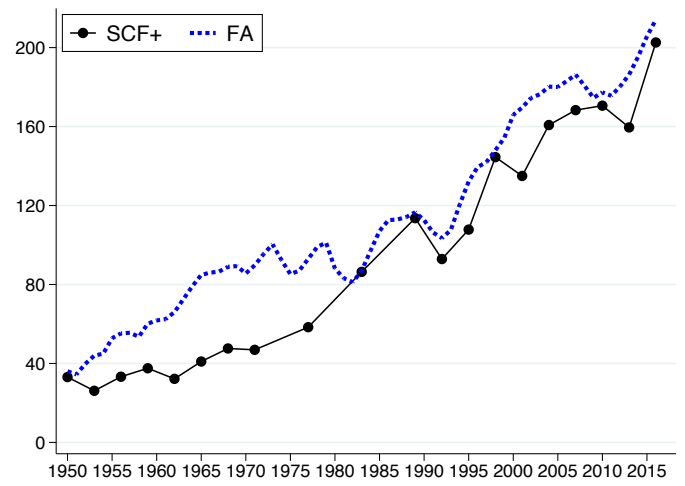

Notes: The figure shows income and total debt from the SCF + in comparison to income data from the NIPA and total debt data from the FA. All series have been indexed to the period 1983-1989 (=100). The SCF + data are shown as black lines with circles, NIPA and FA data as a dashed blue line. Over the index period, the SCF + values correspond to $89 \%$ for income, $78 \%$ of total debt, $80 \%$ of housing debt, and $73 \%$ for non-housing debt.

\footnotetext{
${ }^{4}$ Income components of the NIPA tables that are included are wages and salaries, proprietors' income, rental income, personal income receipts, social security, unemployment insurance, veterans' benefits, other transfers, and the net value of other current transfer receipts from business. Mortgages and consumer credit are included as FA debt components. Henriques and Hsu (2014) and Dettling et al. (2015) provide excellent discussions of the different measurement concepts between SCF, NIPA, and FA data.
} 
Figure 3: Total and housing debt-to-income ratios

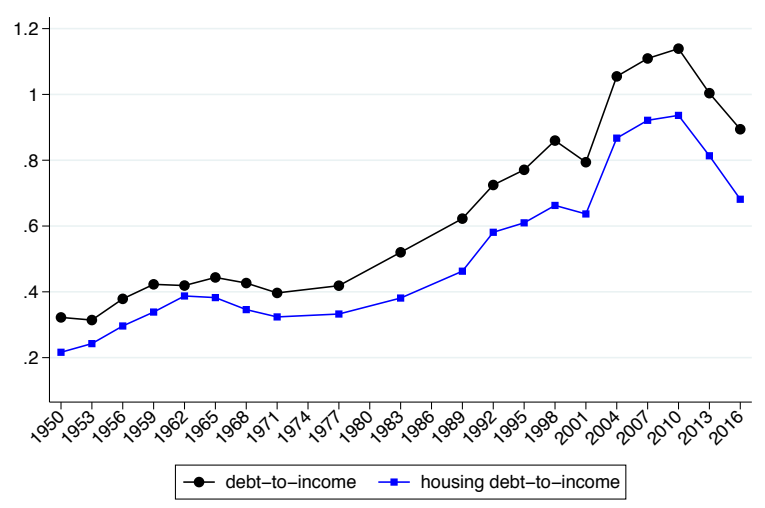

Notes: The graph shows the debt-to-income ratio for total debt and housing debt from the SCF + over time.

perfectly. Non-housing debt also aligns well with the FA data, albeit there is a certain discrepancy before the 1980s. All in all, the close alignment in growth trends effectively alleviates concerns that the microdata systematically miss parts of the distributional changes underlying the observed macroeconomic growth trends.

Figure 3 shows the evolution of debt-to-income ratios over the last seven decades. Debtto-income ratios effectively quadrupled between 1950 and the 2007 crisis. They have fallen by about 20 percentage points since then. Housing debt accounts for $78 \%$ of the increase in the debt-to-income ratio from 30\% to $92 \%$ between 1950 and 2016 .

This long-run increase in household indebtedness is well documented on the macro level in the FA statistics. However, with the SCF + data, we are in a position to track the historical evolution of the distribution of household debt and study its drivers.

\section{The American household debt boom, 1950-2016}

In this section, we will use the SCF + to track the growth and distribution of household debt and its relation to income dynamics over the past seven decades. Which households borrowed so much more, and for what purposes?

The analysis will proceed in three steps. We will first look at the distribution of debt among income groups over time and then establish that the middle class accounts for the largest part of both outstanding debt and new borrowing. In a second step, we will decompose the overall debt increase into changes at the intensive and extensive margin of different debt components. In a last step, we exploit a further key strength of the $\mathrm{SCF}+$ data, the availability of demographic information of households, by looking across generations when we will study the changing life-cycle patterns of household debt. 


\subsection{The distribution of household debt}

How is household debt distributed among rich and poor households, and how has this distribution changed over time? To address these questions, we stratify households by income. Following standard practices in the literature, we divide the population into three groups according to their position in the income distribution (see Piketty and Saez 2003, Saez and Zucman 2016, and Alvaredo et al. 2018).

The first group is made up of households in the bottom $50 \%$ of the income distribution, and the second covers households between the 50th and 90th percentiles. We refer to this group as the "middle class" throughout the paper. The third group consists of the top $10 \%$ of the income distribution. We will only occasionally talk about the top $1 \%$ to illustrate dynamics at the very top. Even very rich households owe considerable amounts of debt despite their high net wealth (with tax considerations likely playing an important role). Yet as borrowers, they are not central for trends in aggregate debt. This being said, very top incomes might have played an important role for the supply of funds (see Mian, Straub, and Sufi 2019). Before we study the evolution of debt shares and debtto-income ratios of these different groups over time, it is important to recognize that the $\mathrm{SCF}+$ is a repeated cross section. This means that households can move between income groups over time. Our groups are reasonably large so that inter-group mobility can be expected to be low, but we will use PSID panel data to test this assumption, along the lines of Díaz-Giménez, Glover, and Ríos-Rull (2011). The PSID reveals that around 84\% of households in the bottom $50 \%$ were already in this group two years ago (Table A.1). The numbers for the 50\%-90\% and top $10 \%$ are $75 \%$ and $66 \%$, respectively. When we extend the intervals to six years, the share of households who are in the same group six years later is still $77 \%$ for the bottom half, $68 \%$ for the middle class, and $53 \%$ for the top $10 \%$. Moreover, households that change income groups tend to remain close to the "border" with the previous group. For instance, among households who changed into the middle-class group, $64 \%$ were no more than two deciles away from this group two years earlier. On average, households remain in the same income group for $77 \%$ of the periods in which we observe their income. ${ }^{5}$

Figure 4 shows the share of total debt owed by the three different income groups. Debt shares have been rather stable over time. Over the entire postwar period, middle-class households have always accounted for the largest share of total debt, on average about $50 \%$ to $60 \%$ of total outstanding debt. Low-income households in the bottom half make up another 20\%. The debt share of the top $10 \%$ fluctuated around $20 \%$ before the 1980 s and then increased to around 30\%. It is clear from Figure 4 that the upper half of the income

\footnotetext{
${ }^{5}$ As a further robustness check, Appendix Figure A.2 presents additional evidence for income group stability. It shows income and housing debt, two key variables for our analyses, for households aged 30 to 55. We examine if the trends in debt look different depending on whether we sort households using their contemporaneous income or the initial income at the beginning of a decade. The trends look very similar.
} 
Figure 4: Debt shares by income group

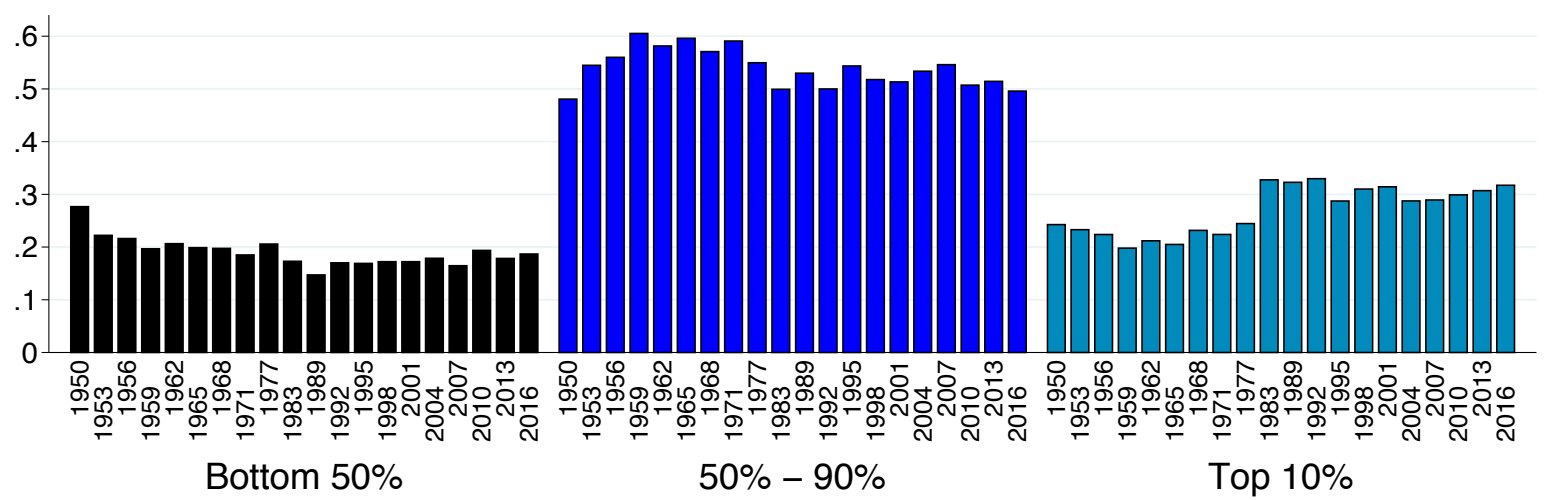

Notes: The figure shows shares in total debt for the different income groups over time.

distribution has always accounted for about $80 \%$ of total household debt outstanding.

Figure 5: Share of increase in debt, 1950-2007

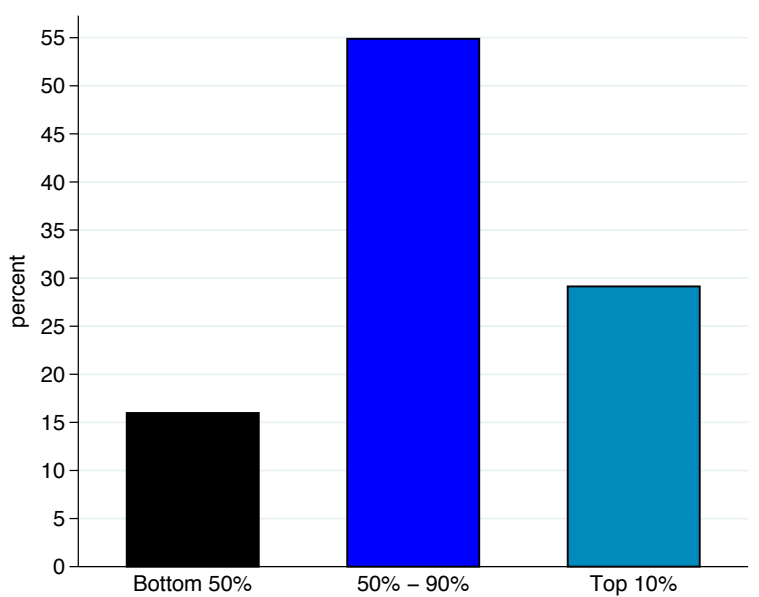

Notes: The graph shows the share of each income group in the total increase of household debt from 1950 to 2007 .

It follows from the relative stability of the debt shares over the past seven decades that the middle class also played a dominant role in the growth of debt. Figure 5 confirms this visually. From 1950 to 2007, middle-class households accounted for 55\% of the total debt increase, whereas households from the bottom $50 \%$ of the income distribution contributed only $15 \%$, even less than the top $10 \%$ with almost $30 \%$. This insight is important in itself. We see that $85 \%$ of the increase in U.S. household debt occurred within the upper $50 \%$ of the income distribution. The explanation for soaring household debt in the United States lies in the borrowing behavior of these incomes groups, and in particular of middle-class households (see also Adelino, Schoar, and Severino 2018).

We next turn to debt-to-income ratios. Over the past 70 years, substantial changes have taken place in the distribution of income in the United States. On a CPI-adjusted basis, the average income of households in the top $10 \%$ increased by a factor of 2.5 between 1971 
Figure 6: Income growth

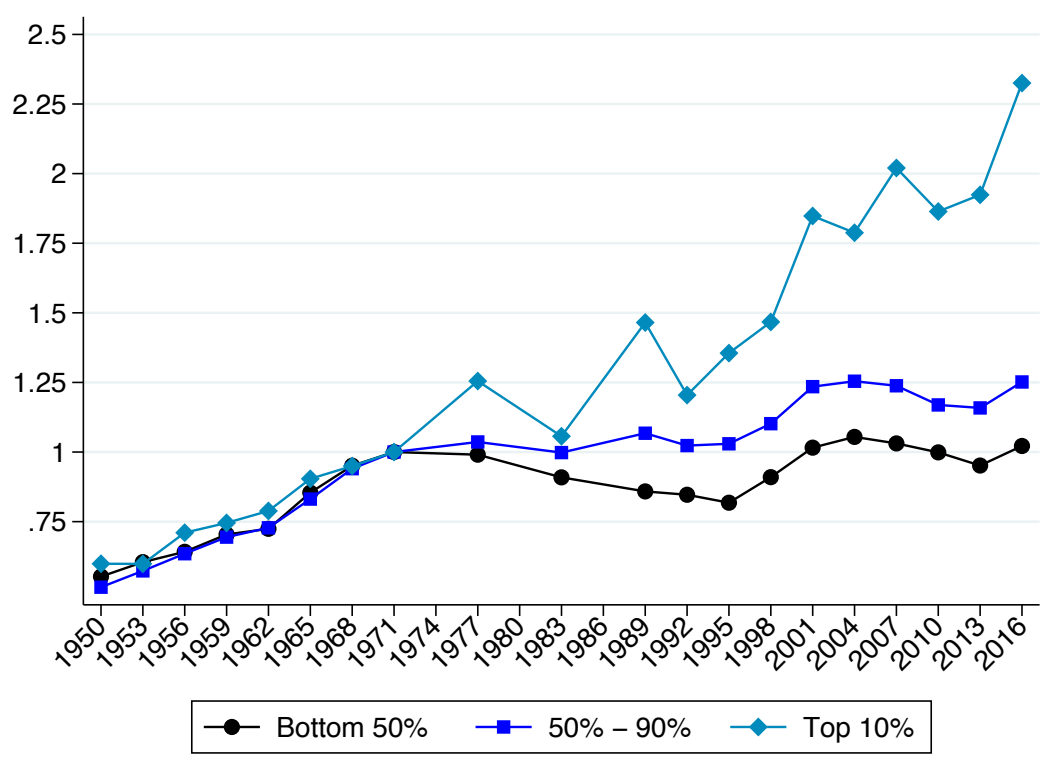

Notes: The graph shows average income of the three income groups from the SCF+. All series are normalized to one in 1971.

and 2016, while the average income of the middle class grew by only $25 \%$, and that of the bottom $50 \%$ stagnated in real terms. Figure 6 displays the diverging income growth trajectories of the different parts of the American income distribution.

Figure 7: Debt-to-income ratios

(a) Debt-to-income ratio

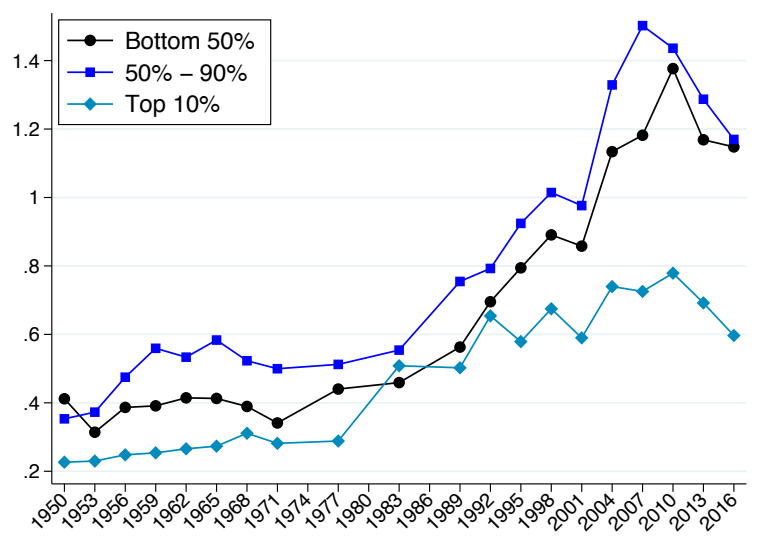

(b) Debt-to-income ratio

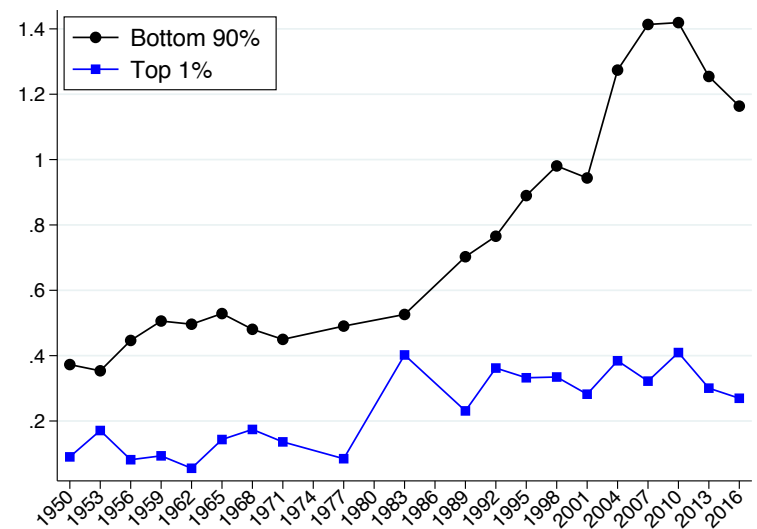

Notes: The left panel shows housing debt-to-income ratios for the different income groups. The right panel compares debt-to-income ratios of the bottom $90 \%$ and top $1 \%$.

These differential trends in income growth across the groups have important consequences for the resulting trends in debt-to-income ratios that are shown in Figure 7. Figure 7a shows surging debt-to-income ratios for middle-class and low-income households. For both income groups, debt-to-income ratios rose from around $40 \%$ in the early 1950 s to close to $140 \%$ by 2007 . For the top $10 \%$, the increase is much more muted, even though the group accounts for a higher share in total debt compared to the 1950s. This is because 
their incomes have risen almost proportionally. Appendix Figure A.3 shows that from the 1950s to the 1970s, debt and income have grown at almost identical rates for all three groups, resulting in the observed stability of debt-to-income ratios over this period.

Figure $7 \mathrm{~b}$ shows debt-to-income ratios of the top 1\%, compared to the bottom $90 \%$. The chart underscores the divergent debt trajectories at the top and in the rest of the economy. For the very top, debt ratios have remained relatively constant. The bottom 90\% witnessed a sharp rise in debt-to-income ratios over the past decades. The chart nicely captures that debt-to-income ratios at the top and bottom evolved in tandem until the late 1970s and then sharply diverged as income concentration at the top increased. In the past four decades, debt ratios have increased most for parts of the population whose income growth was low. ${ }^{6}$

Figure 8: Debt along the income distribution

(a) Total debt-to-income ratio

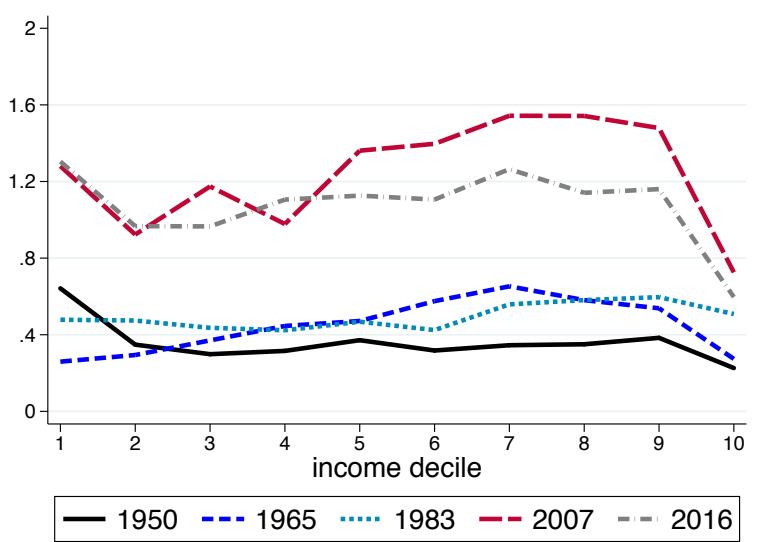

(b) Housing debt-to-income ratio

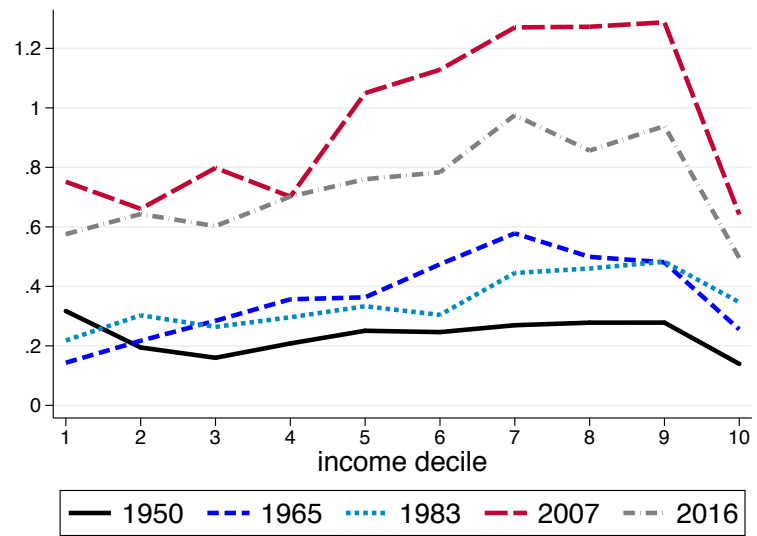

Notes: The graph shows the evolution of average total (left) and housing (right) debt-to-income ratios by deciles of the aggregate income distribution for the SCF+ waves 1950, 1965, 1983, 2007, and 2016. We excluded households with total income below $10 \%$ of the annual wage of a household with a single earner receiving the contemporaneous minimum wage.

An even more comprehensive picture of the distributional dimension of the American household debt boom emerges from Figure 8. For different survey waves, the figure shows the evolution of debt-to-income ratios across the entire distribution. The lefthand side shows total household debt relative to income, and the right-hand side shows housing debt ratios only. Debt-to-income ratios were relatively constant in 1950, with debt ratios being less than $50 \%$ across the entire income spectrum. By 1983, debt-toincome ratios had increased somewhat, but were not far off their levels in the 1950s. Since then, indebtedness has risen strongly across all income groups, but soaring debt ratios of middle-class households stand out. For households between the 50th and 90th percentiles, debt-to-income ratios have approximately tripled within 25 years. $^{7}$

\footnotetext{
${ }^{6}$ Appendix Figure A.4 shows that the debt-to-asset ratio has equally stayed largely flat for high-income households. Both debt-to-income and debt-to-asset ratios have increased most strongly for the middle class.

${ }^{7}$ In Appendix Figure A.5, we show that leverage has also increased most strongly for households from
} 


\subsection{The composition of household debt}

In the next step, we dissect the increase of debt-to-income ratios over time. Figure 8 illustrates the important role that housing debt plays for debt trends of households in the upper half of the income distribution. Adding information on the number of households with outstanding debt and the type of debt, we decompose the debt increase into its extensive and intensive margins. In other words, we answer to what extent the total number of indebted households has increased and to what extent indebted households have taken on larger amounts of debt. Additionally, we calculate the extensive and intensive margin effects separately for different types of debt (i.e., housing and non-housing debt).

Let $d_{i, t}$ stand for the mean debt-to-income ratio of income group $i$ in period $t$. The expression $s_{i, t}^{H^{+}}$is the share of households with positive housing debt (i.e., the extensive margin), and $d_{i, t}^{H^{+}}$is the average housing debt-to-income ratio of households with positive housing debt (i.e. the intensive margin). The values $s_{i, t}^{N^{+}}$and $d_{i, t}^{N^{+}}$are the respective values for non-housing debt. The mean debt-to-income ratio, $d_{i, t}$, can be written as $d_{i, t}=s_{i, t}^{H^{+}} d_{i, t}^{H^{+}}+s_{i, t}^{N^{+}} d_{i, t}^{N^{+}}$. The percentage point change in debt-to-income ratios between period $t$ and $t-1$ is then calculated as

$$
\begin{aligned}
& d_{i, t}-d_{i, t-1}= \\
& \underbrace{\left(s_{i, t}^{H^{+}}-s_{i, t-1}^{H^{+}}\right) d_{i, t-1}^{H^{+}}}_{\Delta \text { extensive housing }}+\underbrace{s_{i, t}^{H^{+}}\left(d_{i, t}^{H^{+}}-d_{i, t-1}^{H^{+}}\right)}_{\Delta \text { intensive housing }}+\underbrace{\left(s_{i, t}^{N^{+}}-s_{i, t-1}^{N^{+}}\right) d_{i, t-1}^{N^{+}}}_{\Delta \text { extensive non-housing }}+\underbrace{s_{i, t}^{N^{+}}\left(d_{i, t}^{N^{+}}-d_{i, t-1}^{N^{+}}\right)}_{\Delta \text { intensive non-housing }} .
\end{aligned}
$$

The first part of this expression is the change in household indebtedness due to a change in

Table 1: Decomposition of the increase in debt-to-income ratios between 1950 and 2016

\begin{tabular}{llc}
\hline housing debt & intensive margin & 32.9 \\
& extensive margin & 19.7 \\
non-housing debt & intensive margin & 14.5 \\
& extensive margin & 7.5 \\
\hline total & & 74.5 \\
\hline
\end{tabular}

Notes: The table shows the percentage point change in the average debt-to-income ratio between 1950 and 2016, decomposed into extensive and intensive margin effects for housing and non-housing debt according to equation (1).

the extensive margin of housing debt. In other words, it captures by how much household indebtedness would have risen if only the share of households with housing debt, $s_{i, t}^{H}$, had changed, everything else being at the level of period $t-1$. The second part is the effect due to variations in the intensive margin, that is, changes in household indebtedness due

the middle of the income distribution. 
to an increase in the level of debt of borrowers, $d_{t}^{H}$, with the extensive margin of housing debt, $s_{i, t}^{H}$, constant at the level of period $t$ and all non-housing debt components at the level of period $t-1$. The third and fourth parts are the respective effects for non-housing debt.

Table 1 shows the extensive and intensive margin effects of the increase in the average debt-to-income ratio between 1950 and 2016. Overall, we find that the intensive margin of housing debt accounts for 31.5 percentage points of the 75 percentage point increase in the average household debt-to-income ratio. Another 20 percentage points are due to the extensive margin of housing debt. The remaining 23.5 percentage points are due to non-housing debt. This finding confirms that mortgage lending has played a dominant role relative to non-housing debt (e.g., credit cards or student loans) in the debt boom.

Figure 9: Extensive and intensive margins of debt-to-income ratios

(a) Extensive

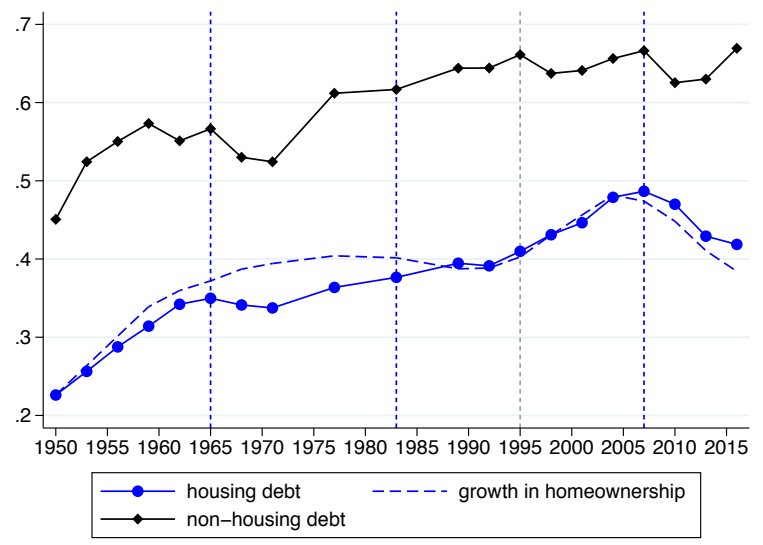

(b) Intensive

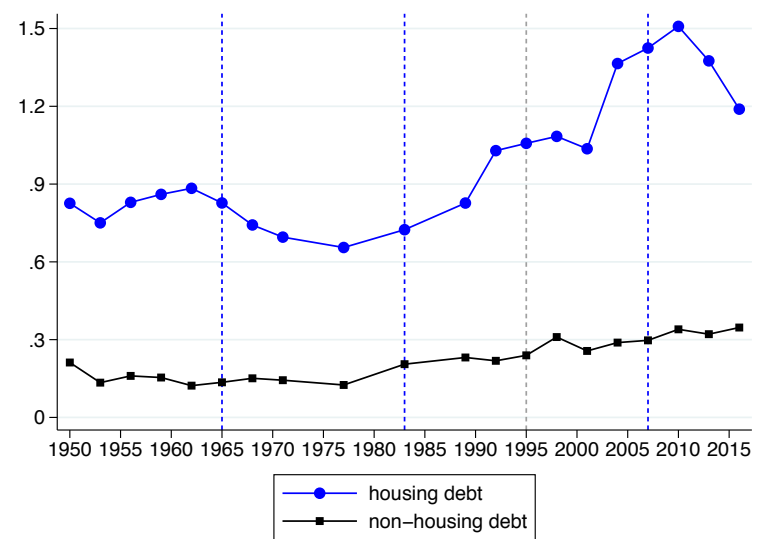

Notes: The left panel shows the share of households with positive housing debt (blue line with dots) and positive non-housing debt (black line with squares). Moreover, it shows the growth rate of the homeownership rate since 1950, normalized to extensive margin housing debt in 1950 for comparison. The right panel shows the (non-)housing debt-to-income ratio of households with positive (non-)housing debt. Black vertical lines indicate pivotal dates related to the debt boom. The gray dashed line marks the year 1995, when house price growth accelerated and homeownership started to increase.

Figure 9 shows the intensive and extensive margins of indebtedness over time for both types of debt. The extensive margin in the left panel captures the share of households with positive (non-)housing debt balances. A closer look at Figure 9 reveals that the extensive margin of housing debt closely tracks changes in the homeownership rate (dashed line). The intensive margin in the right panel is represented by the debt-to-income ratio for households with positive levels of (non-)housing debt. Overall, more households have personal debt than housing debt. In particular, the rollout of credit cards in the 1970s led to a substantial increase in the share of households with personal debt (Appendix Figure A.6). Yet the amount that households owe is small compared to the average amount owed on housing debt, as the right-hand side shows. 


\subsection{Four phases of the postwar debt boom}

From Figure 9, we identify four different phases of the postwar debt increase, which we will explore in more detail. To do so, Figure 10a decomposes the change in debt-to-income ratios into the extensive and intensive margins stratified by income. The figure shows two boom phases (1950-1965 and 1983-2007), followed by two periods of deleveraging (19651983 and 2007-2016). Figure 10b shows a similar picture for loan-to-value ratios. There are substantial differences between the four periods.

The postwar homeownership boom, 1950-1965: The first period is characterized by the rise in homeownership after World War II until the mid-1960s, aided by public policies to increase homeownership (Fetter 2013, 2014). The debt-to-income ratios approximately

Figure 10: Decomposition of changes in debt-to-income and loan-to-value ratios by income group

(a) Debt-to-income

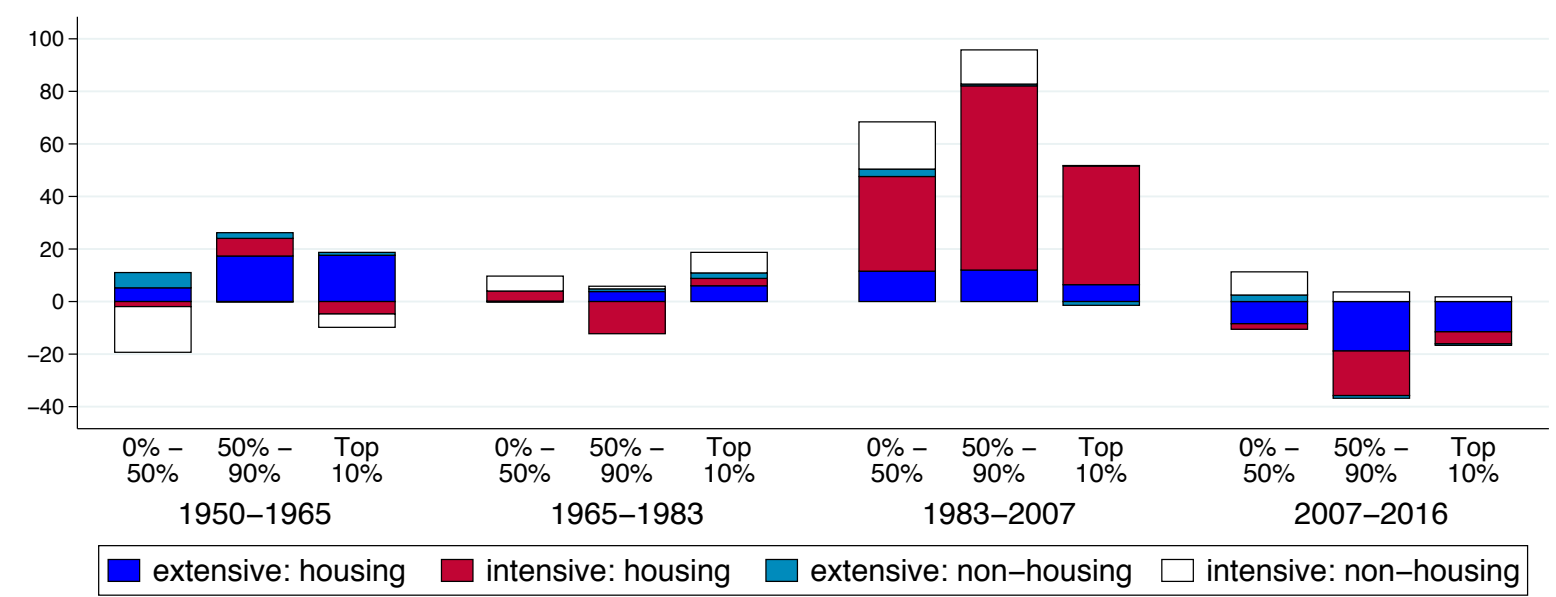

(b) Loan-to-value

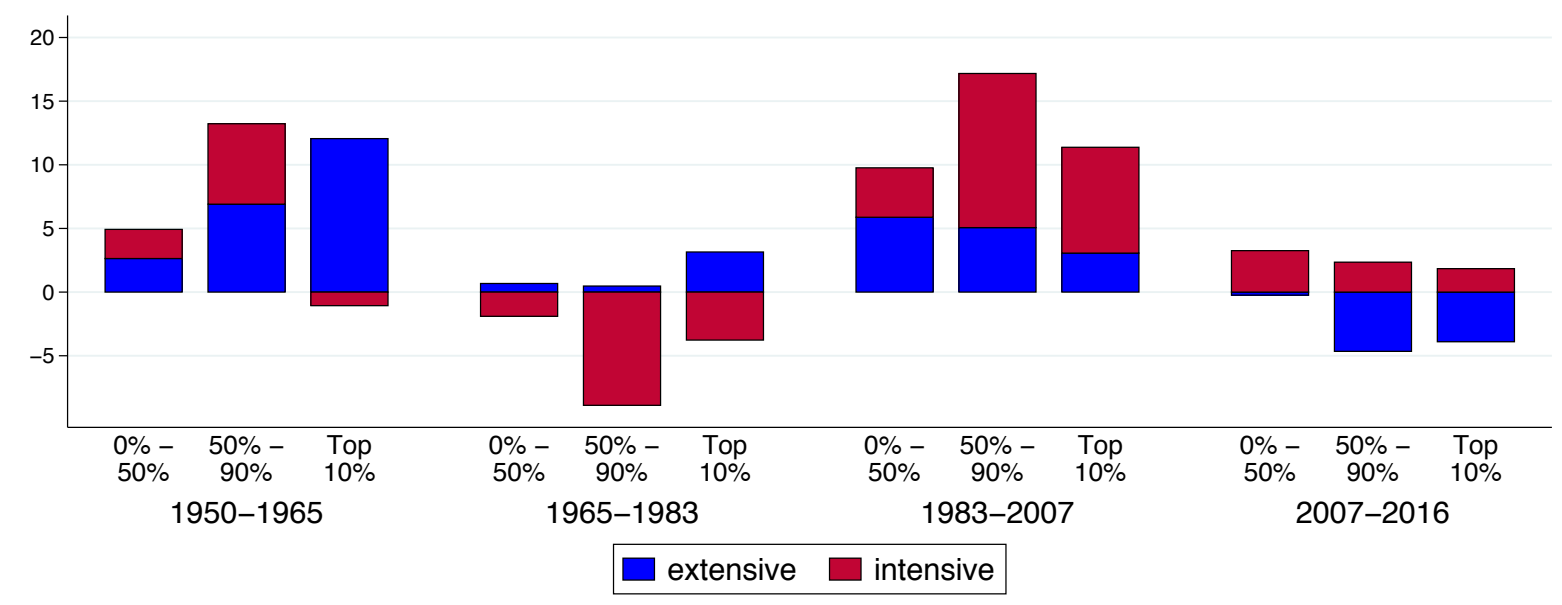

Notes: The upper panel shows the decomposition into extensive and intensive margin effects from equation (1) over the four phases of the debt boom, stratified by income. The lower panel shows an analogous decomposition of the loan-to-value ratio. Observations with debt-to-income ratios above 50 in absolute value were excluded. 
doubled in this period (Figure 3), mainly driven by the extensive margin of housing debt and by the upper half of the income distribution. Likewise, average loan-to-value ratios increased, driven predominantly by the extensive margin and some increase in LTVs of homeowners in the lower half of the distribution.

Stability, 1965-1983: The second period spans the years from roughly 1965 to 1983 . It is characterized by almost stable debt-to-income ratios and a slight decline in the intensive margin housing debt of the middle class, with marginal increases at the extensive margin. At both the top and the bottom 50\%, non-housing debt (car loans and credit cards) make a small but positive contribution to debt ratios. Loan-to-value ratios decrease across income groups.

The second debt boom, 1983-2007: Starting in the 1980s, the United States entered a second debt boom, which came to an end with the crisis. Debt-to-income ratios more than doubled within the 25 years between 1983 and 2007, from roughly $60 \%$ of income to above $130 \%$. This time, the increase was mainly driven by higher intensive margins of housing debt, as Figure 10a shows. Overall, the extensive margin made a relatively small contribution, but the effect is larger in the 2000s, as we will see below. The boom was fueled by households from all parts of the income distribution, but the intensive margin effect of the middle class (50\%-90\%) stands out, for both debt-to-income and loan-to-value ratios.

Crisis and deleveraging, 2007-2016: The final period covers the decade after the crisis and is marked by deleveraging. Overall, the debt-to-income ratio fell by about 30 percentage points. For the bottom 50\%, non-housing debt, mainly education loans, showed positive growth. The middle class and the top $10 \%$ deleveraged at both margins but chiefly at the extensive margin. Homeownership rates have fallen across all income groups. The decline in LTVs was also mainly driven by a decline in the extensive margin.

Recently, the consequences of strongly rising student debt have received increased attention (see, for example, Looney and Yannelis 2015, Avery and Turner 2012). Rising student debt shows up in Figure 10a as a part of the intensive margin of non-housing debt. Since 1983, we find a significant contribution from this component, especially in the lower half of the income distribution. These increasing debt levels might shape the financial decision making of young generations of American households in the future. However, Figure 10a also shows that from a macroeconomic perspective, the contribution of student debt is still much smaller than the increase in housing debt over the same period of time (see also Appendix Figure A.6).

Figure 11 zooms in on the second post-1980 debt boom. In its first phase, from 1983 to 1995, the debt increase was similar for all income groups, and intensive margin housing debt played the central role. In the second phase, from 1995 to 2007, the quality of the debt boom changed considerably. The middle-class debt-to-income ratio grew twice as much as 
Figure 11: Two stages of the second debt boom

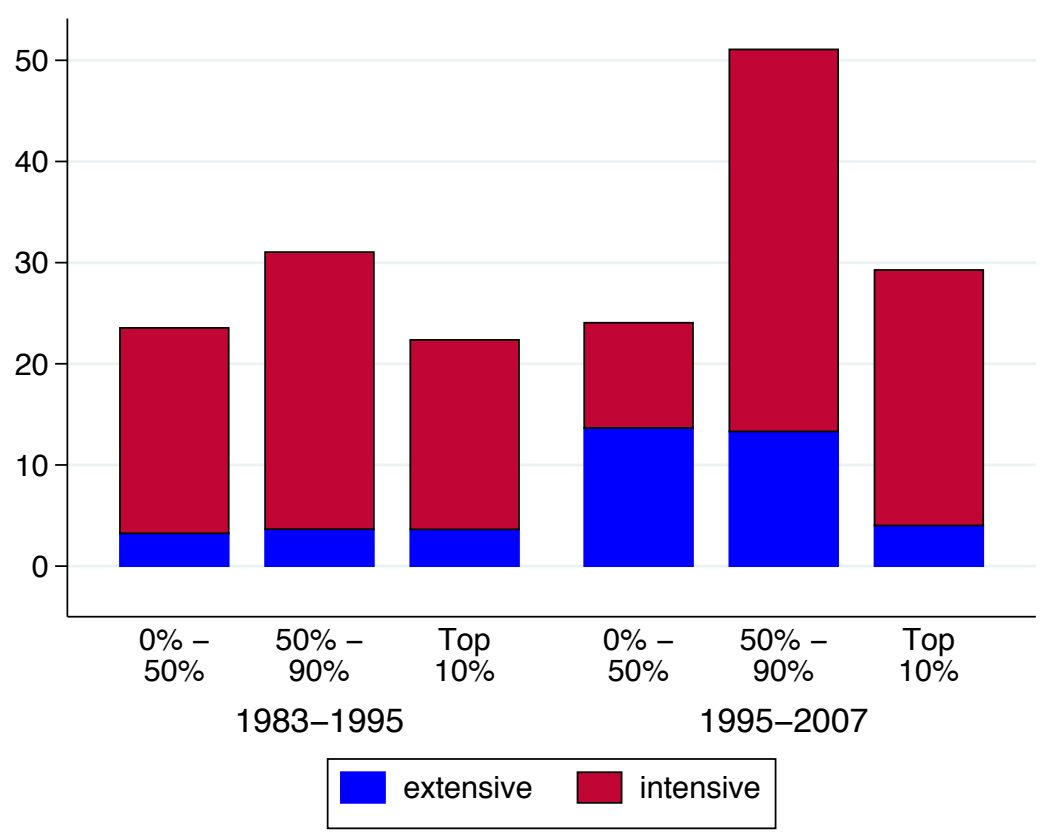

Notes: The graph repeats the analysis from Figure 10a, zooming in on the second debt boom. Observations with debt-to-income ratios above 50 in absolute value were excluded.

that of the other income groups. The significant increase in the debt ratio in the top $10 \%$ is also noteworthy, as it effectively outpaced the increase in debt ratios in the bottom half of the income distribution. In the middle and lower half of the distribution, the extensive margin also made a substantial contribution to rising debt levels after 1995. This reflects the homeownership boom of the 2000s, partly driven by lending to households from the lower half of the distribution. Over the entire boom from 1983 to 2007, the middle-class debt-to-income ratio increased by 82 percentage points, predominantly because of higher intensive margin indebtedness.

\subsection{Life-cycle profiles of household debt}

So far, we have shown that the middle class and the intensive margin of housing debt were the main drivers of the debt boom in the past decades. In this section, we will ask how the debt increase has affected households of different generations across the different stages of their life cycles. We will encounter substantial changes in the life cycle of debt. Most importantly, we will see that the slope of debt-to-income profiles flattened substantially over time.

Instead of stratifying the data by income group, we trace different generations of American households. The long time span of the SCF+ data gives us the unique opportunity to follow individual birth cohorts and their indebtedness over several decades. Since the $\mathrm{SCF}+$ is not a panel, we construct synthetic birth cohorts. Households with heads born 
between 1915 and 1924 are our oldest cohort, and households with heads born between 1965 and 1974 are our youngest cohort. Correspondingly, our oldest cohort is on average 30 in 1950, and our youngest cohort is on average 46 in 2016. We estimate the life-cycle profiles of total and housing debt-to-income ratios for each synthetic cohort by regressing individual ratios on six age group dummies. We focus on households between 25 and 85 years of age. The groups comprise households with a head of 25-34, 35-44, 45-54, 55-64, 65-74, and 75-85 years, respectively. ${ }^{8}$

Figure 12: Debt over the life cycle

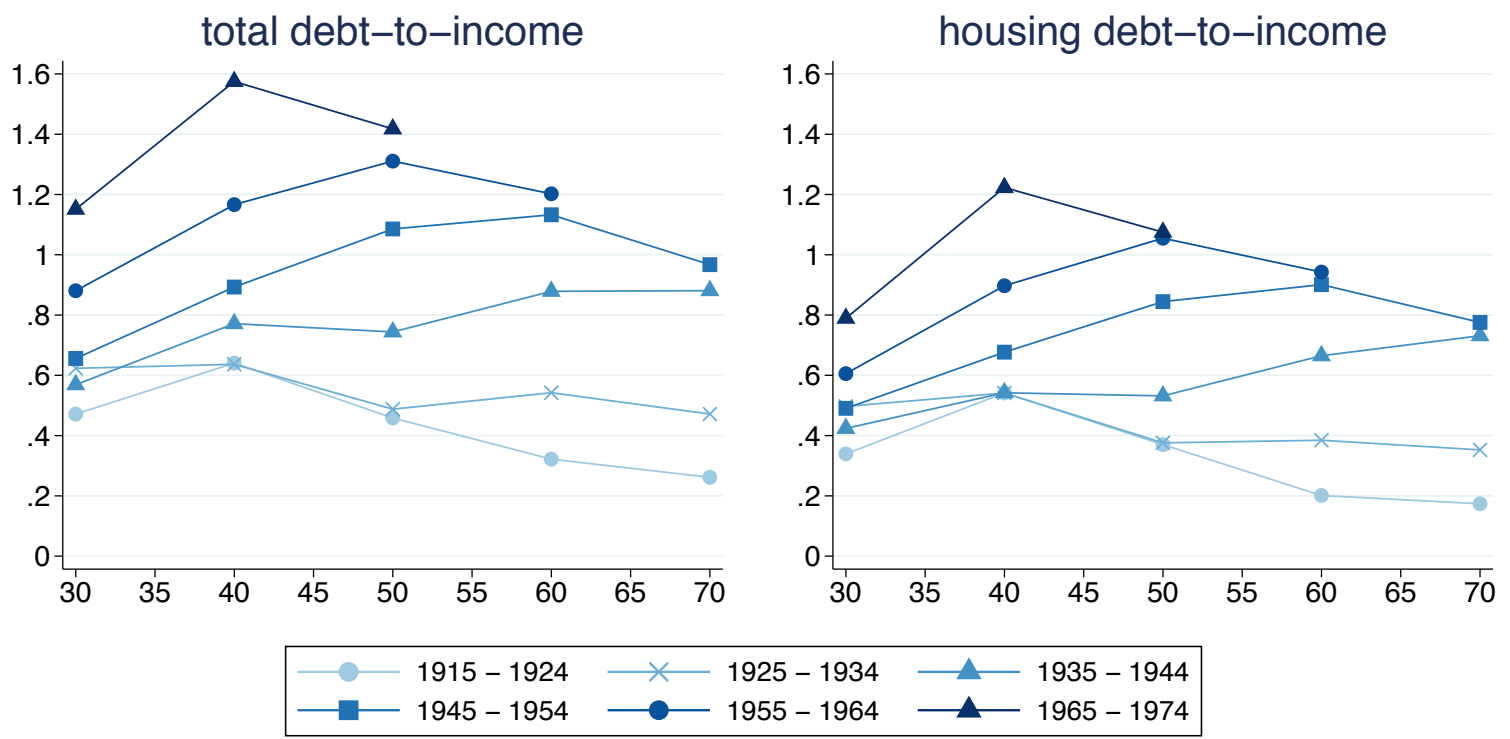

Notes: The panel shows the life-cycle profiles of total and housing debt-to-income ratios for our synthetic cohorts.

The resulting life-cycle profiles are shown in Figure 12. We observe a striking increase in debt-to-income ratios from one generation to the next, leading to an upward shift in life-cycle profiles across cohorts. For instance, the generations born before World War II started with an average debt-to-income ratio of around 0.5. The debt ratios of the two baby boomer cohorts, born in the two decades after World War II, were slightly higher at the beginning of their (economic) life cycle. At age 30, they started with debt ratios between 0.5 and 0.6 , possibly reflecting the effects of the postwar credit policies that encouraged homeownership and sustained markedly higher LTVs (Fetter 2013).

Apart from the level shift, we also observe a turning of the life-cycle profiles. This upward rotation occurs when the average household from the 1915-1924 cohort is 60 , the average household from the 1925-1934 cohort is 50, and the average household from the 1935-1944 cohort is 40 (i.e., the turn coincides with the onset of the second debt boom around 1980). These households reach retirement age with substantially elevated debt levels compared to previous cohorts (see also Lusardi, Mitchell, and Oggero 2018).

\footnotetext{
${ }^{8}$ We exclude households with extreme debt-to-income or housing-to-income ratios of larger than 50 in absolute value. Very small incomes of less than 10 in absolute value and house values of less than $\$ 500$ (in real terms) are treated as zero.
} 
At age 70, the visual contrast is stark. The prewar generations typically entered retirement with modest debt ratios of around $30 \%$ to $50 \%$ of income. Yet households in the first baby boomer cohort (1945-1954) had debt ratios of almost $120 \%$ on average at the same age (i.e., more than twice as high). Generally, younger cohorts reach retirement age with considerably higher debt levels than before. We also note that the effect of the shift in the slope of the life-cycle profiles is considerably stronger than the upward shift in the profiles at the beginning of the life cycle. ${ }^{9}$

Any explanation for the increase in American debt will have to be able to account for these stylized life-cycle facts on household finances over time. We next turn to examining the drivers of this change in debt profiles over the life cycle.

\section{House prices, wealth growth, and the debt boom}

We have established that the intensive margin of middle-class housing debt was the key driver for the increase in household debt. At the same time, income growth of middle-class households was low at best. Is this evidence supportive of the popular view that those parts of the population that were cut off from income growth increasingly had to rely on debt to finance consumption? How can we rationalize this substantial middle-class debt accumulation in the presence of stagnant incomes? To address these question in this section, we exploit a key strength of the SCF + data. They provide a comprehensive picture of the entire household balance sheet, including the asset side. We also complement the analysis with data from the PSID, which has a panel structure that allows us to study the debt accumulation of individual households over time.

We start the discussion by pointing to an important fact, displayed in Figure 13. The graph shows the long-run trend in debt-to-income ratios for the bottom $90 \%$ next to the trajectory of their (net) wealth-to-income ratios. The chart demonstrates that the increase in debt is dwarfed by the rise in net wealth. The figure tells us that the average value of assets grew by a larger absolute amount than the average value of debt. ${ }^{10}$ Put differently, despite the pronounced rise in debt-to-income ratios since the 1980s, middleclass households became considerably richer. Middle-class wealth and income growth diverged substantially.

An increase in asset holdings has two potential sources. First, higher savings may lead to a more rapid accumulation of assets. Second, existing assets may have had valuation gains. For the first channel to be quantitatively important at a time of low income growth for low- and middle-class households, we would have to see a substantial rise in savings

\footnotetext{
${ }^{9}$ Appendix A.9 shows that the same patterns are visible in the PSID data, which allow to follow actual instead of synthetic cohorts.

${ }^{10}$ Given the relatively low initial debt-to-asset ratios, which only increased moderately over time (Appendix Figure A.4), this outcome is not surprising.
} 
Figure 13: Debt-to-income vs. wealth-to-income ratios

(a) Bottom $90 \%$

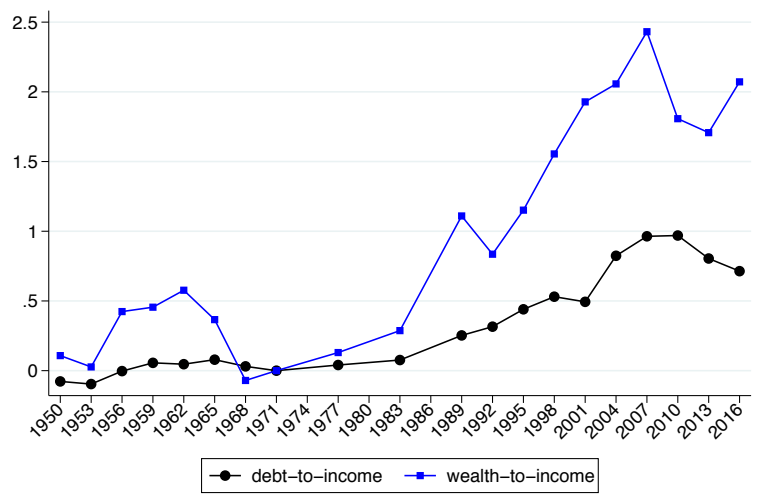

(b) $50 \%-90 \%$

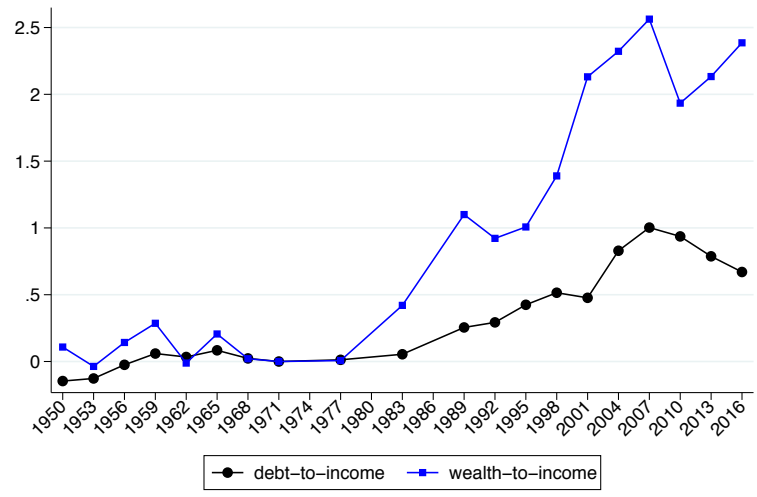

Notes: The left panel shows average debt-to-income and wealth-to-income ratios for the bottom $90 \%$ of the income distribution, normalized to zero in 1971. The right panel shows the same series for the 50th to 90 th percentiles of the income distribution.

rates. However, the data show that savings rates actually decreased for these households over time (Mian, Straub, and Sufi 2019, Saez and Zucman 2016, Zandi 2019), so we are left with the second channel: capital gains on existing assets. We will argue that such valuation gains, predominantly on residential real estate, played the dominant role in rising middle-class wealth in the face of stagnant incomes. Rising house prices, against the background of the high exposure of the typical middle-class household portfolio to the housing market, led to substantial equity gains that pushed up middle-class net worth (Wolff 2016, Kuhn, Schularick, and Steins forthcoming).

Figure 14a shows that between the early 1980s and 2007, real house prices, adjusted for quality changes, increased by almost $70 \%$. Figure $14 \mathrm{~b}$ shows the increase in housing assets relative to income across the income distribution. The housing-to-income ratio rose most strongly for middle- and low-income households, considerably more than at the top. Between the late 1970s and the 2008 crisis, the average housing-to-income ratio of the middle class increased by more than 160 percentage points (Figure 14b), and thereby more than doubled from a level of $145 \%$ to $300 \%$. Price increases can account for about two-thirds of this increase, according to our data.

We will argue that these housing wealth gains hold the key to understanding the middleclass borrowing surge of the past decades. This is because a substantial share of the debt increase was a reaction to such house-price-induced wealth gains. As the value of their real estate increased, middle-class households became wealthier and turned part of this new wealth into additional spending through home-equity-based borrowing. We will show that a significant share of the debt buildup was a Modigliani-style life-cycle consumption smoothing response of (mainly) middle-class households to large wealth gains resulting from concentrated housing portfolios. 
Figure 14: House prices and housing wealth-to-income ratios

(a) House prices

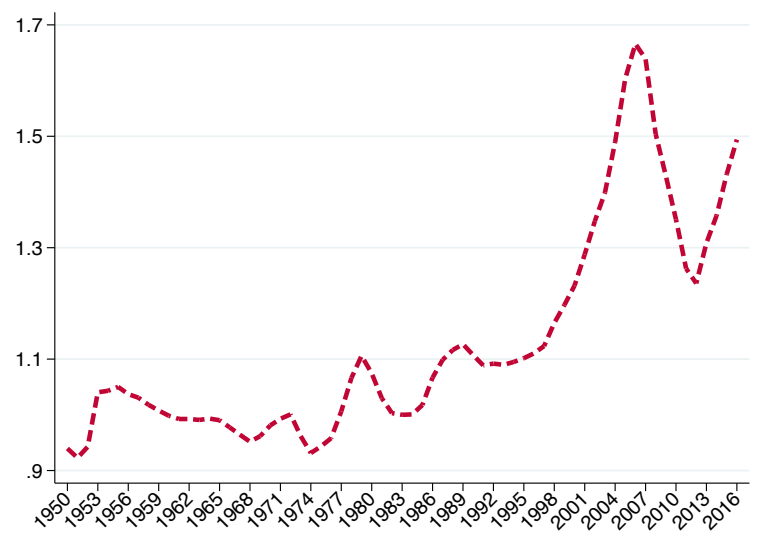

(b) Housing-to-income ratio

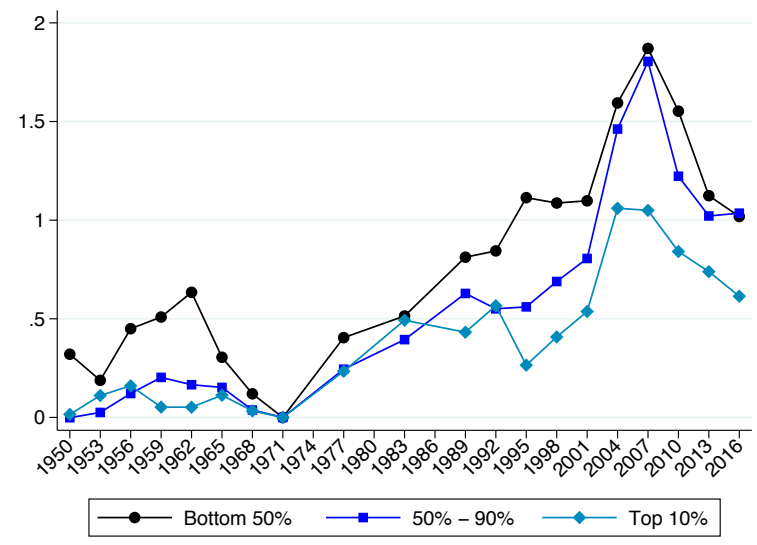

Notes: The left panel shows the house price index from the Macrohistory Database, deflated by the CPI. The right panel shows average housing wealth relative to average income from the $\mathrm{SCF}+$, normalized to zero in 1971.

When putting the empirical facts together, we still find middle-class households with low income growth at the center of the debt boom, yet in a way that challenges existing hypotheses. While most of the borrowing was done by households from groups with stagnant incomes, it turns out that until 2007, the same groups also experienced high wealth growth. Rapid debt growth can, to a large extent, be rationalized as a consumption smoothing response to this price-induced growth of middle-class wealth. Clearly, this "rational" explanation for debt growth does not preclude that behavioral factors also played a role at some point in the process. For instance, households might have mistakenly assumed housing wealth gains to persist when they did not. But the data suggest that households acted as if these wealth gains were assumed to be persistent.

To make the argument, we will proceed in three steps. First, we will substantiate the idea that the net wealth position of households in the bottom $90 \%$ of the income distribution is particularly exposed to house prices and that rising real estate prices led to substantial capital gains for middle-class households. In a second step, we will show that households reacted to these capital gains by extracting home equity in a way that is quantitatively important for the overall trajectory of household debt. For this step, we complement the SCF + data with housing and mortgage panel data from the PSID that allow us to decompose debt dynamics and quantify the contributions of equity extraction, new ownership, and upgrading to the debt increase.

In the last step, we will contend that the observed home-equity-based borrowing is consistent with optimizing household behavior in state-of-the-art life-cycle models (Berger et al. 2017). The discussion will also deal with the question of whether households are "right" to treat wealth gains from house prices in a similar way to, say, gains in the stock market, and what the financial stability implications are. 


\subsection{House prices and middle-class wealth}

To quantify the exposure of middle-class households to the housing market, Figure 15a presents the elasticities of household wealth with respect to house price changes for our three income groups. The elasticity of around 0.5 that we observe on average for the bottom $50 \%$ and the middle class (50\%-90\%) implies that a $1 \%$ increase in house prices increases the wealth of these households by $0.5 \%$. Clearly, also the top $10 \%$ own houses, and the average amount of their housing wealth is high. Yet as a share of total wealth, houses constitute a smaller share for this group, and leverage is lower. Consequently, we find a substantially smaller elasticity for the top 10\%, varying around 0.2 . The house price exposure of the bottom $90 \%$ is, hence, on average more than twice as large. Figure 15 a shows little variation in house price exposure between the bottom $50 \%$ and the middle class (50\%-90\%). Yet, the average level of housing assets is much smaller for the bottom $50 \%$, which implies that this group matters less for aggregate household debt. ${ }^{11}$

Figure 15: House price exposure and capital gains

(a) House price exposure

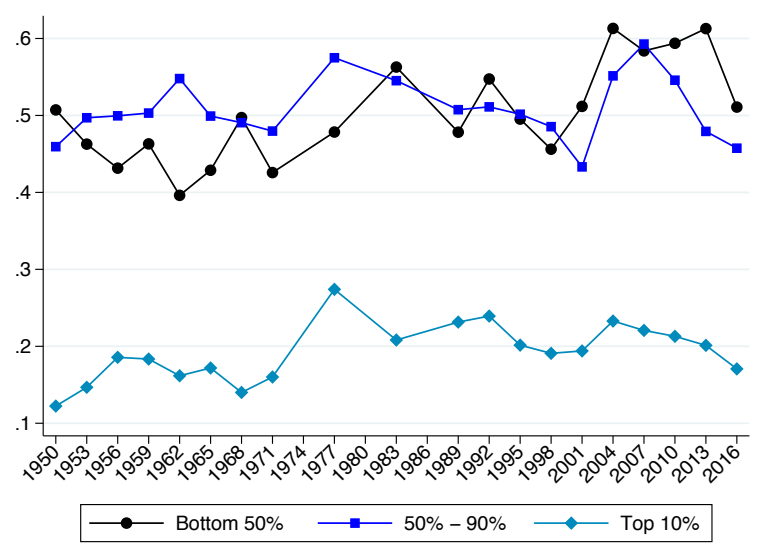

(b) Capital gains over assets

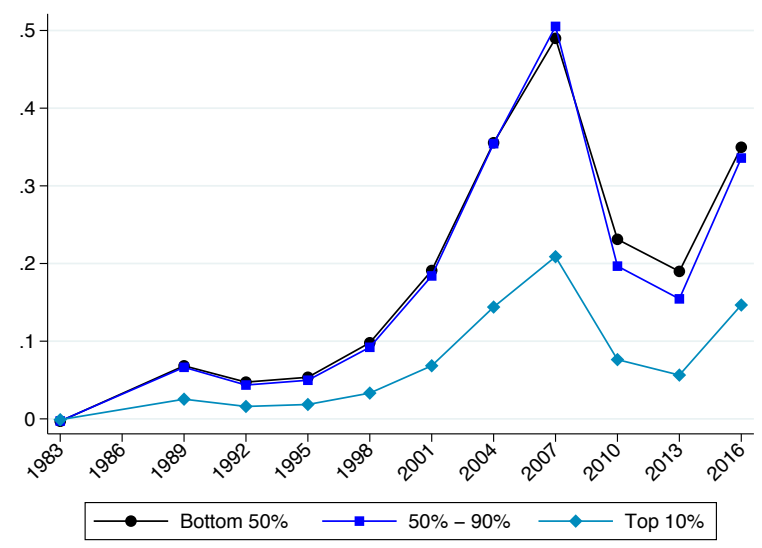

Notes: The left panel shows house price exposure, computed as $\frac{\text { house }}{\text { wealth }}$. The right panel shows capital gains (see text for details).

Figure 15b combines the information from Figures 14a and 15a for a first approximation of housing capital gains along the income distribution. We multiply housing assets of each income group in period $t$ with the observed rate of constant-quality house price growth from $t$ to $t+1$, and sum these capital gains over time. We normalize the resulting series by the average wealth of each group in 1983. We get that without saving any income, the average household from the bottom $90 \%$ experienced capital gains equivalent to $50 \%$ of its 1983 wealth until the peak of the housing boom in the 2000s, in contrast to only $20 \%$ for the average top $10 \%$ household.

\footnotetext{
${ }^{11}$ For the bottom $50 \%$, housing is, with $\$ 55,800$ across survey years, substantially smaller compared to the middle class (50\%-90\%) with an average of $\$ 135,000$ across survey years (see also Adelino, Schoar, and Severino 2018).
} 


\subsection{Quantifying home-equity-based borrowing}

How did households react to these gains in housing wealth, and what role did the reaction play for the increase in household debt? To quantify the contribution of home-equitybased borrowing for the debt increase, we complement the SCF+ data with panel data from the PSID. As discussed in Section 2.2, we use the SRC sample, which tracks the original households from the first PSID wave in 1968 over time, as well as the new households formed by former members of these households (e.g., adult children moving out). We will focus the analysis on housing debt as the largest component of debt that has driven the overall increase in debt, as discussed in Section 3. Information on net wealth is available from the PSID since 1984. However, information on housing is available since 1968, and on mortgage balance since 1969 (with the exceptions of 1973-1975 and 1982). The initial sample size was about 2,930 households in 1968 and increased to 5,601 by 2017. The PSID was conducted at an annual frequency until 1997 and every two years thereafter. To ensure consistency over time, we discard all even years from the sample. ${ }^{12}$

To isolate the contribution of home equity withdrawal (HEW), we need to separate it from other channels that affect debt levels over time: transitions from renting to ownership and vice versa, upgrading to bigger or better homes, and downgrading. We employ the following definitions:

New owners are defined as households who (1) bought a house and (2) were not homeowners in the previous survey.

Upgraders are households who (1) were homeowners before, (2) bought a new house, and (3) either explicitly stated upgrading as a reason to move or moved to a home with a larger number of rooms.

Downgraders are the mirror image of upgraders. ${ }^{13}$

Extractors are defined following an approach similar to Bhutta and Keys (2016) and Duca and Kumar (2014). In particular, these are households who (1) did not purchase a new home and (2) increased their nominal mortgage balance from one survey to the next. ${ }^{14}$ The debt change is computed in real terms.

The sum of first and second mortgages is our outcome variable. Since 1996, the PSID provides detailed information on mortgage types. These reveal that on average, $92 \%$

\footnotetext{
${ }^{12}$ The only information we use from the even years is whether a household has moved over the last year. We use this information to construct a measure of whether the household has moved during the last two years, consistent with the data from the post-1997 waves.

${ }^{13}$ The number of rooms was averaged across all years a household is living in a given house to avoid spurious classifications due to one-time misreporting. Households who increased (decreased) both the size and value of their house by more than $1.5(0.5)$ were defined as upgraders (downgraders) even if they did not explicitly indicate to have moved.

${ }^{14}$ We also include a relatively small number of households who increased their nominal mortgage balance but moved to a less expensive, smaller, or same-sized home.
} 
of first mortgages are conventional mortgages, and 5\% are home equity loans. Before 1994, the PSID only reports the remaining balance on first and second mortgages in one variable. However, the largest part of extraction happens via first mortgages, as the overall quantity of second mortgages is small (see Appendix Figures A.7 to A.9). Even at the peak of the boom in 2007, only $9 \%$ of households had a second mortgage according to the PSID, with an average balance of $\$ 4,200$. By contrast, $46 \%$ had a first mortgage, with an average balance of about $\$ 70,000$.

Figure 16: Intensive and extensive margins by type
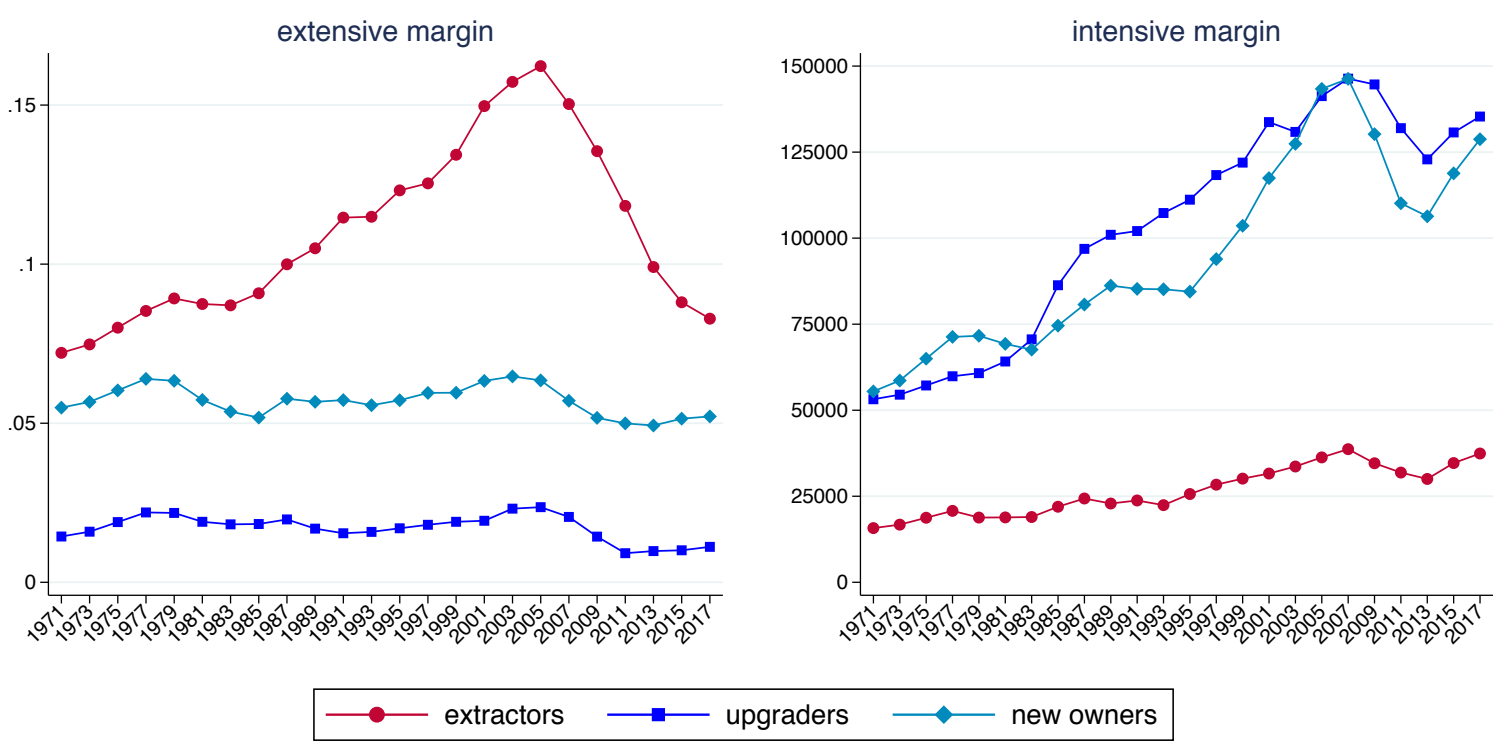

Notes: The left panel shows the share of households who extracted equity, upgraded, or bought a new home over time. The right panel shows the average debt increase of these households. The series were smoothed by taking a moving average across three neighboring waves.

Figure 16 shows the extensive and intensive margins of the different groups over time. At each point in time, we report the share of households who extracted equity, upgraded, or bought a new home (extensive margin). ${ }^{15}$ We see a pronounced increase in the share of extractors since the mid-1980s, whereas the shares of upgraders and new owners remained relatively constant over time.

The right-hand side of Figure 16 documents a surge in the amount by which households change their debt conditional on extracting, upgrading, or changing from renting to owning (intensive margin). In the PSID, the average extraction amount is approximately $\$ 35,000$ between 1999 and 2010. This number is close to the estimate by Bhutta and Keys (2016) of $\$ 40,000$ for this period. The SCF has had a question on equity extraction related to first mortgages since 2004. Despite some differences in mortgage classifications between the SCF and the PSID, the SCF also shows an average extraction amount of

\footnotetext{
${ }^{15}$ We focus on these groups because they will be most important for our following analysis. A full version with downgraders and households who sell their homes to become renters can be found in Appendix Figure A.10.
} 
$\$ 39,000$ between 2004 and 2010. Appendix Section C discusses different estimates from the literature in detail and provides in Table C.1 a comparison of equity extraction estimates from the PSID and SCF.

To quantify the relative importance of extractors, new owners, and upgraders for the growth of household debt, we use the following accounting approach. Let $D_{t}$ denote the stock of housing debt in period $t ; D_{t}^{+}$the new debt taken out by extractors, upgraders, or new owners; $D_{t}^{-}$the debt paid back by households who downgrade or switch to renting; and $A_{t}$ the regular amortization of households who do not move or refinance. Then the law of motion for aggregate housing debt is

$$
D_{t}=D_{t-1}+D_{t-1}^{+}-D_{t-1}^{-}-A_{t-1}
$$

Between the mid-1960s and early 1980s, the aggregate debt stock was relatively constant (see Figure 2c). In other words, we had a situation in which $D_{t+1}-D_{t} \approx 0$, and therefore $D_{t}^{+} \approx D_{t}^{-}+A_{t}$. For $D_{t+1}$ to increase beyond $D_{t}$, we need to observe increases in $D_{t}^{+}$or decreases in $D_{t}^{-}$or $A_{t}$.

As a specific example, consider a change in equity extraction $D^{+}$. Two reasons account for additional debt due to equity extraction: First, there may be more households extracting equity (extensive margin). Second, conditional on extracting equity, households may extract larger amounts (intensive margin). Let $b$ denote the base year, and let $\Delta_{t} D$ denote the average debt change in households who extracted equity in period $t$ (i.e., the intensive margin). Further let $s_{t}$ denote the sample share of extractors in period $t$ (i.e., the extensive margin). The additional debt due to increases in the share of extractors since the base year is $\Delta D_{t}^{e x t}=\Delta D_{t} \times\left(s_{t}-s_{b}\right)$. The additional debt due to changes in the average amount by which households increase their debt at the time of extracting is $\Delta D_{t}^{i n t}=s_{b} \times\left(\Delta D_{t}-\Delta D_{b}\right)$. Adding these two numbers yields our estimate for the amount by which average housing debt would have been lower each period if the share and amount of extractors had stayed at their base year levels. We total these series to compute the amount by which the stock of housing debt would have been lowered over time in the absence of additional equity extraction. Analogous calculations are done for upgraders, downgraders, and new homeowners.

Figure 17 reports the results and plots the contribution of the different household types to the increase in housing debt relative to the base year. We consider data between 1981 and 2007 to cover the whole debt boom period since the 1980s. The dashed line in the figure shows the observed increase in housing debt since 1981.

The first important observation is that our accounting framework closely matches the total housing debt increase between 1981 and 2007. The combined growth in debt across all individual groups accounts for almost the entire debt increase with only a small residual. 
Figure 17: Decomposition of the housing debt boom

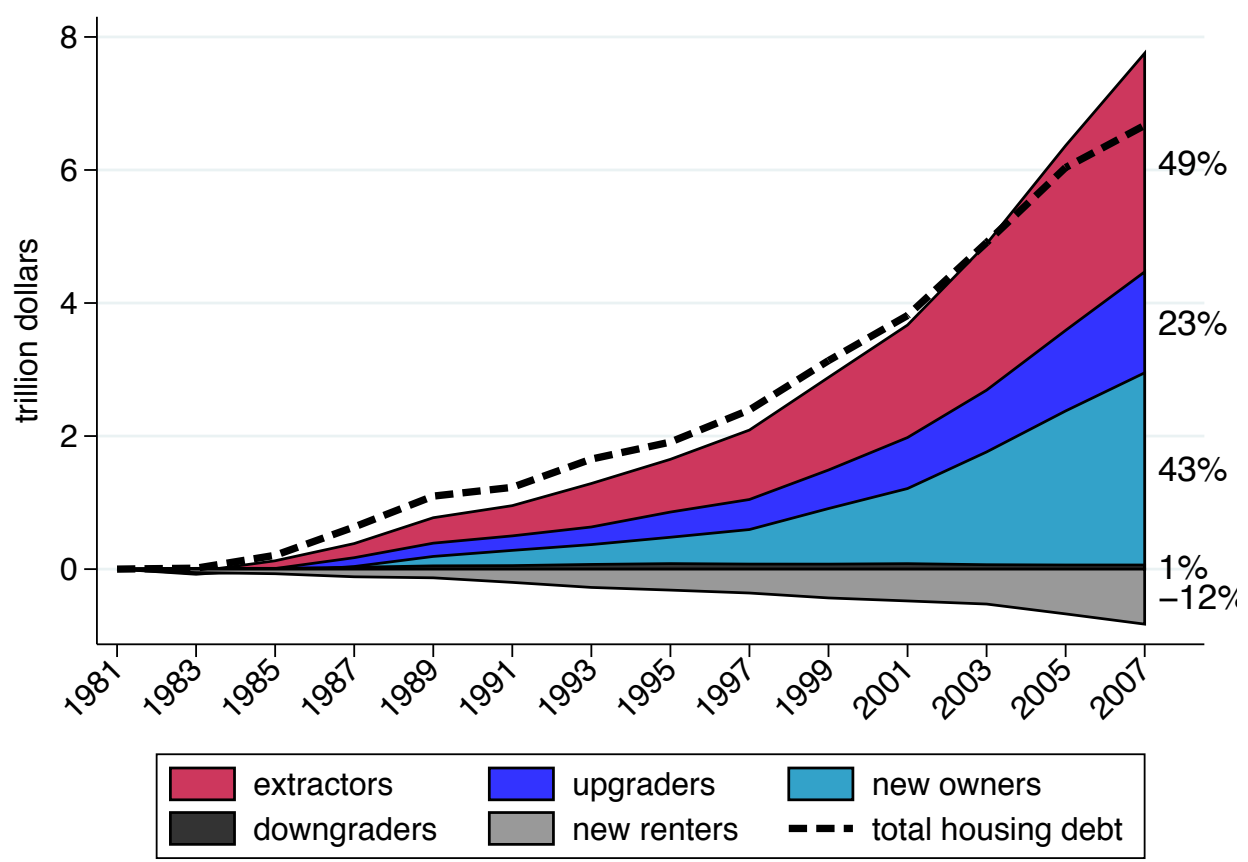

Notes: The graph shows the change in total housing debt since 1981 as a dashed black line, together with estimates of the change in the stock of housing debt due to HEW, upgrading, downgrading, new homeownership, and giving up homeownership. Please refer to the text for details on the construction of these estimates. The percentages on the right side are the shares of each shaded area relative to the actual increase (indicated by the dashed line) in 2007.

Going back to equation (2), this implies that no major changes took place in amortization behavior.

The second important result is that home equity extraction has played the key quantitative role in driving the debt boom. It accounts for about $49 \%$ of the total increase in housing debt. In other words, about half of the increase in housing debt is driven by incumbent owners borrowing against their home equity. New owners account for a slightly smaller share, around $43 \%$. Upgraders account for about $23 \%$, while new renters contribute negatively to the total increase. The net contribution of downgraders was negligible over the considered period.

Together, upgrading and home equity extraction account for more than $70 \%$ of additional housing debt since 1981. This corroborates our previous finding that the intensive margin of housing debt is the key driver of the debt boom. Note that both extractors and upgraders tap into home equity for additional spending. Upgraders increase housing consumption by buying a larger house, while extractors may use the funds for home improvements or other consumption purposes. ${ }^{16}$

\footnotetext{
${ }^{16}$ In the SCF, households are asked about the purpose for which they extracted home equity since 1995. Among the households who extracted equity, around one-third use the money for home improvements and repairs. Another $30 \%$ to $40 \%$ spend the money on consumption and the repayment of other debts. Other important purposes are the purchase of vehicles, vacation properties, and investments in other
} 
The relative contribution of new homeownership rose in the mid-1990s, reflecting the increase in homeownership rates prior to the 2008 crisis. While rising house prices bring capital gains to existing homeowners, they imply less purchasing power for prospective homeowners who have saved for the down payment. With falling purchasing power, prospective homeowners have to accumulate more savings out of income or rely on additional debt to finance their home purchase. As most households who change from renting to owning are young, this drove young households deeper into debt than in previous generations. Figure A.11 shows that loan-to-value ratios of young homeowners increased from around $40 \%$ in 1950 to almost $80 \%$ by 2007 . Yet the overall picture is dominated by incumbent homeowners and variations in their intensive margin of debt.

\subsection{Regulatory and tax changes}

Home-equity-based borrowing started to surge in the mid-1980s. The timing is not coincidental, as regulatory changes in taxation prepared the ground. The most important change came with the Tax Reform Act of 1986, which limited the deductibility of interest on debt to interest on debt secured by first and second homes. This change meant that homeowners could retain the tax deductibility of interest payments by shifting other debt to housing debt, for example, home equity lines (HELs) (Kowalewski 1987). In addition, interest rates charged on such HELs were considerably lower than credit card debt (Canner, Fergus, and Luckett 1988). Maki (1996) and Maki (2001) show how households took advantage of this reform and changed their debt portfolios from consumer debt toward housing debt after the abolition of the consumer interest rate deductibility.

Financial institutions started to aggressively market new home equity borrowing products in the 1980s. In the mid-1980s, nearly half of the country's largest financial institutions spent more advertising dollars on these products than on anything else (Canner, Fergus, and Luckett 1988). For instance, Citibank advertised its new "Equity Source Account" by linking house prices to individual achievement: "Now, when the value of your home goes up, you can take credit for it" (Story 2008). Banks were successful in overcoming the negative connotation of second mortgage products, which were traditionally seen as a last resort for households in financial trouble. HELs were now branded as a cheap and convenient way to tap into home equity (Kowalewski 1987).

Within a few years in the 1980s, the HEL market grew from close to zero to $\$ 100$ billion in volume (Story 2008). Regulatory change played a role in the kicking off of the 1980s equity extraction boom, too. Until its amendment in 1982, the Truth in Lending Act gave consumers the right to rescind credit transactions secured by home equity within three days. This made second mortgage credit burdensome and expensive for the banks. Other Depression-era regulations on the mortgage market were also abolished during these years,

assets, with average response rates of around 5\%-10\% each. 
allowing mainstream banks to sell secondary mortgage products (Story 2008).

A second withdrawal boom got under way in the 1990s. Conforming real mortgage interest rates fell from around 6\% in the mid-1990s to 3\% in the 2000s (Appendix Figure A.12), and house price growth accelerated. This boom provided strong incentives for households to refinance, and many of them extracted home equity on the way via cash-out refinancing. Bhutta and Keys (2016) show that cash-outs accounted for the largest share of equity extraction between the early 2000s and the crisis in 2008, followed by HELOCs and second mortgages. Correspondingly, our measure of equity extraction is correlated with refinancing, and the correlation increases in years which have been identified as periods of refinancing booms in the literature (see Appendix Figure A.13).

In Appendix Figure A.14, we show how mentions of the term "home equity loan" in American books have evolved over time. The data come from the Google Books Ngram Viewer, an online search engine that displays the frequency of search strings (n-grams) in sources printed until 2008 (see also Michel et al. 2011). The graph clearly mirrors the historical evidence: Until 1982, the term "home equity loan" was hardly mentioned at all. By 1983, the share of mentions starts to go up and then rises steeply in 1986. After reaching a plateau in the late 1980s, the share surges rapidly again in 1995, consistent with the timing of the second withdrawal boom.

\subsection{Middle-class equity extraction}

How was the equity extraction boom distributed across the different income groups? Is there evidence that middle-class households played an active role in the process? Based on the PSID data, we answer these questions and show that, in particular, households between the 50th and 90th percentiles accounted for the dominant share of equity extraction. These middle-class households also exhibit higher extraction elasticities with respect to house price changes.

Figure 18 shows total home equity extraction as a share of total annual household income for the bottom $50 \%$, the $50 \%-90 \%$, and the top $10 \%$ of the income distribution. ${ }^{17} \mathrm{We}$ smoothed the data by taking a moving average across three neighboring waves. Before 1986, the ratio of extraction to income was similar for all three groups, at around 2\%-3\% for the bottom $90 \%$ and $2 \%$ for the top $10 \%$. In the mid-1980s, we see an increase in extraction relative to income, which is particularly pronounced for the top $10 \%$. This again points to the Tax Reform Act of 1986, which arguably had a larger effect on households with higher incomes.

Over the 1990s, extraction rose from around $3 \%$ to more than $6 \%$ of annual income for

\footnotetext{
${ }^{17}$ Note that our measure refers to total extraction over the previous two years. The results of Bhutta and Keys (2016) suggest that between $10 \%$ and $20 \%$ of households extract in two consecutive years.
} 
households from the bottom $90 \%$. After the crisis in 2008, it dropped to a level of around $3.5 \%$, where it has remained since 2013. By contrast, extraction was falling over the 1990s for the top $10 \%$ and only rose again in the early 2000s. Even at the peak of the debt boom, it did not exceed $5 \%$ of income.

For households with low income growth, additional extraction will translate almost oneto-one into higher debt-to-income ratios. To see this, let us reconsider equation (2) and divide by income $Y_{t-1}$ on both sides:

$$
\frac{Y_{t}}{Y_{t-1}} \frac{D_{t}}{Y_{t}}=\frac{D_{t-1}}{Y_{t-1}}+\frac{D_{t-1}^{+}}{Y_{t-1}}-\frac{D_{t-1}^{-}}{Y_{t-1}}-\frac{A_{t-1}}{Y_{t-1}}
$$

To ease notation, we will express ratios relative to income in small letters and denote the income growth rate by $g$ :

$$
d_{t}=(1+g)^{-1}\left[d_{t-1}+d_{t-1}^{+}-d_{t-1}^{-}-a_{t-1}\right] .
$$

For households with low income growth, we have $g \approx 0$. Iterating backward, we obtain

$$
d_{t}-d_{0}=\sum_{i=0}^{t-1}\left[d_{i}^{+}-d_{i}^{-}-a_{i}\right]
$$

Until 1985, middle-class households on average extracted 2.6 percent of their annual income over a two-year period. For the period between 1986 and 2007, this figure increased by 2.3 percentage points. Over 20 years, such additional 2.3 percentage point annual extraction alone translates into a 23 percentage points higher housing debt-to-income ratio.

\subsubsection{State-level evidence}

To estimate the association between house price growth and equity extraction relative to income over time, we estimate local projections (Jordà 2005) on state-level data. Previous research has stressed that house price exposure can vary considerably across geographies because of heterogeneity in house price developments (Bhutta and Keys 2016, Aladangady 2017, Fuster, Guttman-Kenney, and Haughwout 2018). ${ }^{18}$ We use the state-level version of the FHFA house price index and estimate the following equation for different horizons $h$ :

$$
Y_{i s, t+h}=\beta_{0}+\beta_{1} g_{s t}^{P}+\Gamma^{\prime} X_{i s t}+\Psi^{\prime} \delta_{t}+\Phi^{\prime} \gamma_{i}+\epsilon_{i t}
$$

\footnotetext{
${ }^{18}$ Appendix Figure A.15 combines regional information from the SCF+, where we observe the state of residence until 1971, with the PSID. It shows a close comovement of housing and housing debt across regions. Appendix Figure A.16 further confirms that our measure of equity extraction comoves with regional house prices, and Appendix Figure A.17 shows that it is also closely correlated with house values across states.
} 
Figure 18: Extraction relative to income, by income group

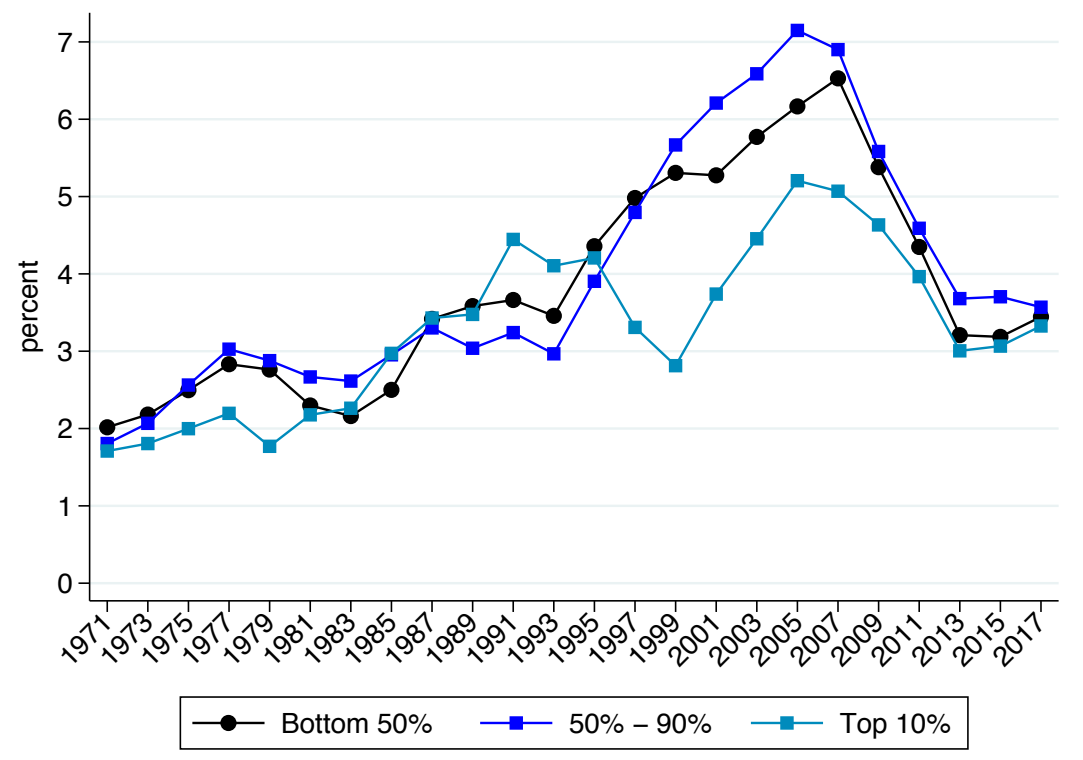

Notes: The graph shows total extraction relative to total income by income group. The series were linearly interpolated for 1973-1977, as mortgage information is not available for the years 1973-1975. Data series have been smoothed by taking a moving average over three neighboring waves.

where $Y_{i s, t}$ denotes extraction relative to income for household $i$ living in state $s$ in year $t$. We focus exclusively on households who do not move. The expression $Y_{i s, t+h}$ denotes the cumulative extraction relative to income between period $t$ and period $t+h ; g_{s t}^{P}$ is the growth rate of the state-level FHFA house price index between two survey waves; and $X_{i s t}$ is a set of household-level demographic controls that are plausibly related to equity extraction. ${ }^{19}$ The regressions also include time and household fixed effects $\delta_{t}$ and $\gamma_{i}$ to capture aggregate conditions and time-invariant household characteristics. As mentioned before, the PSID changed its frequency from annual to biennial in 1997. To get consistent results over time, we discard the even survey waves before 1997 and re-compute equity extraction based on the remaining information. Hence, one period corresponds to two years.

Figure 19 plots the estimated coefficients $\hat{\beta}_{1}$ for $h=1, \ldots, 5$ from equation (4). The results imply that after a 10 percent increase in house prices, which corresponds to one standard deviation of house price growth, the average homeowner extracts equity equal to about $0.9 \%$ of annual income over the following six years. Importantly, for the middle class, the effect is about one-third larger, with a cumulative response of around $1.2 \%$ of annual income over six years. Hence, these estimates corroborate that the association between house price growth and equity extraction is most pronounced in the middle of the income distribution.

To also put these estimates into perspective, we do a simple back-of-the-envelope cal-

\footnotetext{
${ }^{19}$ We include age group dummies to capture the life cycle, as well as dummies for the total number of children, the birth of an additional child, and business ownership.
} 
Figure 19: Effect of house prices over time

(a) All income groups

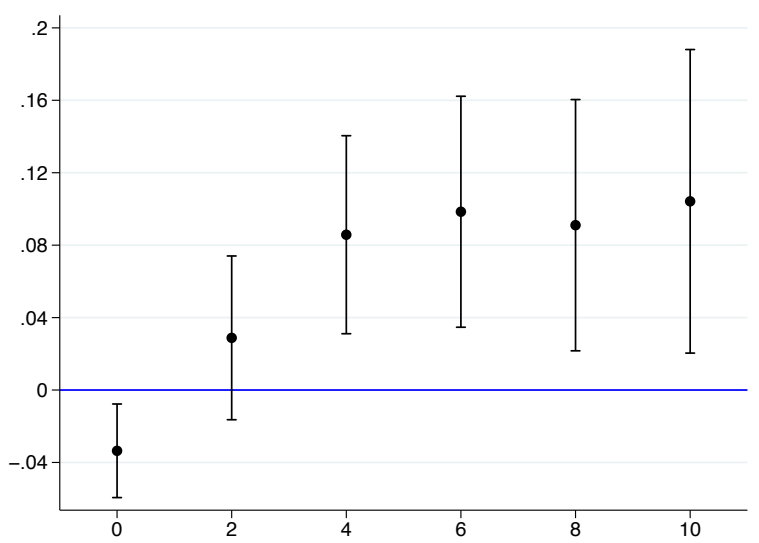

(b) $50 \%-90 \%$ only

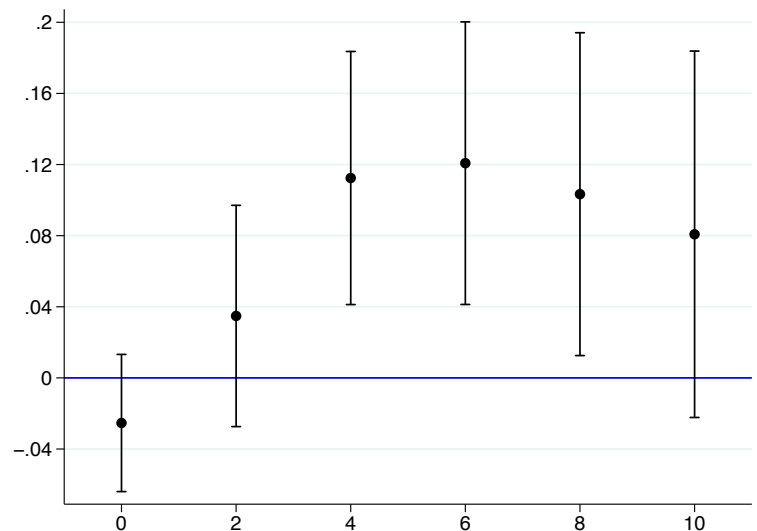

Notes: The left panel shows the coefficient on house price growth at various horizons from equation (4). The right panel shows the corresponding coefficients after restricting the sample to middle-class households. Observations with extraction amounts larger than twice the annual income or with negative income were excluded. Two-year periods were considered throughout. Controls include dummies for age, children, and business ownership, as well as time fixed effects. Standard errors are clustered at the household level.

culation. Figure 18 reports an average increase in equity extraction to income by 2.3 percentage points between 1986 and 2007. When doing this calculation, an important caveat to keep in mind is that the estimates from Figure 19 do not directly translate to this change in extraction behavior. If we apply the estimate, then the point estimate for the six-year horizon implies that a $25 \%$ house price increase is necessary to account for such an increase in extraction behavior. Between 1986 and 2007, house prices increased at the peak by roughly $60 \%$, but on average they were only slightly more than $20 \%$ higher (Figure 14a). This average increase of $20 \%$ implies a 1.8 percentage point increase in extraction and therefore is similar in magnitude to the increase in equity extraction from Figure 18.

Finally, we also estimated event-study regressions around the extraction date, using the reported value of a household's home as the outcome variable. The results show that the house values of extractors increased substantially more than those of non-extractors in the six years prior to extraction, consistent with the evidence from the local projections (Appendix Figure A.18).

\subsubsection{Aggregate importance of middle-class equity extraction}

In a final step, we aggregate the group-specific house price responses back to the level of the macroeconomy to calculate the importance of equity extraction by the different income groups. To do this, we compute the average amount of additional debt due to extraction, as in Figure 17, and multiply it with the total number of households to obtain 
the aggregate effect. We then add up the resulting series to find the amount by which equity extraction contributed to the aggregate stock of housing debt each period. Finally, we subtract this estimate from total aggregate housing debt, which provides us with an estimate of how much debt would have increased absent the contribution from equity extraction. ${ }^{20}$ The black line in Figure 20a shows the actual housing debt-to-income ratio from the PSID data. ${ }^{21}$ The blue line shows the counterfactual housing debt-to-income ratio after subtracting our estimate of additional debt due to extraction.

Figure 20: Quantitative importance of middle-class extraction

(a) Counterfactual housing debt-to-income ratio

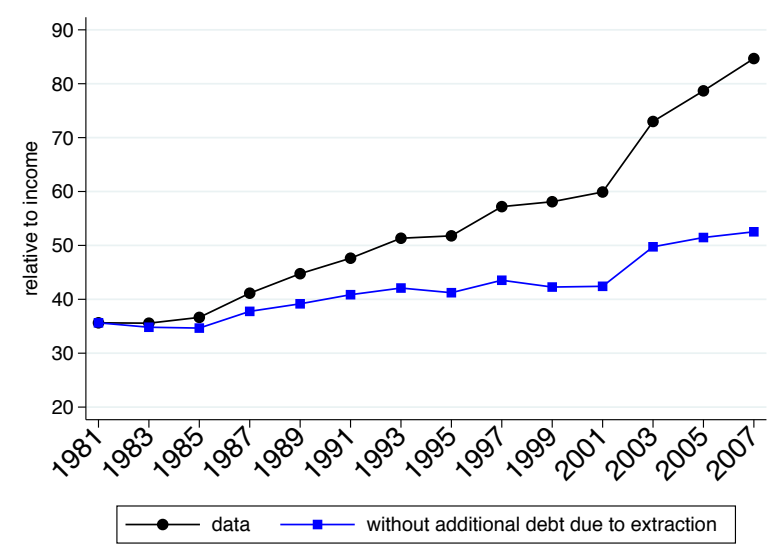

(b) Role of the middle class

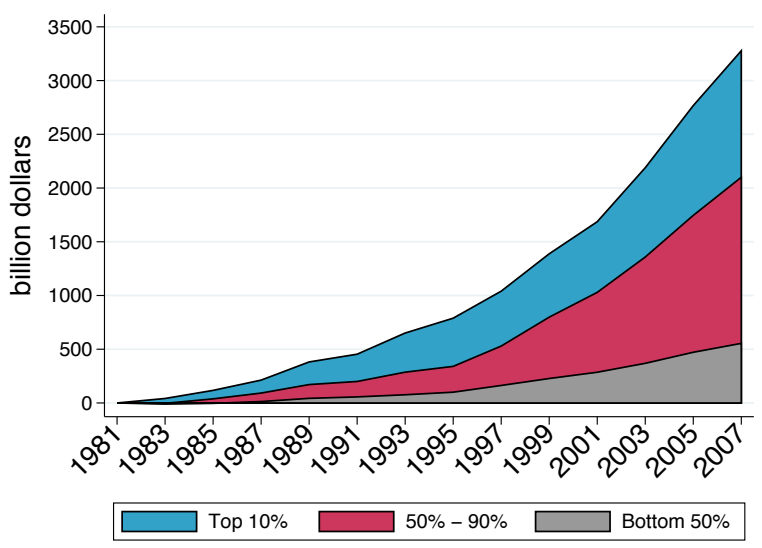

Notes: The left panel shows the housing debt-to-income ratio from the PSID. The blue line with squares shows actual housing debt minus additional debt due to extraction relative to income. The right panel shows additional debt due to extraction by income group.

Without equity extraction, housing debt would have increased by half as much over the 1981 to 2007 period. Debt-to-income ratios would have stayed at around 40\% until 2001 and increased only during the boom of the 2000s, when new homeowners increased aggregate housing debt (see also Figure 17). Compared to the observed increase, the counterfactual increase would have been much more modest. By 2007, we estimate that the housing debt-to-income ratio would barely have exceeded $50 \%$ of income.

We can also approximate the effect on total household debt based on SCF + data, which also include non-housing debt. If we assume that housing debt had increased by $50 \%$ less from 1983 to 2007 and that non-housing debt had not been affected by the slower increase in housing debt, total household debt would have peaked a third lower in 2007 at around $74 \%$ of income (Figure 3). ${ }^{22}$ Figure 20b highlights the role of the middle class in this development. Equity extraction of the middle class accounts for the lion's share of total equity extraction and the largest part of the increase in household debt.

\footnotetext{
${ }^{20}$ This simple estimate rules out behavioral and general equilibrium responses.

${ }^{21}$ Note that the housing debt-to-income ratio has increased somewhat less in the PSID than in the SCF+, reaching 0.84 in 2007, compared to 0.92 in the SCF+ (Appendix Figure B.2).

${ }^{22}$ In the PSID, information on non-housing debt is only available since 1984, and the quality and detail of the data are lower than in the SCF+. However, comparing the debt increase in the PSID since 1984 and the SCF since 1983 yields similar results.
} 


\section{A Modigliani perspective on home-equity-based bor- rowing}

In the data, home-equity-based borrowing is the main driver of the American debt boom in recent decades. Can we rationalize this behavior with the predictions of a theoretical model of household consumption? The idea that house price changes affect household behavior is intuitive. If house prices rise, the value of home equity on the household balance sheet increases ceteris paribus. If households expect this increase in house prices to be persistent, they want to extract these capital gains to finance additional consumption. Households increase their consumption because of a positive wealth effect.

Two arguments against such a wealth effect are often put forward. The first is that housing wealth is not wealth because housing is a consumption good. If house prices rise, future housing consumption becomes more expensive so that households effectively do not get wealthier. This intuition is derived by Sinai and Souleles (2005) in an infinitehorizon model with fixed housing consumption. ${ }^{23}$ Key to their "neutrality" result for house price changes is the infinite housing tenure of agents. Introducing finite lifetimes, life-cycle variation in housing demand, contemporaneous ownership of housing by different generations, or imperfectly correlated local housing markets will imply that rising housing wealth triggers consumption responses of homeowners also in the model of Sinai and Souleles (2005). This can be seen very intuitively when taking a Modigliani perspective with a life-cycle model without bequests (Modigliani and Brumberg, 1954). In such a model, households will reduce housing consumption to zero at the end of their life, which implies that they will always realize capital gains from house price changes, so that the wealth effect arises naturally. ${ }^{24}$ Equity extraction by raising housing debt allows households to increase non-housing consumption while still keeping housing consumption constant.

The second argument put forward against a large housing wealth effect is quantitative rather than qualitative, namely, that under the permanent income hypothesis (PIH), marginal propensities to consume (MPCs) out of wealth are small. Again, it is crucial to take a Modigliani perspective for two reasons. First, housing makes up a large share of total wealth for the typical homeowner, so that house price changes have large effects on the lifetime budget constraint. Second, the shorter the remaining life span is, the larger is the MPC out of wealth. The infinite-horizon abstraction is the polar case along both dimensions. First, human capital is largest because of infinite working lives, and housing

\footnotetext{
${ }^{23}$ This view is also prominently discussed in Case, Glaeser, and Parker (2000).

${ }^{24}$ Sinai and Souleles (2005) discuss conditions under which a wealth effect is ruled out even in models with finite lifetimes. Effectively, what is needed are infinite housing tenure across generations and no adjustment to housing consumption. Moreover, financial markets have to work without frictions, as loosening borrowing constraints due to house price increases can also lead to a positive consumption response.
} 
wealth accounts for only a small share of total household wealth. Second, the infinite horizon also implies that the remaining lifetime is infinite. By contrast, in a life-cycle model with finite working lives and lifetime, MPCs out of wealth are substantially larger, consistent with empirical estimates. The point that large MPCs out of housing wealth are consistent with economic theory is shown in great detail in Berger et al. (2017).

For our discussion, we rely on a life-cycle model adapted from Berger et al. (2017). To keep the model analytically tractable, we abstract from idiosyncratic income risk, borrowing constraints, and trading costs, but the consumption response to house price changes in our model is still quantitatively in line with the preferred estimate of Berger et al. (2017).

We consider the following economic environment. Households live for $J+1$ periods, have an exogenous income profile $\left\{y_{j}\right\}_{j=0}^{J}$, and aim at maximizing their lifetime utility from consumption. Instead of considering (net) household wealth, we split household wealth into housing assets $h$ and financial assets (mortgage debt) $d$, of which households receive fixed initial endowments $h_{-1}$ and $d_{0}$. Housing can be traded without frictions at price $p_{h}$ each period and depreciates at rate $\delta$. The (mortgage) interest rate is denoted by $r$. We abstract from bequests and assume that at the end of life, households sell their homes, repay their debt, and consume all available resources.

We assume that at each age $j$, households have a time-separable log utility function over a Cobb-Douglas composite of housing $h_{j}$ and non-housing consumption $c_{j}$, specifically, $u(c, h)=\rho \log (c)+(1-\rho) \log (h)$. In this case, the household problem has a well-known solution with a constant expenditure share $\rho$ for non-housing consumption and an optimal consumption path $c_{j}^{*}=c_{0}^{*}(\beta(1+r))^{j}$, where $\beta$ denotes the time discount factor. ${ }^{25}$ The level of the consumption path $c_{0}^{*}$ is determined by total household wealth $W$, which is the sum of human capital $Y$, equal to the discounted incomes $y_{j}$ at all ages $j$, and initial home equity $E$,

$$
W=E+Y \quad \text { with } Y=\sum_{j=0}^{J} y_{j}(1+r)^{-j} \text { and } E=(1-\delta) p_{h} h_{-1}-(1+r) d_{0},
$$

multiplied by the MPC $\alpha$ and the optimal expenditure share $\rho$,

$$
c_{0}^{*}=\alpha \rho W \quad \text { with } \alpha=\frac{1-\beta}{1-\beta^{J+1}} .
$$

It follows immediately that any change in home equity $E$ from either higher house prices $p_{h}$ or lower debt levels $d_{0}$ will lead to an upward shift in the consumption profile. The optimal consumption dynamics, however, will remain unaffected, as they only depend on the wedge between the time discount factor $\beta$ and the interest rate $r{ }^{26}$

Deriving the elasticity of the optimal consumption level $c_{0}^{*}$ with respect to a persistent increase in house price $p_{h}$, we get a simple, intuitive expression (see equation (A.1) in

\footnotetext{
${ }^{25}$ See Appendix D for details of the derivation.

${ }^{26} \mathrm{Key}$ for this result is that we rule out potentially binding borrowing constraints.
} 
Berger et al. 2017):

$$
\frac{\partial c_{0}^{*}}{\partial p_{h}} \frac{p_{h}}{c_{0}^{*}}=\frac{(1-\delta) p_{h} h_{-1}}{W}=\theta_{h},
$$

where $\theta_{h}$ denotes the portfolio share of housing $(1-\delta) p_{h} h_{-1}$ in total wealth $W$. This elasticity for house price changes keeps human capital constant when changing the house price, thereby capturing a situation with rising house prices and stagnant incomes. Note that the formula applies to each point in the life cycle if lifetime $J$ represents the remaining lifetime and the current period is interpreted as $j=0$.

This simple expression for the elasticity states that the larger the exposure of household wealth $W$ to house prices, the higher the elasticity of consumption with respect to house price shocks. Exposure to house prices in the model is determined by the portfolio share of housing in total wealth $\theta_{h}$. Intuitively, a larger portfolio share of housing implies that a larger share of lifetime consumption is financed out of non-human wealth. This further implies that the elasticity of consumption with respect to house price shocks is increasing in leverage, as leverage reduces $W$ while leaving housing assets $(1-\delta) p_{h} h_{-1}$ unaffected so that $\theta_{h}$ increases. ${ }^{27}$ Equation (7) therefore explains why the typical middleclass household with a large exposure to the housing market responds more strongly to house price shocks than households in the top $10 \%$ of the income distribution. A second important implication is that in housing boom phases, when $\theta_{h}$ is typically increasing, households' sensitivity with respect to house price shocks also increases.

When discussing the consumption response under the PIH, Berger et al. (2017) parametrize the expression for the consumption elasticity in equation (7) based on an infinite-horizon abstraction that results in a small consumption response to house price shocks due to a very large value of human capital $Y$. When we take a Modigliani perspective by considering finite working lives and a typical homeowner of age 51, we get an elasticity of consumption that is almost four times larger (0.18 vs. 0.05$)$ with respect to house prices. ${ }^{28}$ This consumption response is only slightly lower than the preferred empirical estimate of 0.23 by Berger et al. (2017). Key for the lower elasticity in our model is that we abstract from income risk and borrowing constraints that shape MPCs in the cross section. Berger et al. (2017) demonstrate that their richer model matches MPCs so that the theoretical consumption response in equation (7) approximates observed consumption responses to house price shocks very well.

These consumption dynamics induce corresponding debt dynamics according to the law of motion $d_{j+1}=(1+r) d_{j}-\left(y_{j}-c_{j}\right)+p_{h}\left(h_{j}-(1-\delta) h_{j-1}\right)$. Intuitively, future debt $d_{j+1}$ depends positively on the current level of debt $d_{j}$ and on the current repayment

\footnotetext{
${ }^{27}$ This may not extend to extreme cases such as underwater borrowers (Ganong and Noel 2017).

${ }^{28}$ Specifically, we follow Krebs, Kuhn, and Wright (2017) to estimate the human capital stock $Y$ in equation (7) and focus on home equity as non-human wealth. We set the end of working life to age 65, the (mortgage) interest rate to $5.5 \%$ (average debt-weighted mortgage interest rate in 1992-2001 SCF data), and use cross-sectional SCF data from 2001 as in Berger et al. (2017).
} 
$\left(y_{j}-c_{j}>0\right)$ or extraction flow $\left(y_{j}-c_{j}<0\right)$, and adjustments to the housing stock including depreciation $p_{h}\left(h_{j}-(1-\delta) h_{j-1}\right)$. Iterating the law of motion forward, we get that, at any age $j+1$, the current debt level is simply the initial debt level $d_{0}$ plus the accumulated sum of repayment and extraction flows, housing adjustments, and accrued interest payments: ${ }^{29}$

$$
d_{j+1}=(1+r)^{j+1} d_{0}+\sum_{s=0}^{j}(1+r)^{j-s}\left(c_{s}-y_{s}\right)+\sum_{s=0}^{j}(1+r)^{j-s} p_{h}\left(h_{s}-(1-\delta) h_{s-1}\right) .
$$

These debt dynamics also highlight that any consumption response financed by equity extraction will lead to additional interest payments and accrued interest as part of future debt levels. This highlights again the particular role of housing on the household balance sheet. Unlike in the case of financial assets such as stocks, households can realize capital gains from house price changes by increasing debt rather than selling (part of) their house.

An alternative response to equity extraction is an adjustment to savings rates, for example, through a reduction in amortization of mortgage debt. Such an adjustment to amortization rates will allow for an upward shift of the consumption profile and will lead to higher future debt levels. Yet, it is important to note that such a response can go hand in hand with declining debt levels over the life cycle, but now these debt levels decline by less than originally (before the house price increase) planned. In our empirical approach above, such a reduction in amortization would not be included in our measure of equity extraction as a household's mortgage debt does not increase over time. Thus, our estimate for the contribution of equity extraction to the debt increase should instead be considered as a conservative lower bound. At the level of the macroeconomy, the reduction in amortization contributes to an upward shift in life-cycle debt profiles and to higher household debt (see Section 3.4).

Finally, it is important to acknowledge that our model is very stylized. In Appendix D, we discuss in detail the simplifying assumptions made and how they might be relaxed. Yet despite its simplicity, this stylized model shows that the observed household behavior can be rationalized from a Modigliani perspective.

This section demonstrated that from a microeconomic perspective, increased borrowing in response to rising house prices is the optimal response for households who want to smooth their lifetime consumption. At the level of the macroeconomy, more households with more debt may, however, lead not only to higher aggregate debt levels but also to more financial fragility. Such macroeconomic consequences are not taken into account in microeconomic decision making, but might be of first-order importance when evaluating the consequences of rising household indebtedness. In the last section, we will explore these macroeconomic consequences of individual behavior by asking if the Modigliani response of households

\footnotetext{
${ }^{29}$ The model provides the stylized implication of a constant extraction of home equity over the remaining lifetime. Introducing financial frictions in a two-asset extension with liquid and illiquid (housing) wealth will induce a lumpy adjustment of home equity.
} 
makes the macroeconomy more fragile.

\section{Modigliani meets Minsky}

In the last section, we return to the macroeconomy to explore the consequences of the surge in debt-financed home equity extraction for financial stability. The gist of the argument will be that home-equity-based borrowing, while optimal at an individual level from a Modigliani perspective, has made the economy and especially the balance sheets of middle-class families more fragile. We will show that the sensitivity of households to income shocks has risen substantially as debt ratios have surged. The surge in home equity borrowing since the 1980s played an important role in this process. We call this the Minsky aspect of the equity extraction boom.

Financial fragility is a complex and multidimensional issue. For the analysis here, we focus on household liquidity as one important dimension of financial risk. Liquidity has been emphasized in recent research as an important driver of household consumption decisions (Kaplan and Violante 2014) and mortgage defaults (Ganong and Noel 2018). We quantify growing vulnerability using a stress testing approach, not dissimilar to the stress tests used for financial institutions.

Our analysis of the macroeconomic consequences of home-equity-based borrowing builds on the work of Mian and Sufi (2011) that explores the link between equity extraction and default rates in the crisis. In a similar spirit, Fuster, Guttman-Kenney, and Haughwout (2018) conduct a stress test for households based on Equifax CRISM data, shocking home equity positions. The latter paper focuses on a relatively short time period from 2005 to 2017. Playing on the strength of the long-run SCF + data, we are able to track the trends in financial fragility of the U.S. household sector over a long time period and demonstrate secular changes in macroeconomic financial fragility.

We start our discussion of the evolution of financial fragility with the evolution of debtservice ratios, as they provide a key link between household debt and household liquidity. The previous sections have shown a substantial rise in debt-to-income ratios among the bottom $90 \%$ of the income distribution. Figure 21a shows that the rise in debt-to-income ratios also led to rising debt-service ratios. Falling interest rates cushioned the effect of rising debt on debt-service ratios, but the share of income devoted to debt service went up by $50 \%$ between the early 1980s and mid-1990s, with particularly pronounced increases for the bottom $50 \%$ and the middle class. Typically, the bottom $50 \%$ devote a 1.5 times larger share of their income to debt service relative to the middle class. A similar gap exists between the middle class and the top 10\%. Figure $21 \mathrm{~b}$ shows loan-to-value ratios for these groups. They evolved largely in lockstep over time. The diverging trends between debt-service-to-income ratios and loan-to-value ratios reiterate on the point of 
Figure 21: Debt-service-to-income and loan-to-value ratios

(a) by income group

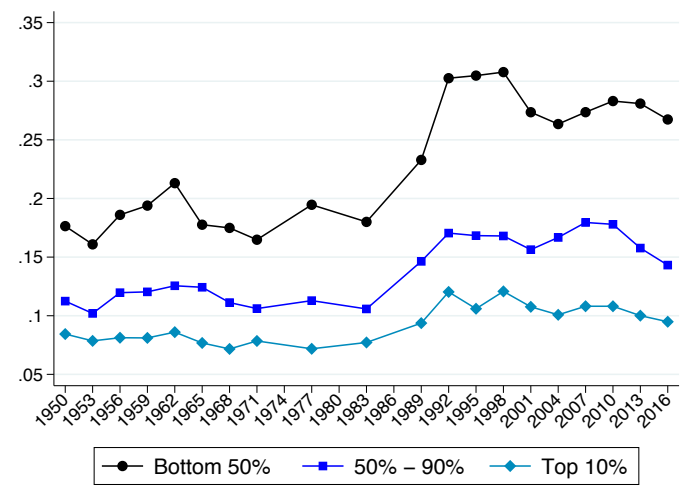

(b) Loan-to-value ratios

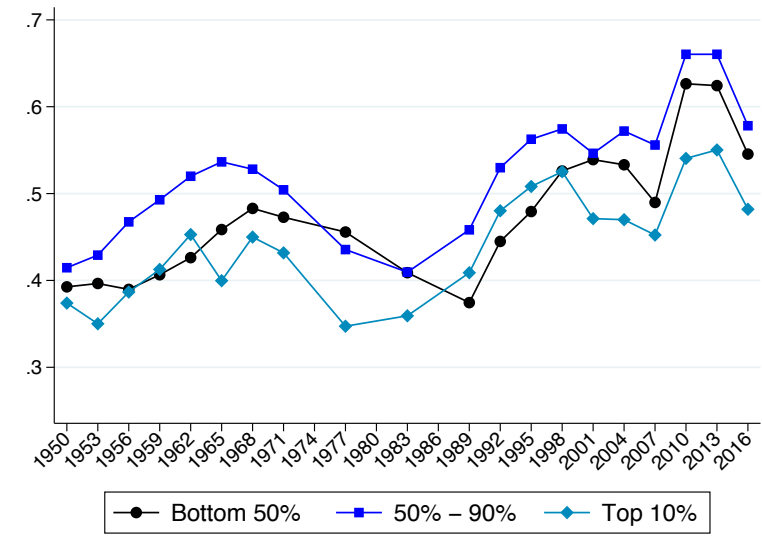

Notes: The left panel shows average debt service relative to income among households with positive housing debt, stratified by income. The right panel shows loan-to-value ratios for household groups stratified by income.

the diverging trends between incomes and asset values along the income distribution in the United States since the 1980s, which we have discussed in detail.

For our main stress test scenario, we construct shocks that constrain the debt-servicing ability of households. Drops in income reduce liquidity and put households under financial stress. This in turn requires them to cut their consumption or forces them into loan delinquency or even default. For the income drop, we employ the estimates on earnings losses following job displacement by Davis and von Wachter (2011). They document that earnings losses are particularly pronounced in recessions, amounting to losses of $39 \%$ in the first year after displacement (Figure 4 in Davis and von Wachter 2011). We use this number and let the income of the main wage earner of all households drop by $39 \%{ }^{30}$ Following the literature, we then consider a household to be under financial stress if the debt-service-to-income ratio exceeds $40 \%$ after the income shock. ${ }^{31}$

In a second scenario, we consider a joint income and house price shock. The house price shock reduces home equity and pushes some households into negative equity territory. A strand of the literature has emphasized the importance of such "double trigger" events for fragility and default (see, e.g., Adelino, Schoar, and Severino 2018, Fuster, GuttmanKenney, and Haughwout 2018). The condition for financial stress under this scenario is more demanding, as we require the debt-service-to-income ratio to exceed $40 \%$ and home equity to be negative.

\footnotetext{
${ }^{30}$ We exclude households with negative income. Before 1956, we do not have separate information on the labor income of head and spouse. We therefore impute the earnings share of the principal earner based on data from 1956 to 1959. The average share of the main earner in total household labor income was between $88 \%$ and $93 \%$ in these years.

${ }^{31}$ The value of 0.4 is used in the Financial Stability Reports of the Bank of England. We are grateful to Anil Kashyap for suggesting this source. The value of 0.4 also lies between the thresholds of 0.36 and 0.45 in the "eligibility matrix" used by the Federal National Mortgage Association (Fannie Mae).
} 
In the following, we focus on the income shock scenario and present the results for the "double trigger" in Appendix E. ${ }^{32}$ We report the share of households that will be under financial stress after receiving the shock and the loan value at risk, computed as the value of outstanding mortgage balances of all households under financial stress. Our results reflect a shock potential by applying the income shock to all households, and we abstain from a quantification of the further macroeconomic consequences. We compare the shock impact over time. Clearly, the quantification of the macroeconomic consequences will depend on general equilibrium effects and household default decisions, changes in consumption and saving behavior, and monetary and fiscal reactions to the initial shock. Characterizing and quantifying all these effects is beyond the scope of this exercise.

We report the value at risk as a share of income and as a share of bank equity, as the latter is particularly informative for the resilience of the financial sector to absorb the household sector's financial fragility. We take the total amount of equity capital in the U.S. banking system from Jordà et al. (2017). It is important to note that bank equity has been reasonably stable relative to income (Jordà et al. 2017), so that the reported changes in the value at risk stem from the household side of the economy.

Table 2: Households at risk and loan value at risk as share of income and bank equity

\begin{tabular}{cccccccccccccc}
\hline & \multicolumn{3}{c}{ Aggregate } & \multicolumn{2}{c}{ Bottom $50 \%$} & & $50 \%-90 \%$ & & \multicolumn{2}{c}{ Top $10 \%$} \\
\hline & HH & INC & BE & HH & INC & BE & HH & INC & BE & HH & INC & BE \\
\hline 1950 & $1.8 \%$ & $2.3 \%$ & $46.1 \%$ & $2.6 \%$ & $1.4 \%$ & $28.9 \%$ & $1.1 \%$ & $0.7 \%$ & $13.9 \%$ & $0.5 \%$ & $0.2 \%$ & $3.3 \%$ \\
1971 & $1.2 \%$ & $1.4 \%$ & $33.4 \%$ & $2.3 \%$ & $1.1 \%$ & $25.9 \%$ & $0.3 \%$ & $0.3 \%$ & $7.4 \%$ & $0.0 \%$ & $0.0 \%$ & $0.0 \%$ \\
1983 & $2.2 \%$ & $4.1 \%$ & $96.6 \%$ & $3.3 \%$ & $2.0 \%$ & $46.4 \%$ & $1.3 \%$ & $1.3 \%$ & $31.3 \%$ & $0.6 \%$ & $0.8 \%$ & $18.9 \%$ \\
1992 & $6.5 \%$ & $14.1 \%$ & $212.0 \%$ & $6.5 \%$ & $3.9 \%$ & $59.3 \%$ & $7.3 \%$ & $7.3 \%$ & $110.5 \%$ & $3.4 \%$ & $2.8 \%$ & $42.2 \%$ \\
2001 & $6.8 \%$ & $12.1 \%$ & $167.9 \%$ & $9.0 \%$ & $5.1 \%$ & $70.7 \%$ & $5.2 \%$ & $5.5 \%$ & $76.1 \%$ & $2.3 \%$ & $1.5 \%$ & $21.1 \%$ \\
2007 & $8.5 \%$ & $23.6 \%$ & $251.7 \%$ & $9.6 \%$ & $7.7 \%$ & $81.9 \%$ & $8.6 \%$ & $13.0 \%$ & $138.9 \%$ & $2.4 \%$ & $2.9 \%$ & $30.9 \%$ \\
2016 & $5.2 \%$ & $10.4 \%$ & $86.5 \%$ & $7.4 \%$ & $5.0 \%$ & $42.0 \%$ & $3.4 \%$ & $4.6 \%$ & $38.2 \%$ & $0.7 \%$ & $0.8 \%$ & $6.4 \%$ \\
\hline
\end{tabular}

Notes: The table shows the share of households and the loan value at risk relative to income and bank equity after a $39 \%$ drop in the main earner's income. The share of households is shown in the columns labeled $H H$, the loan value at risk relative to income in the columns labeled $I N C$, and relative to bank equity in the columns labeled $B E$. The column labeled Aggregate shows results for all households. Columns show bottom $50 \%, 50 \%-90 \%$, and top $10 \%$ for the respective household groups. The calculations are based on $\mathrm{SCF}+$ data. Households are assumed to be at risk if they have a debt-service-to-income ratio $>40 \%$.

\footnotetext{
${ }^{32}$ The "double trigger" scenario combines our baseline income shock scenario with a $20 \%$ drop in real house prices, which is similar to the fall in average U.S. house prices from 2007 to 2012 (-16.5\% in nominal terms according to the FHFA house price index). Households are assumed to be at risk if their home equity turns negative on top of having a debt-service-to-income ratio above 0.4 after the shock.
} 
Table 2 reports estimates at selected years for the share of households (column $H H$ ) and the loan value at risk as a share of household income (column $I N C$ ) and as a share of bank equity (column $B E$ ). We show figures with the entire time series in Appendix E. The left panel shows aggregate numbers, and the three other panels attribute the estimates to the three income groups so that the sum across income groups corresponds again to the numbers for the aggregate.

Looking at Table 2, we make three observations. First, the share of households who come under financial stress after a drop in income increased from around 2\% between 1950 and 1980 to up to $8.5 \%$ by 2007 . Second, there is also a pronounced increase in the loan value at risk over time. Relative to income, we find that it increased from less than $5 \%$ over the four decades after 1950 to its peak of $24 \%$ by 2007 , so that financial fragility risk originating from the household sector increased fivefold over six decades. Third, we observe that bank balance sheets have become less resilient to shocks from the household sector. Relative to bank equity, the shock potential increased from less than $50 \%$ in 1950 to more than $250 \%$ by 2007 , so that, again, the aggregate financial risk for bank balance sheets from the more indebted household sector increased fivefold over time.

The next three panels of Table 2 zoom in on the income distribution. They show that the increase in fragility was mainly attributable to households in the bottom $90 \%$ of the income distribution. The share of households under financial stress after a drop in income increased substantially for the bottom $50 \%$, but the increase was most dramatic for the middle class. Starting from shares around $1 \%$ in 1950, the share of middle-class households susceptible to financial stress increased almost eightfold by 2007. Looking at the value at risk as a share of income, we find the "baseline level" of fragility has always been between $1 \%$ and $2 \%$ for the bottom $50 \%$ and slightly lower for the middle class. The fragility of income groups evolved in lockstep until 1980 and has increased substantially for both groups since then. In particular, the vulnerability of the middle class surged over these four decades. ${ }^{33}$ As a share of bank equity, the loan value at risk originating from the middle class increased tenfold and much more than the fivefold increase in the aggregate between 1950 and 2007. By contrast, the high incomes of the top $10 \%$ largely shielded this group from a similar increase in financial fragility. In 2007, only $2.4 \%$ of households from the top $10 \%$ would have exceeded the debt service threshold after the shock, and the loan value at risk for this group never exceeds $3 \%$ of total income. While quantifying the macroeconomic consequences of such financial risks is beyond the scope of this paper, the results show that the potential of the underlying financial risk increased fivefold to tenfold over recent decades and is still high today.

The results also highlight how the middle class turned from being an anchor of financial stability to the epicenter of financial risks. These dynamics underscore the considerable macroeconomic consequences of middle-class home-equity-based borrowing. Financial

\footnotetext{
${ }^{33}$ Figure E.2 in the Appendix shows that qualitatively similar patterns emerge when using PSID data.
} 
fragility rose in the background while households reacted to the rising house prices and implied rising wealth levels. To paraphrase Minsky, the seeds of the increase in financial vulnerability were sown in good times.

Our stress testing of household balance sheets also points to an existing tension for regulation of debt markets when Modigliani meets Minsky. Through the lens of economic theory, equity extraction provides an opportunity for welfare-enhancing life-cycle consumption smoothing - a key aspect of functioning financial markets. Yet, when turning to the macroeconomy, such optimizing behavior can come at the cost of elevated levels of financial fragility. This connects our paper to recent work on excessive leverage and aggregate demand externalities (Korinek and Simsek 2016, Schmitt-Grohé and Uribe 2016), as well as research that discusses the high sensitivity of high-leverage economies to business cycle shocks (Jordà, Schularick, and Taylor, 2017).

\section{Conclusion}

This paper studied the increase in household debt in the United States since World War II. Relative to income, household debt has risen by a factor of four. Yet the financial history of the United States' postwar surge in household debt has remained unwritten. Using long-run household-level data from the $\mathrm{SCF}+$, this paper helps to close this gap. We document the growth of U.S. household debt, its composition and distribution, as well as the link to developments on the asset side of the household balance sheet. We emphasize the nexus between house prices, housing wealth, and equity extraction. House price increases led to a substantial increase in household wealth, to which optimizing middleclass households responded by extracting home equity via debt. Such home-equity-based borrowing accounts for about half of the increase in U.S. household indebtedness in the past four decades. At the same time, our study documents the increase in financial stability risks that arise when households treat asset-price-induced wealth gains as permanent and borrow against them. This interaction between asset prices and home-equity-based borrowing is central to the surge in household debt since World War II. Our findings provide new and potentially important insights for future research on household portfolio choices and their implications for financial stability. 


\section{References}

Adelino, Manuel, Antoinette Schoar, and Felipe Severino (2016). "Loan originations and defaults in the mortgage crisis: The role of the middle class". In: The Review of Financial Studies 29.7, pp. 1635-1670.

- (2018). "The Role of Housing and Mortgage Markets in the Financial Crisis". In: Annual Review of Financial Economics 10.1, pp. 25-41.

Aladangady, Aditya (2017). "Housing Wealth and Consumption: Evidence from GeographicallyLinked Microdata". In: American Economic Review 107.11, pp. 3415-46.

Albanesi, Stefania, Giacomo De Giorgi, and Jaromir Nosal (2017). Credit Growth and the Financial Crisis: A New Narrative. Working Paper.

Alvaredo, Facundo, Lucas Chancel, Thomas Piketty, Emmanuel Saez, and Gabriel Zucman (2018). World Inequality Report 2018. Harvard University Press.

Andersen, Henrik Yde and Søren Leth-Petersen (2019). Housing Wealth Effects and Mortgage Borrowing: The Effect of Subjective Unanticipated Changes in Home Values on Home Equity Extraction in Denmark. CEPR Discussion Papers 13926. C.E.P.R. Discussion Papers.

Avery, Christopher and Sarah Turner (2012). "Student Loans: Do College Students Borrow Too Much-Or Not Enough?" In: Journal of Economic Perspectives 26.1, pp. 165-92.

Berger, David, Veronica Guerrieri, Guido Lorenzoni, and Joseph Vavra (2017). "House Prices and Consumer Spending". In: The Review of Economic Studies 85.3, pp. 15021542.

Bernanke, Ben S. (2005). The Global Saving Glut and the U.S. Current Account Deficit. Speech 77. Board of Governors of the Federal Reserve System.

Bhutta, Neil (2015). "The Ins and Outs of Mortgage Debt during the Housing Boom and Bust". In: Journal of Monetary Economics 76, pp. $284-298$.

Bhutta, Neil and Benjamin J. Keys (2016). "Interest Rates and Equity Extraction during the Housing Boom". In: American Economic Review 106.7, pp. 1742-74.

Bricker, Jesse et al. (2017). "Changes in U.S. Family Finances from 2013 to 2016: Evidence from the Survey of Consumer Finances". In: Federal Reserve Bulletin 103.3.

Calomiris, Charles W., Stanley D. Longhofer, and William Miles (2013). "The Housing Wealth Effect: The Crucial Roles of Demographics, Wealth Distribution and Wealth Shares". In: Critical Finance Review 2.1, pp. 49-99. 
Campbell, John Y and Joao F Cocco (2007). "How do house prices affect consumption? Evidence from micro data". In: Journal of monetary Economics 54.3, pp. 591-621.

Canner, Glenn B., Karen E. Dynan, and Wayne Passmore (2002). "Mortgage refinancing in 2001 and early 2002". In: Federal Reserve Bulletin Dec, pp. 469-481.

Canner, Glenn B., James T. Fergus, and Charles A. Luckett (1988). "Home Equity Lines of Credit". In: Federal Reserve Bulletin 74, p. 361.

Case, Karl E, Edward L Glaeser, and Jonathan A Parker (2000). "Real estate and the macroeconomy". In: Brookings Papers on Economic Activity 2000.2, pp. 119-162.

Cloyne, James, Kilian Huber, Ethan Ilzetzki, and Henrik Kleven (2017). The Effect of House Prices on Household Borrowing: A New Approach. Working Paper.

Coibion, Olivier, Yuriy Gorodnichenko, Marianna Kudlyak, and John Mondragon (Jan. 2020). "Greater Inequality and Household Borrowing: New Evidence from Household Data". In: Journal of the European Economic Association.

Cooper, Daniel (2010). Did Easy Credit Lead to Overspending? Home Equity Borrowing and Household Behavior in the Early 2000s. Working Paper.

Davis, Steven J. and Till von Wachter (2011). "Recessions and the Costs of Job Loss". In: Brookings Papers on Economic Activity.

De Stefani, Alessia (2018). "Debt, Inequality and House Prices: Explaining the Dynamics of Household Borrowing Prior to the Great Recession". In: Journal of Housing Economics.

DeFusco, Anthony A., Charles G. Nathanson, and Eric Zwick (2017). Speculative Dynamics of Prices and Volume. Working Paper 23449. National Bureau of Economic Research.

Dettling, Lisa J, Sebastian Devlin-Foltz, Jacob Krimmel, Sarah Pack, and Jeffrey P Thompson (2015). "Comparing micro and macro sources for household accounts in the United States: evidence from the Survey of Consumer Finances". In: Available at SSRN 2669590.

Di Maggio, Marco and Amir Kermani (2017). "Credit-Induced Boom and Bust". In: The Review of Financial Studies 30.11, pp. 3711-3758.

Díaz-Giménez, Javier, Andy Glover, and José-Víctor Ríos-Rull (2011). "Facts on the Distributions of Earnings, Income, and Wealth in the United States: 2007 Update". In: Federal Reserve Bank of Minneapolis Quarterly Review 34. 
Duca, John V. and Anil Kumar (2014). "Financial Literacy and Mortgage Equity Withdrawals". In: Journal of Urban Economics 80, pp. $62-75$.

Dynan, Karen E and Donald L Kohn (2007). "The rise in US household indebtedness: Causes and consequences". In:

Favara, Giovanni and Jean Imbs (2015). "Credit Supply and the Price of Housing". In: American Economic Review 105.3, pp. 958-92.

Fetter, Daniel K. (2013). "How Do Mortgage Subsidies Affect Home Ownership? Evidence from the Mid-century GI Bills". In: American Economic Journal: Economic Policy 5.2 , pp. $111-147$.

- (2014). "The Twentieth-Century Increase in U.S. Home Ownership: Facts and Hypotheses". In: Housing and Mortgage Markets in Historical Perspective. University of Chicago Press. Chap. 10, pp. 329-350.

Fligstein, Neil, Orestes P. Hastings, and Adam Goldstein (2017). "Keeping up with the Joneses: How Households Fared in the Era of High Income Inequality and the Housing Price Bubble, 1999-2007". In: Socius 3.

Foote, Christopher L, Lara Loewenstein, and Paul S Willen (2016). Cross-sectional patterns of mortgage debt during the housing boom: evidence and implications. Tech. rep. National Bureau of Economic Research.

Fuster, Andreas, Benedict Guttman-Kenney, and Andrew F. Haughwout (2018). "Tracking and Stress-testing U.S. Household Leverage". In: Economic Policy Review 24-1, pp. 35-63.

Ganong, Peter and Pascal Noel (2017). "The Effect of Debt on Default and Consumption: Evidence from Housing Policy in the Great Recession". In: Unpublished Working Paper.

- (2018). Liquidity vs. Wealth in Household Debt Obligations: Evidence from Housing Policy in the Great Recession. Working Paper 24964. National Bureau of Economic Research.

Genesove, David and Christopher J. Mayer (1997). "Equity and Time to Sale in the Real Estate Market". In: The American Economic Review 87.3, pp. 255-269.

Greenspan, Alan and James Kennedy (2008). "Sources and Uses of Equity Extracted from Homes". In: Oxford Review of Economic Policy 24.1, pp. 120-144. 
Guerrieri, V. and H. Uhlig (2016). "Chapter 17 - Housing and Credit Markets: Booms and Busts". In: Handbook of Macroeconomics. Ed. by John B. Taylor and Harald Uhlig. Vol. 2. Elsevier, pp. $1427-1496$.

Guren, Adam M., Alisdair McKay, Emi Nakamura, and Jón Steinsson (2018). Housing Wealth Effects: The Long View. Working Paper.

Haughwout, Andrew, Donghoon Lee, Joseph S. Tracy, and Wilbert Van der Klaauw (2011). "Real Estate Investors, the Leverage Cycle, and the Housing Market Crisis". In: FRB of New York Staff Report 514.

Henriques, Alice M and Joanne W Hsu (2014). "Analysis of wealth using micro-and macrodata: A comparison of the Survey of Consumer Finances and Flow of Funds accounts". In: Measuring Economic Sustainability and Progress. University of Chicago Press, pp. $245-274$.

Hoffmann, Mathias and Iryna Stewen (Sept. 2019). "Holes in the Dike: The Global Savings Glut, U.S. House Prices, and the Long Shadow of Banking Deregulation". In: Journal of the European Economic Association.

Hurst, Erik and Frank Stafford (2004). "Home is where the equity is: Mortgage refinancing and household consumption". In: Journal of Money, credit and Banking, pp. 9851014 .

Iacoviello, Matteo (2005). "House prices, borrowing constraints, and monetary policy in the business cycle". In: American economic review 95.3, pp. 739-764.

Jordà, Òscar (2005). "Estimation and Inference of Impulse Responses by Local Projections". In: American Economic Review 95.1, pp. 161-182.

Jordà, Òscar, Moritz Schularick, and Alan M. Taylor (2013). "When Credit Bites Back". In: Journal of Money, Credit and Banking 45.s2, pp. 3-28.

Jordà, Òscar, Moritz Schularick, and Alan M. Taylor (2017). "Macrofinancial History and the New Business Cycle Facts". In: NBER Macroeconomics Annual 31.1, pp. 213263.

Jordà, Òscar, Björn Richter, Moritz Schularick, and Alan M. Taylor (2017). Bank Capital Redux: Solvency, Liquidity, and Crisis. Working Paper. National Bureau of Economic Research.

Kaplan, Greg, Kurt Mitman, and Giovanni L Violante (2017). The housing boom and bust: Model meets evidence. Tech. rep. National Bureau of Economic Research. 
Kaplan, Greg and Giovanni L Violante (2014). "A model of the consumption response to fiscal stimulus payments". In: Econometrica 82.4, pp. 1199-1239.

Kaplan, Greg, Giovanni L. Violante, and Justin Weidner (2014). "The Wealthy Hand-toMouth". In: Brookings Papers on Economic Activity 45.1, pp. 77-153.

Klyuev, Vladimir and Paul Mills (2007). "Is Housing Wealth an "ATM"? The Relationship between Household Wealth, Home Equity Withdrawal, and Saving Rates". In: IMF Staff Papers 54.3, pp. 539-561.

Korinek, Anton and Alp Simsek (2016). "Liquidity Trap and Excessive Leverage". In: American Economic Review 106.3, pp. 699-738.

Kowalewski, Kim J. (1987). "Home Equity Lines: Characteristics and Consequences". In: Economic Commentary.

Krebs, Tom, Moritz Kuhn, and Mark Wright (2017). "Under-insurance in human capital models with limited enforcement". In: Review of Economic Dynamics 25. Special Issue on Human Capital and Inequality, pp. $121-150$.

Kuhn, Moritz and José-Vıctor Rıos-Rull (2016). "2013 Update on the US Earnings, Income, and Wealth Distributional Facts: A View from Macroeconomics". In: Federal Reserve Bank of Minneapolis Quarterly Review 37.1.

Kuhn, Moritz, Moritz Schularick, and Ulrike I. Steins (forthcoming). "Income and Wealth Inequality in America". In: Journal of Political Economy.

Kumhof, Michael, Romain Rancière, and Pablo Winant (2015). "Inequality, Leverage, and Crises". In: American Economic Review 105.3, pp. 1217-45.

LaCour-Little, Michael, Eric Rosenblatt, and Vincent Yao (2010). "Home Equity Extraction by Homeowners: 2000-2006". In: Journal of Real Estate Research 32.1, pp. 2346.

Looney, Adam and Constantine Yannelis (2015). "A crisis in student loans?: How changes in the characteristics of borrowers and in the institutions they attended contributed to rising loan defaults". In: Brookings Papers on Economic Activity 2015.2, pp. 1-89.

Lusardi, Annamaria, Olivia S. Mitchell, and Noemi Oggero (2018). "The Changing Face of Debt and Financial Fragility at Older Ages". In: AEA Papers and Proceedings 108, pp. 407-11.

Maki, Dean M. (1996). "Portfolio Shuffling and Tax Reform". In: National Tax Journal, pp. 317-329. 
Maki, Dean M (2001). "Household Debt and the Tax Reform Act of 1986". In: American Economic Review 91.1, pp. 305-319.

Mian, Atif, Ludwig Straub, and Amir Sufi (2019). The Saving Glut of the Rich and the Rise in Household Debt. Working Paper.

Mian, Atif and Amir Sufi (2009). "The Consequences of Mortgage Credit Expansion: Evidence from the U.S. Mortgage Default Crisis". In: The Quarterly Journal of Economics 124.4, pp. 1449-1496.

- (2011). "House Prices, Home Equity-Based Borrowing, and the U.S. Household Leverage Crisis". In: American Economic Review 101.5, pp. 2132-56.

- (2014). House Price Gains and Us Household Spending from 2002 to 2006. Tech. rep. National Bureau of Economic Research.

- (2017). "Household Debt and Defaults from 2000 to 2010: The Credit Supply View". In: Evidence and Innovation in Housing Law and Policy. Ed. by Lee Anne Fennell and Benjamin J. Keys. Cambridge University Press, pp. 257-288.

- (2018). Credit Supply and Housing Speculation. Working Paper 24823. National Bureau of Economic Research.

Mian, Atif R, Ludwig Straub, and Amir Sufi (2020). Indebted Demand. Working Paper. National Bureau of Economic Research.

Michel, Jean-Baptiste et al. (2011). "Quantitative Analysis of Culture Using Millions of Digitized Books". In: Science 331.6014, pp. 176-182.

Modigliani, Franco and Richard Brumberg (1954). "Utility Analysis and the Consumption Function: An Interpretation of Cross-section Data". In: Post-keynesian economics 1, pp. 338-436.

Pfeffer, Fabian T., Robert F. Schoeni, Arthur Kennickell, and Patricia Andreski (2016). "Measuring Wealth and Wealth Inequality: Comparing Two U.S. Surveys". In: Journal of Economic and Social Measurement 41.2, pp. 103-120.

Piketty, Thomas and Emmanuel Saez (2003). "Income Inequality in the United States, 1913-1998". In: The Quarterly Journal of Economics 118.1, pp. 1-39.

Rajan, Raghuram G. (2011). Fault Lines: How Hidden Fractures Still Threaten the World Economy. Princeton University press.

Rappaport, Jordan (2007). "A Guide to Aggregate House Price Measures". In: Federal Reserve Bank of Kansas City Economic Review, pp. 41-71. 
Saez, Emmanuel and Gabriel Zucman (2016). "Wealth Inequality in the United States since 1913: Evidence from Capitalized Income Tax Data". In: The Quarterly Journal of Economics 131.2, pp. 519-578.

Schmitt-Grohé, Stephanie and Martın Uribe (2016). "Downward Nominal Wage Rigidity, Currency Pegs, and Involuntary Unemployment". In: Journal of Political Economy 124.5, pp. 1466-1514.

Shiller, Robert J. (2009). Irrational Exuberance. 2nd ed. New York: Broadway Books.

Sinai, Todd and Nicholas S Souleles (2005). "Owner-occupied housing as a hedge against rent risk". In: The Quarterly Journal of Economics 120.2, pp. 763-789.

Story, Louise (2008). "Home Equity Frenzy Was a Bank Ad Come True". In: The New York Times.

Wolff, Edward N. (2010). Recent Trends in Household Wealth in the United States: Rising Debt and the Middle-Class Squeeze - An Update to 200\%. Working Paper.

- (2016). Deconstructing Household Wealth Trends in the United States, 1983 - 2013. Working Paper 22704. National Bureau of Economic Research.

Zandi, Mark (2019). "How Is the Middle-Class Family Faring in Today's Economy?" In: Written Testimony before U.S. House Committee on Ways and Means.

Zinman, Jonathan (2015). "Household Debt: Facts, Puzzles, Theories, and Policies". In: Annual Review of Economics 7.1, pp. 251-276. 


\section{Appendix}

Section A of this appendix provides additional results to supplement the analysis from the main part of the paper. Section B provides a detailed comparison between housing data from the SCF + and the PSID. We discuss different estimates for equity extraction from the literature in Section C and compare our estimates from PSID and SCF data. Section D provides details on the derivation of the life-cycle model and discusses its assumptions. Finally, we present additional results for the stress test scenario from the main part of the paper and discuss the results on the alternative stress test scenario ("double trigger") in Section E.

\section{A Additional results}

\section{A.1 Debt on primary residence and other real estate debt}

Figure A.1 shows results for the amount of housing debt on primary residences and for other real estate debt. Other real estate debt related to real estate investments. We find that the debt on principal residences is on average eight times larger than the debt on other real estate. The difference is particularly large in the second half of the sample after 1980.

Figure A.1: Other real estate debt

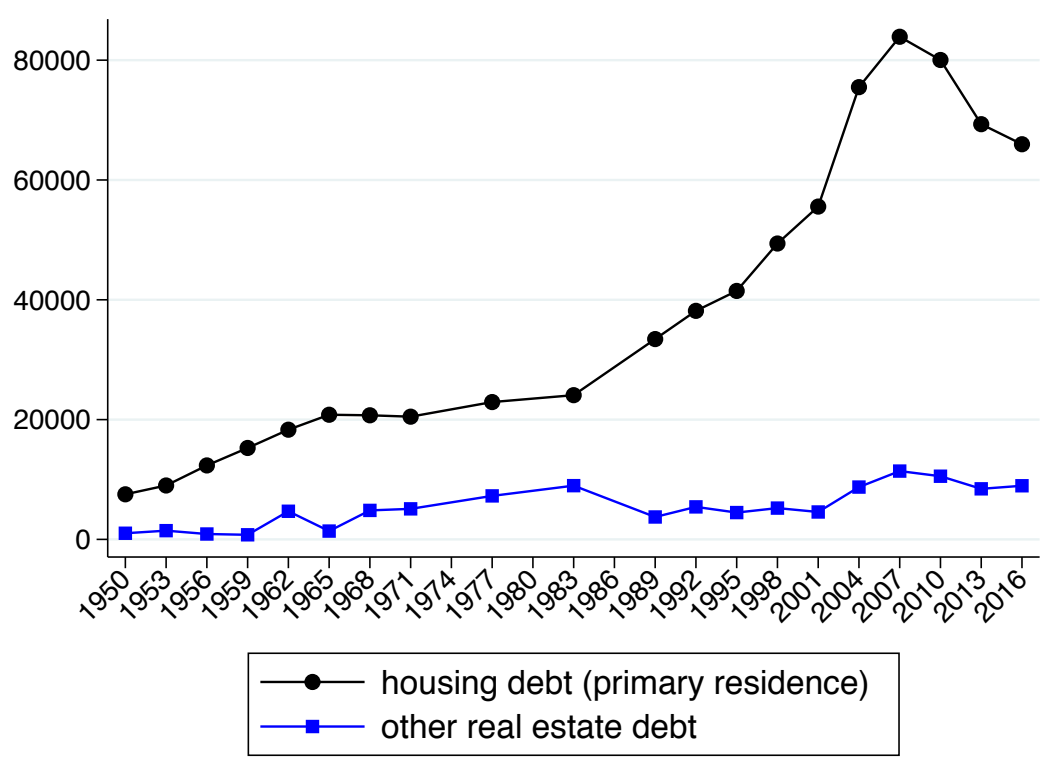

Notes: The graph shows housing debt on owner-occupied real estate in comparison to other real estate debt in the $\mathrm{SCF}+$. 


\section{A.2 Group stability over time}

Table A.1 documents the persistence within income groups in the PSID data. For households ages 30 to 55, Figure A.2 compares the time series for household debt and income in the PSID when households are binned into income groups based on the contemporaneous income or their beginning-of-decade income. The SCF data do not have a panel dimension, so we can only sort households based on their contemporaneous income. Figure A.2 demonstrates that the differences between the two sorting approaches are minor, owing to the high degree of persistence of income groups, as shown in Table A.1.

Table A.1: Income group stability

\begin{tabular}{cccccccc}
\hline year & Bottom 50\% & $50 \%-90 \%$ & Top 10\% & year & Bottom 50\% & $50 \%-90 \%$ & Top 10\% \\
\hline 1970 & 0.85 & 0.73 & 0.66 & 1989 & 0.85 & 0.74 & 0.71 \\
1971 & 0.85 & 0.74 & 0.69 & 1990 & 0.86 & 0.77 & 0.73 \\
1972 & 0.86 & 0.74 & 0.67 & 1991 & 0.86 & 0.77 & 0.70 \\
1973 & 0.86 & 0.74 & 0.64 & 1992 & 0.84 & 0.75 & 0.68 \\
1974 & 0.85 & 0.75 & 0.66 & 1993 & 0.83 & 0.75 & 0.64 \\
1975 & 0.85 & 0.75 & 0.67 & 1994 & 0.83 & 0.72 & 0.61 \\
1976 & 0.84 & 0.75 & 0.65 & 1995 & 0.83 & 0.74 & 0.60 \\
1977 & 0.85 & 0.75 & 0.62 & 1996 & 0.83 & 0.74 & 0.62 \\
1978 & 0.86 & 0.75 & 0.66 & 1997 & 0.83 & 0.72 & 0.63 \\
1979 & 0.86 & 0.74 & 0.64 & 1999 & 0.83 & 0.74 & 0.61 \\
1980 & 0.86 & 0.76 & 0.67 & 2001 & 0.81 & 0.73 & 0.64 \\
1981 & 0.86 & 0.77 & 0.65 & 2003 & 0.82 & 0.74 & 0.65 \\
1982 & 0.85 & 0.75 & 0.65 & 2005 & 0.84 & 0.76 & 0.67 \\
1983 & 0.83 & 0.75 & 0.69 & 2007 & 0.85 & 0.78 & 0.69 \\
1984 & 0.85 & 0.77 & 0.70 & 2009 & 0.85 & 0.76 & 0.64 \\
1985 & 0.86 & 0.75 & 0.65 & 2011 & 0.85 & 0.76 & 0.69 \\
1986 & 0.86 & 0.74 & 0.64 & 2013 & 0.86 & 0.77 & 0.70 \\
1987 & 0.83 & 0.74 & 0.63 & 2015 & 0.86 & 0.76 & 0.70 \\
1988 & 0.83 & 0.75 & 0.68 & 2017 & 0.84 & 0.77 & 0.74 \\
\hline
\end{tabular}

Notes: The table reports for each wave of PSID data (column year) the share of households who stayed in their respective income group since two years ago. 
Figure A.2: Sensitivity: housing debt and income by income group

(a) Housing debt

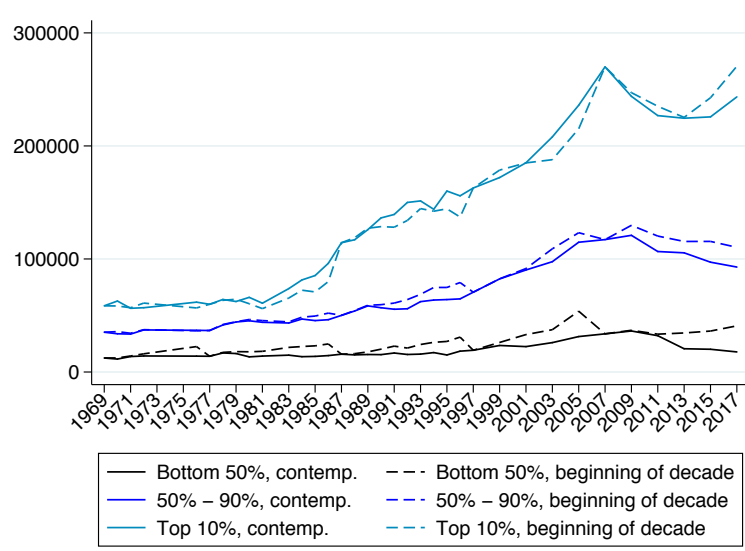

(b) Income

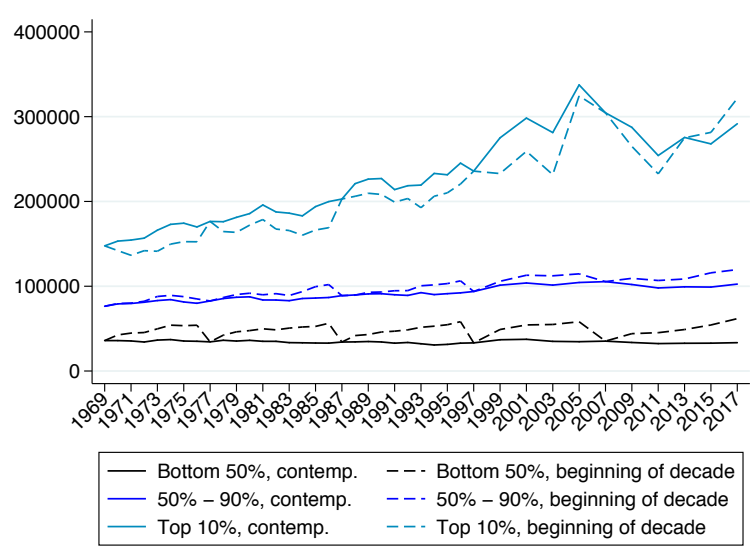

Notes: The graph shows average housing debt (left panel) and income (right panel) by income group for households between ages 30 and 55. We first sort households by their contemporaneous income and show the results as solid lines. For comparison, we sort households by their income at the beginning of each decade $(1969,1977,1987,1997,2007)$. These results are shown as dashed lines.

\section{A.3 Debt and income growth across income groups}

Figure A.3 documents income and debt growth across income groups. All time series are indexed to $1971(1971=1)$. Before 1971 , all time series comove closely so that resulting debt-to-income ratios across income groups are very stable for the pre-1971 period. We also observe a strong divergence of income and debt growth starting in the 1980s.

Figure A.3: Debt and income growth

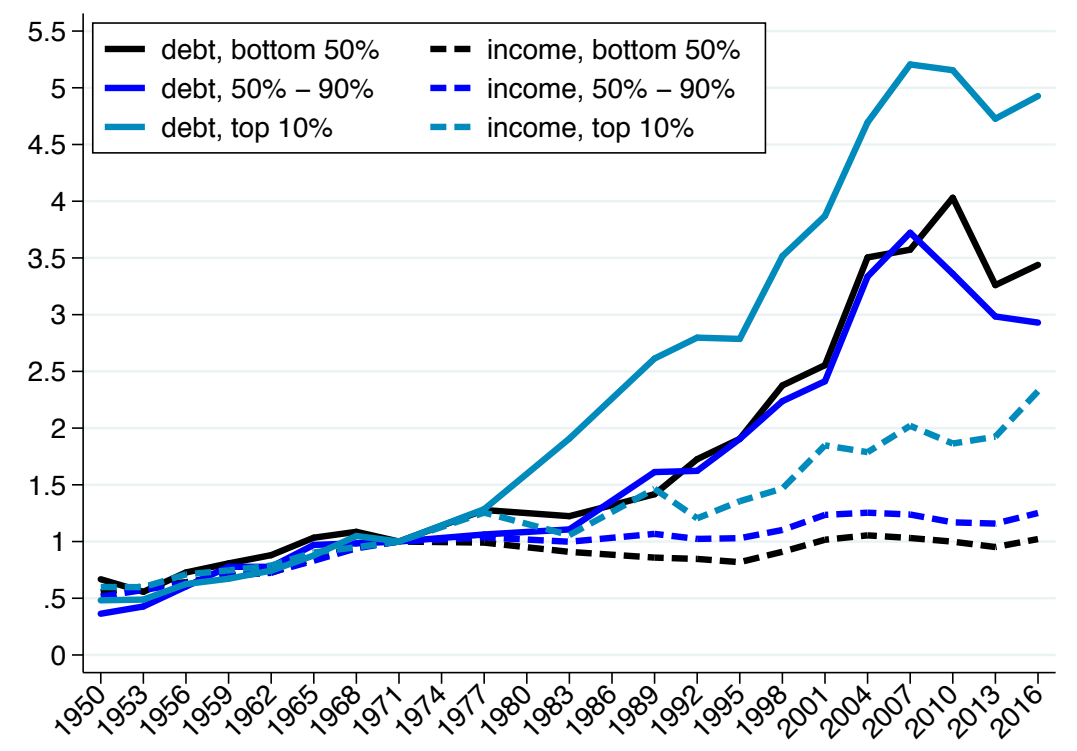

Notes: The graph shows the growth of average total housing debt and income by income group, relative to 1971 . 


\section{A.4 Debt-to-asset ratios over time and along the income distri- bution}

Figure A.4 shows debt-to-asset ratios for different income groups over time. We observe a general upward trend in these ratios, but the overall increase is modest. Even for the top $1 \%$, debt-to-asset ratios vary only between $4 \%$ and $8 \%$ over time. The largest variation is observed for the middle class with an increase in debt-to-asset ratios from $8 \%$ to $20 \%$ between 1950 and 2016 .

Figure A.4: Debt-to-asset ratios

(a) Debt-to-asset ratio

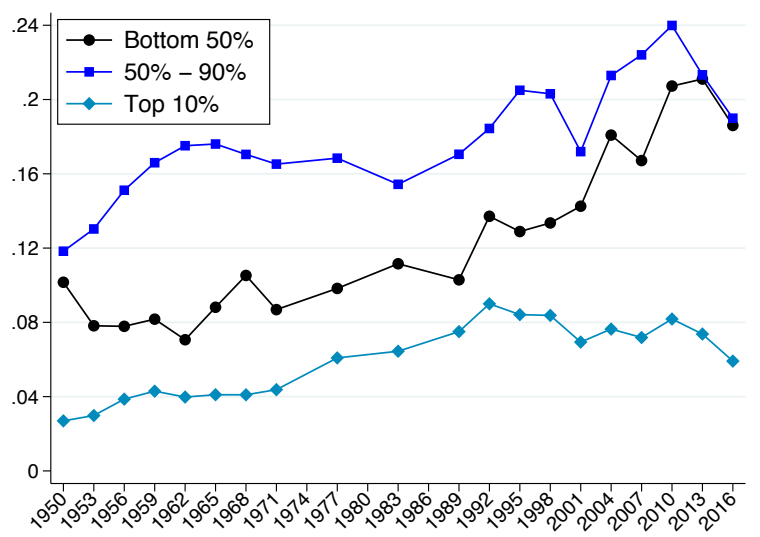

(b) Debt-to-asset ratio

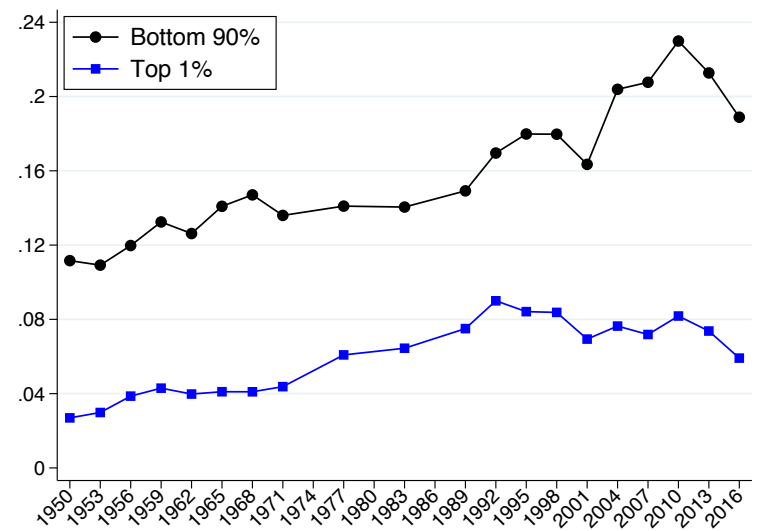

Notes: The left panel shows housing debt-to-asset ratios for the bottom $50 \%, 50 \%-90 \%$, and top $10 \%$ of the income distribution. The right panel compares debt-to-asset ratios of the bottom $90 \%$ and top $1 \%$.

Figure A.5 shows for selected SCF+ years the loan-to-value ratios and debt-to-asset ratios along the entire income distribution. We observe for both ratios a secular increase that happened along the entire income distribution. Figure A.5a shows loan-to-value ratios along the income distribution for the same years as in Figure 8 in the main text. A strong increase in loan-to-value ratios has occurred since 1983. In 2007, LTVs along the whole income distribution exceeded those from the peak of the first debt boom in 1965. Like debt-to-income ratios, leverage has risen most strongly in the middle of the distribution. While middle-class debt-to-income ratios had decreased again in 2016, LTVs were still similar to 2007 because of the simultaneous decline in house values. Debt-to-asset ratios in Figure A.5b also increased along the entire income distribution over time. The increase was more moderate and stronger toward the bottom of the income distribution. 
Figure A.5: LTV and debt-to-asset ratios along the income distribution

(a) Loan-to-value ratios

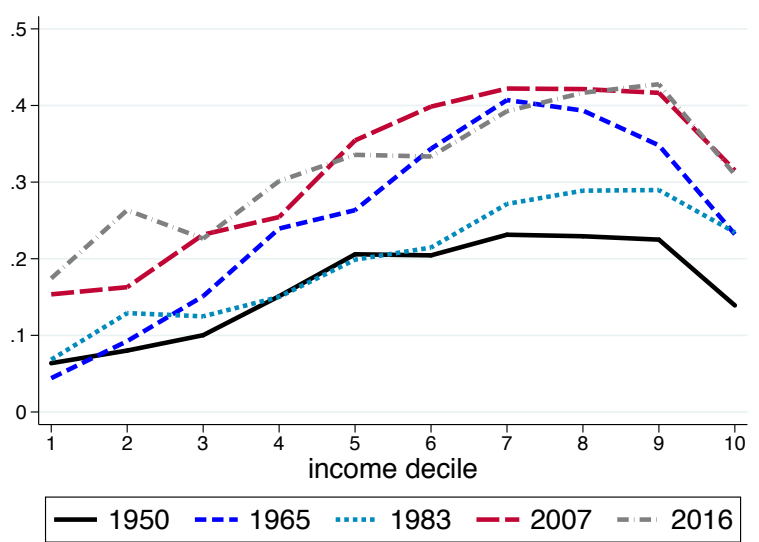

(b) Debt-to-asset ratios

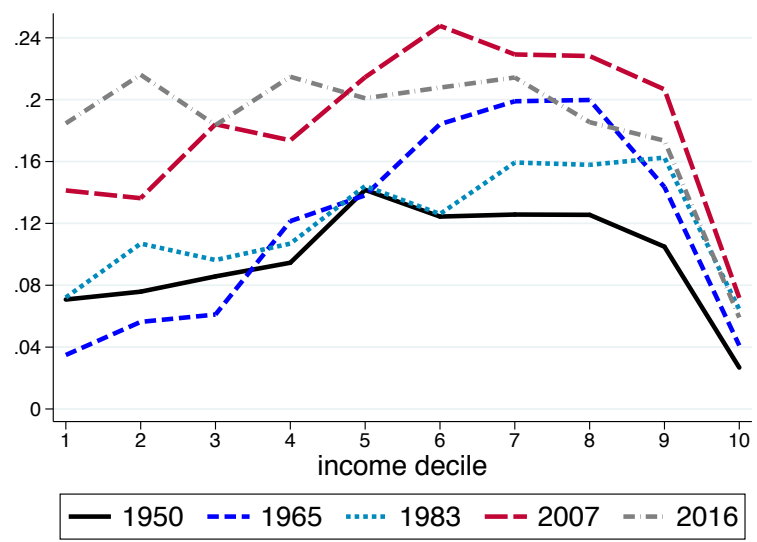

Notes: The left panel shows the evolution of average loan-to-value ratios by deciles of the aggregate income distribution for the SCF + waves 1950, 1965, 1983, 2007, and 2016. The right panel shows the evolution of total debt to total assets. We exclude households with total income below $10 \%$ of the annual wage of a household with a single earner receiving the contemporaneous minimum wage.

\section{A.5 Credit cards, education debt, and composition of mortgages}

Figure A.6 decomposes the extensive margin of personal debt over time. It shows the extensive margin for all non-housing debt, for the case when education debt is excluded, and for the case when education debt and credit card debt are excluded. We observe the largest effect on the extensive margin from excluding credit card debt. Excluding credit card debt reduces the share of households with personal debt by more than 10 percentage points after 1980. Without credit cards, we do not get an increase in the extensive margin of personal debt since 1970 .

Figure A.6: Personal debt, extensive margin

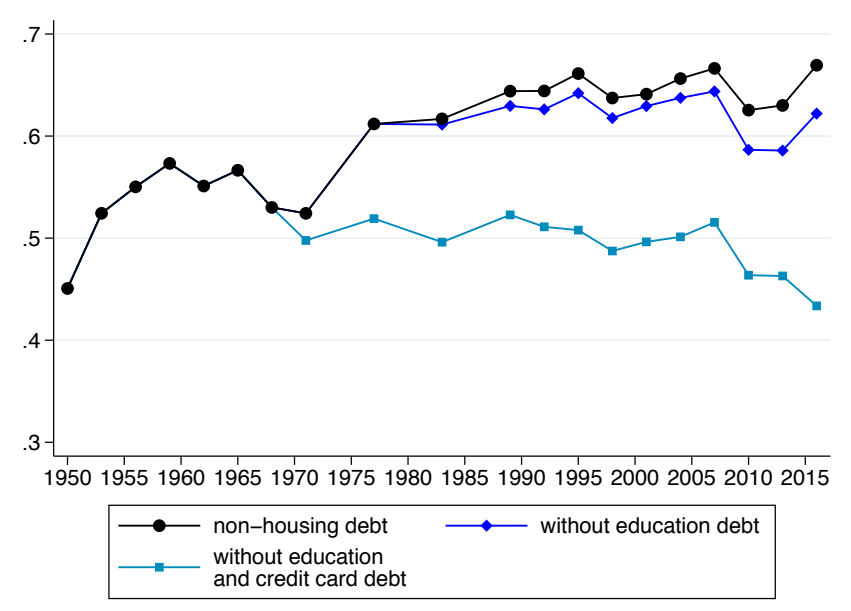

Notes: The graph shows the extensive margin of personal debt from Figure 9, together with counterfactuals in which credit card and education debt were set to zero. 
Figure A.7 decomposes housing debt into first and second mortgages. It shows the average amount of debt in first and second mortgages in the SCF data since 1983. It also shows the extensive margin of the two types of mortgages, the share of households having first and second mortgages, respectively, which we observe since 1955 in the SCF data.

Figure A.7: First and second mortgages, SCF+

(a) Average

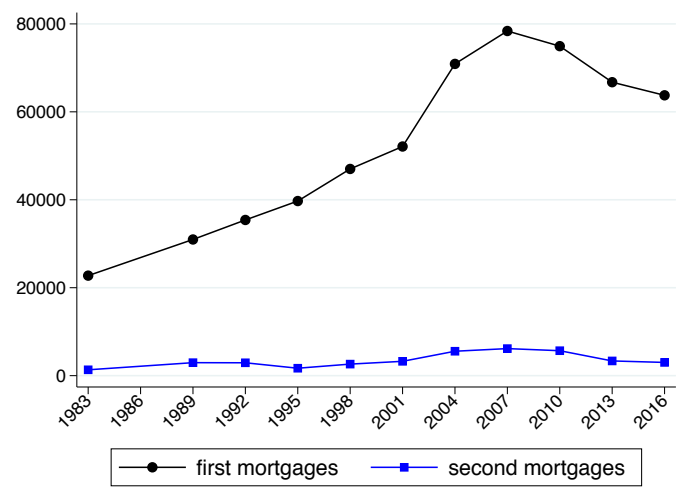

(b) Extensive margin

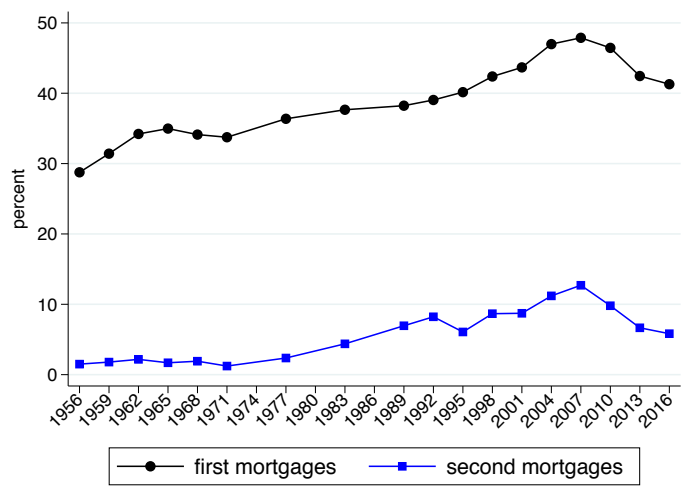

Notes: The left panel shows average first and second mortgages from the SCF. The right graph shows the share of households who have first or second mortgages. HELOCs are included (see text for details).

Figure A.8 looks at the different types of first mortgages in the PSID data. As mentioned above, the SCF counts HELOCs separately, whereas the PSID counts them among the second (or if no other mortgage is held, even the first) mortgages. Therefore, we reclassify HELOCs, which are available in the modern SCFs since 1989, as first mortgages if no other mortgage is available and as second mortgages if only a first mortgage is recorded. HELOCs were only introduced on a relevant scale in the mid-1980s (see Maki 2001). Still, we observe that typically $90 \%$ of all first mortgages in the PSID are traditional mortgages.

Figure A.8: First mortgages, PSID
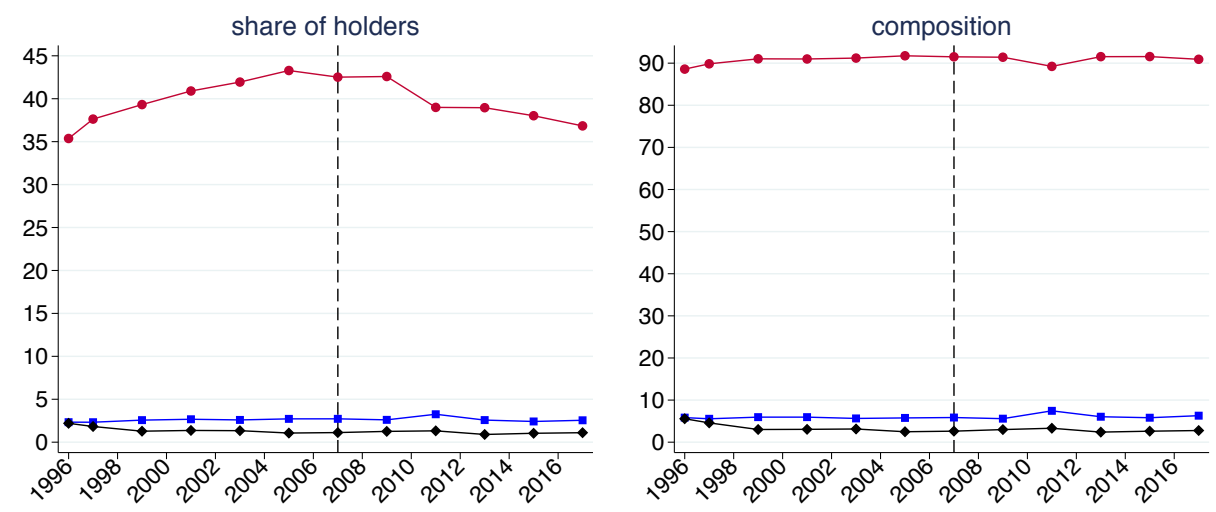

$\rightarrow$ mortgage $\rightarrow$ home equity $\rightarrow$ other

Notes: The left panel shows the share of households in the PSID who hold the respective type of mortgage. The right panel shows the share conditional upon having a first mortgage. 
Figure A.9 considers second mortgages in the PSID data that are observed from 1996 onward. The share of households with second mortgages is increasing over time, but even at the peak of the housing boom in 2007 , not more than $9 \%$ of households had second mortgages. For the households with second mortgages, typically two-thirds were home equity loans, and the share remained quite stable over time.

Figure A.9: Second mortgages, PSID

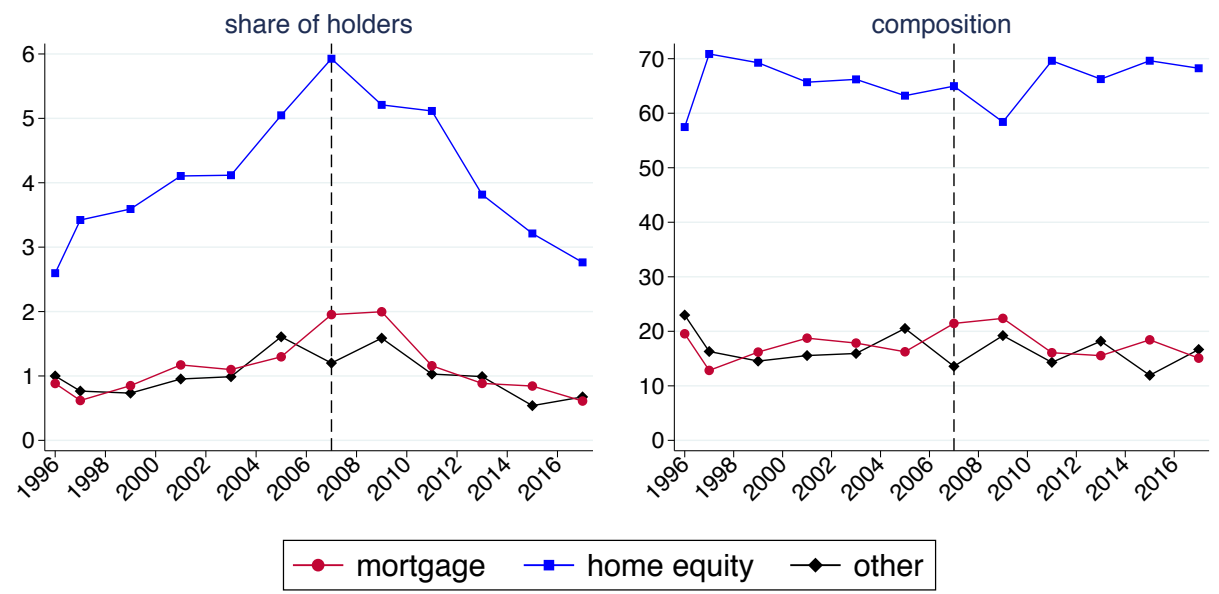

Notes: The left panel shows the share of households in the PSID who hold the respective type of mortgage. The right panel shows the share conditional upon having a second mortgage.

\section{A.6 Household types by debt dynamics}

Figure A.10 reports the extensive and intensive margins for all household types based on the observed debt dynamics in the PSID panel data: extractors, upgraders, new owners, downgraders, and new renters.

Figure A.10: Intensive and extensive margin by type

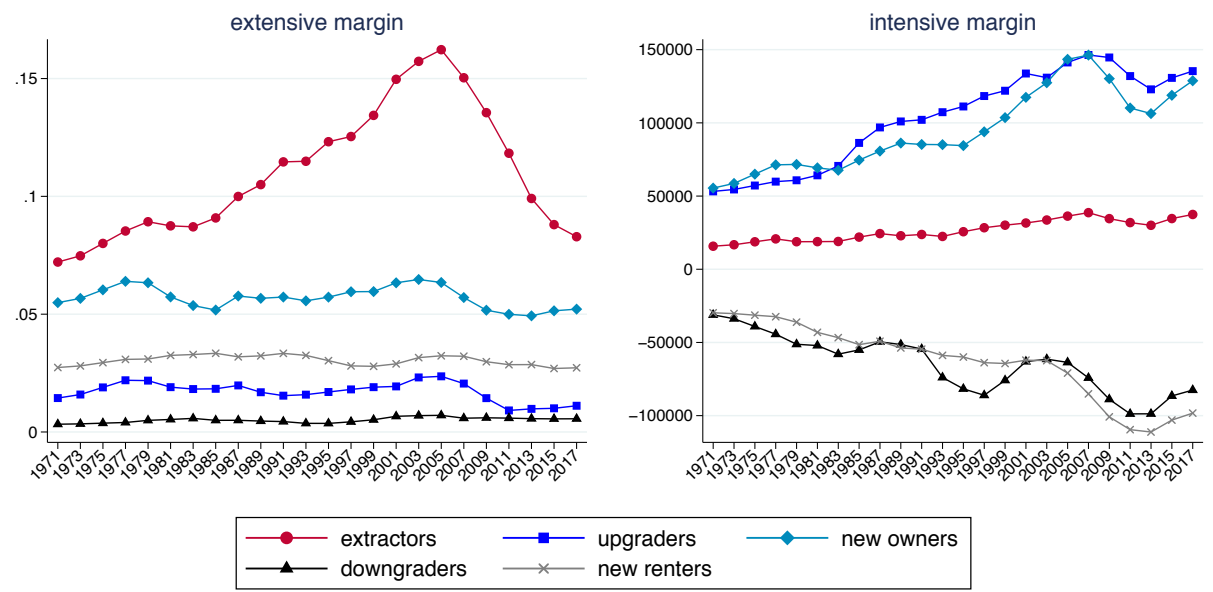

Notes: The left panel shows the share of households who extracted equity, upgraded, downgraded, bought a new home, or sold their home to become a renter. The right panel shows the average debt increase of these households. The series were smoothed by taking a moving average across three neighboring waves. 
New owners are typically younger households. Figure A.11 shows loan-to-value ratios of young homeowners relative to all homeowners in SCF+ data. Young homeowners are all homeowners younger than age 35. We find that LTVs are consistently and substantially higher for younger homeowners but that the difference to all homeowners remained relatively stable over the entire time period covered by our data.

Figure A.11: Loan-to-value ratios of young homeowners

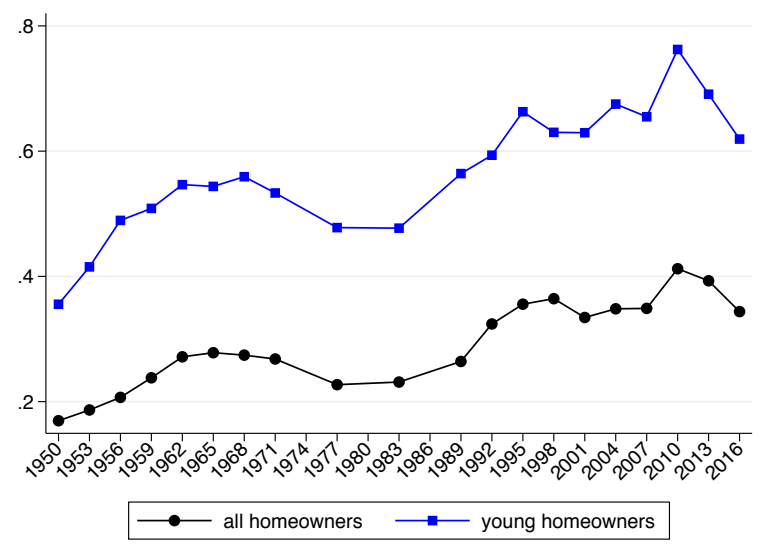

Notes: The graph shows average housing debt relative to average housing for all homeowners and homeowners with a head below age 35 .

\section{A.7 Mortgage interest rates and home equity loans}

Figure A.12 shows time series for average mortgage interest rates estimated from the $\mathrm{SCF}+$ data and from data reported by the Federal Housing Finance Agency (FHFA). The estimates align closely and show a clear downward trend from close or even above $10 \%$ to below $5 \%$ over four decades. 
Figure A.12: Mortgage interest rates (positive housing debt)

(a) Nominal

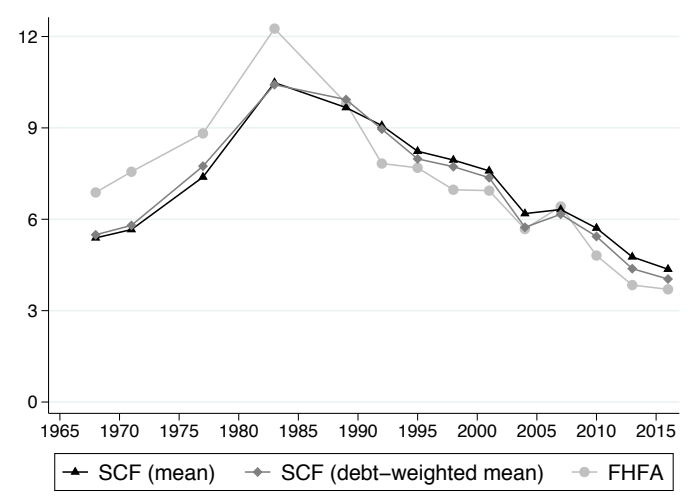

(b) Real

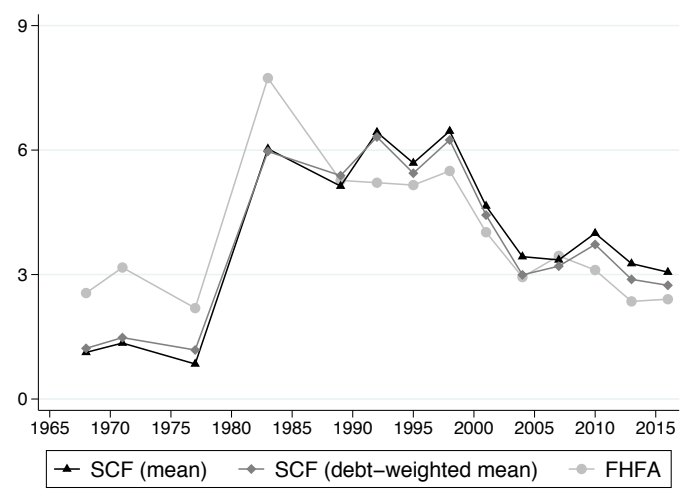

Notes: The graph shows average interest rates on first mortgages in the SCF + among households with positive housing debt. The left panel presents nominal interest rates $i_{t}^{m}$. Real interest rates in the right panel were calculated as $r_{t}^{m}=\left[\left(1+i_{t}^{m}\right) /\left(1+\pi_{t}\right)-1\right] \cdot 100$, where $\pi_{t}$ denotes year-on-year CPI inflation. The black lines with triangles present the simple average, whereas the medium gray lines with diamonds present the housing-debt-weighted average. As a comparison, the light gray lines with dots show the average interest rate on conventional non-farm single-family mortgages on new and previously occupied homes from the Monthly Interest Rate Survey of the FHFA. The survey excludes FHA-insured and VA-guaranteed loans, loans on multifamily buildings and mobile homes, as well as refinancing loans. Note that the $\mathrm{SCF}+$ data shown in this figure have not yet been subject to imputation. The data were top-coded at $9.9 \%$ in $1967,9.7 \%$ in $1968-1970$, and $20 \%$ in 1977 .

Figure A.13 shows the pairwise correlation of our indicator for equity extraction and the PSID indicator for refinancing of first mortgages, which is available since 1996. LaCourLittle, Rosenblatt, and Yao (2010) and Bhutta and Keys (2016) report extraction booms in 1998 and 2003. This is mirrored in a particularly high correlation around these years.

Figure A.13: Extraction and refinancing

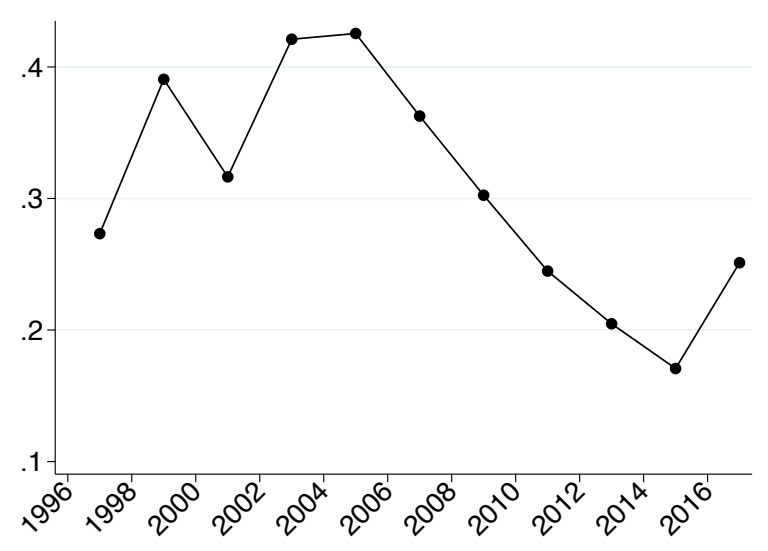

Notes: The graph shows the pairwise correlation of our indicator for equity extraction and the PSID indicator for refinancing of first mortgages over time.

Figure A.14 provides text-search-based evidence on the proliferation of home equity loans. It reports the number of mentions of "home equity loans" from 1950 to 2007. While the 
phrase was virtually not mentioned before 1983, it increased dramatically afterward in line with a widespread proliferation of these products.

Figure A.14: Google Books Ngram Viewer for "home equity loan"

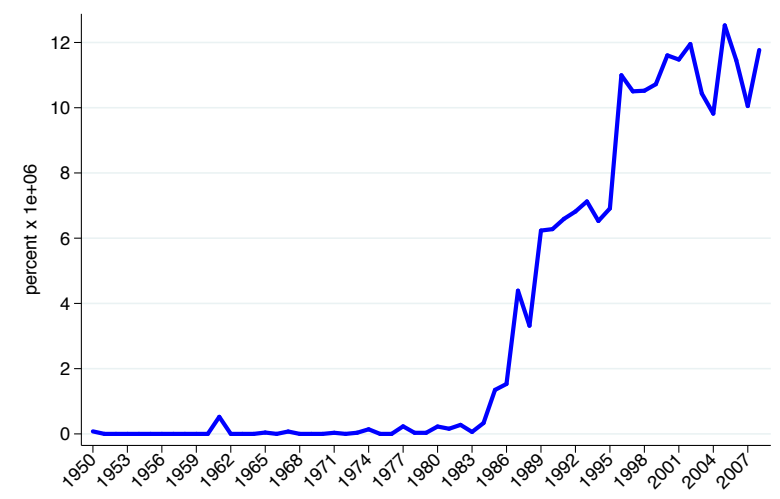

Notes: The graph shows how mentions on the 3-gram "home equity loan" have evolved over time. The figure is based on data from the Google Books Ngram Viewer. The y-axis shows the share of this 3-gram among all 3-grams contained in the Google sample of books written in English and published in the United States. The Google data are normalized with the total number of books published in each year.

\section{A.8 Geographic variation in house values, debt and equity ex- traction}

The left panel of Figure A.15 shows the average value of housing assets for homeowners (intensive margin) for the four Census regions in the United States. The right panel shows the corresponding mortgage debt levels. To construct the time series by Census region, we combine information from the SCF + and the PSID data. We observe a strong comovement of housing assets and housing debt across regions. Figure A.16 shows that our measure of equity extraction moves in tandem with regional house prices. Furthermore, Figure A.17 shows that our extraction measure is closely correlated with house values across states.

Figure A.18 shows the event-study regression that exploits state-level variation in house prices together with PSID data. We find that for extracting households, house values increased substantially more than those of non-extracting households in the six years prior to extraction. 
Figure A.15: Housing and housing debt by Census region (intensive margin)
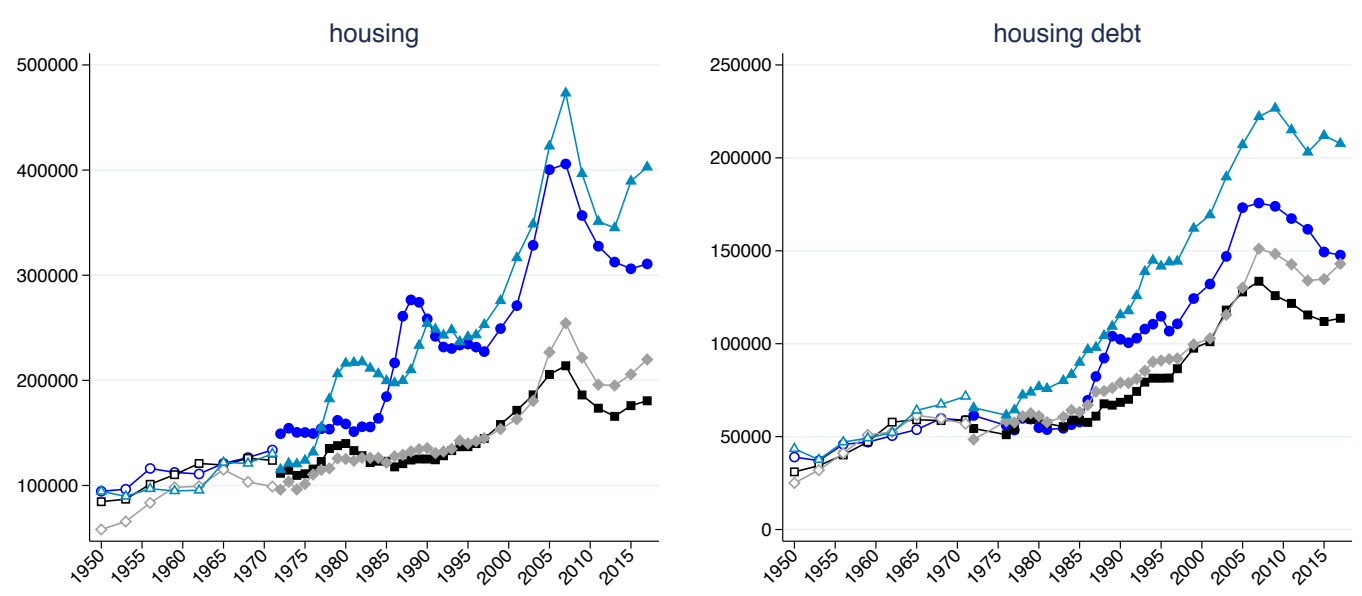

$\longrightarrow$ Northeast $\longrightarrow$ North Central $\longrightarrow$ South $\longrightarrow$ West

Notes: The graph shows the intensive margin of housing and housing debt by Census region. Filled markers show PSID data, and hollow markers show SCF + data.

Figure A.16: House prices and equity extraction by Census region
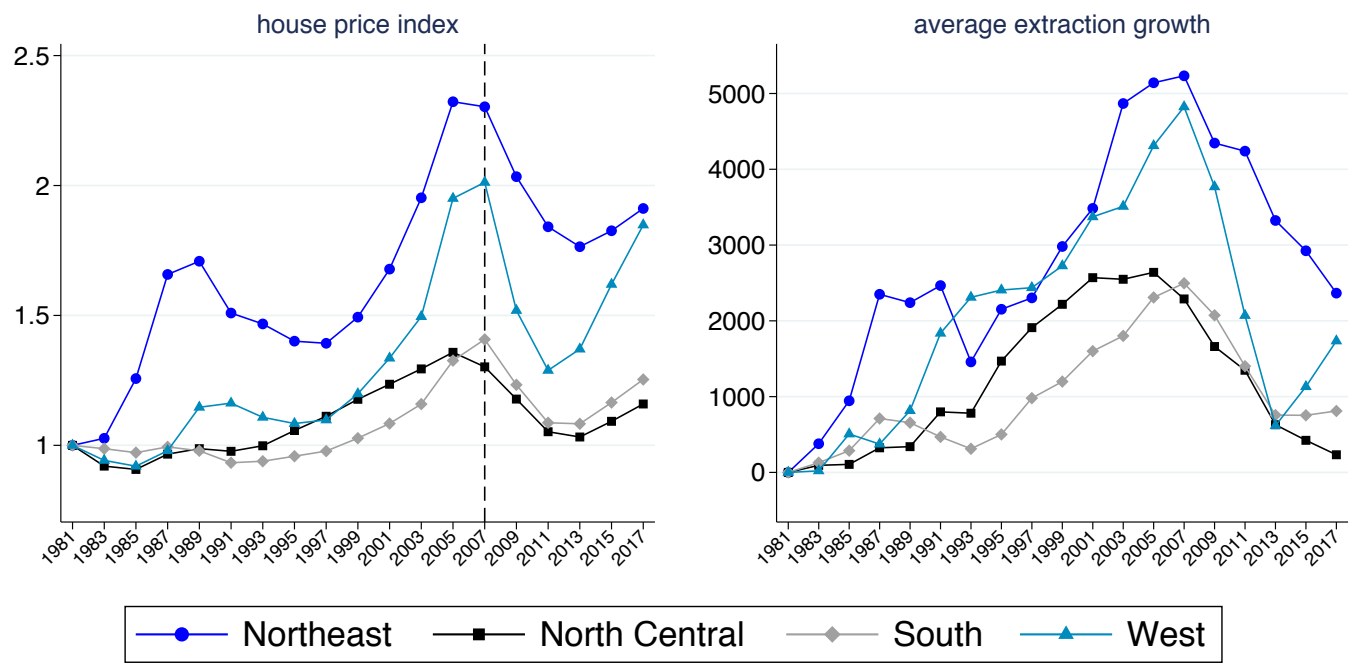

Notes: The left panel shows the growth of state-level FHFA house price indices since 1981, averaged by year and region. The right panel shows the average amount extracted by region, smoothed by taking a moving average across three neighboring waves and normalized by subtracting 1981 levels. 
Figure A.17: Growth of housing and extraction by state (intensive margin)

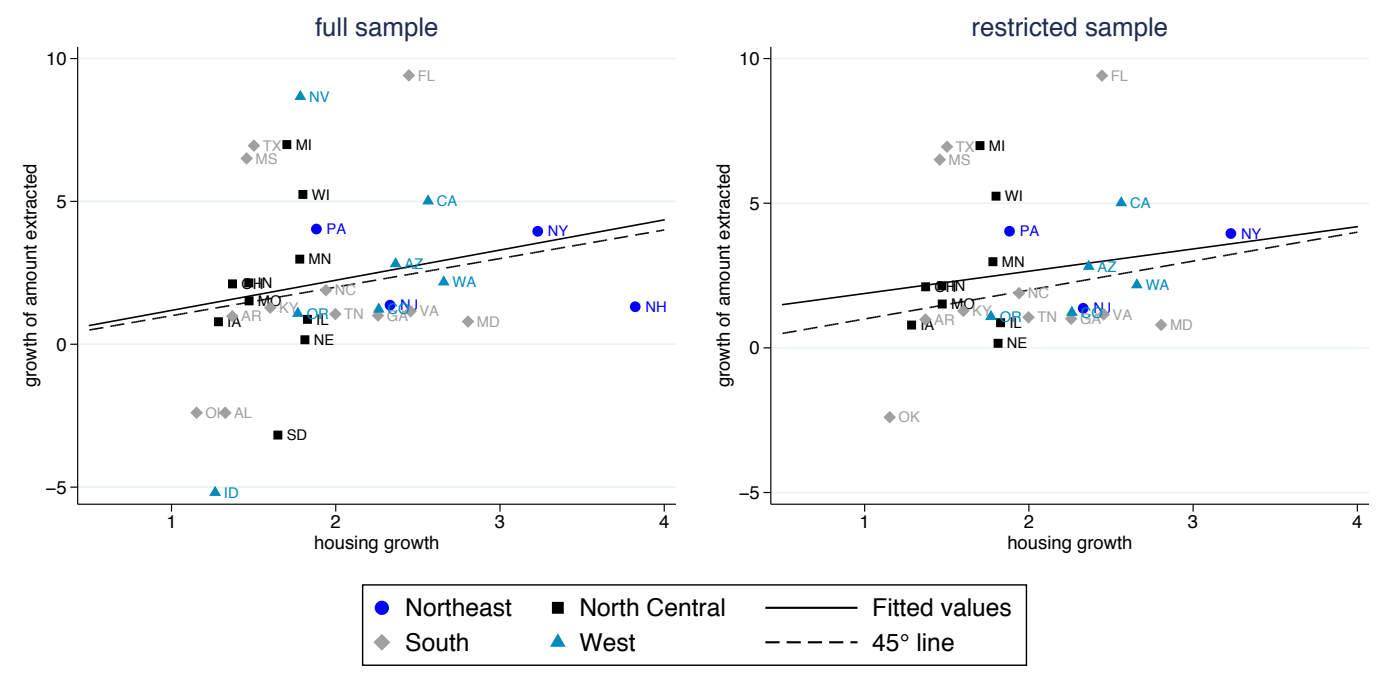

Notes: The graph plots the growth in average house values against the growth in average extraction between 1981 and 2007. Averages are computed at the intensive margin, i.e. conditional on having a house and a mortgage, respectively. The right panel excludes states with less than 50 observations. Massachusetts, Connecticut and South Carolina were excluded as outliers from both panels.

Figure A.18: Event study: extraction

(a) All income groups

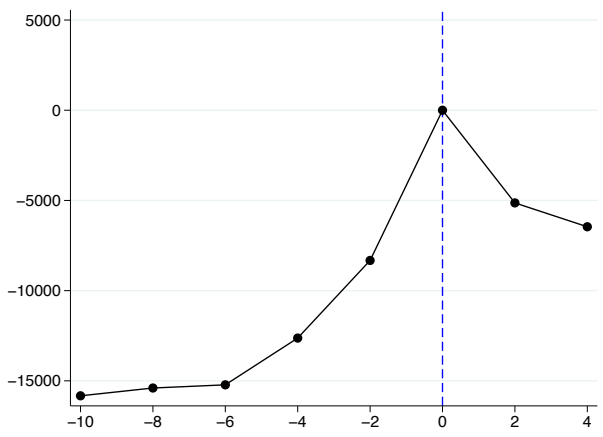

(b) $50 \%-90 \%$ only

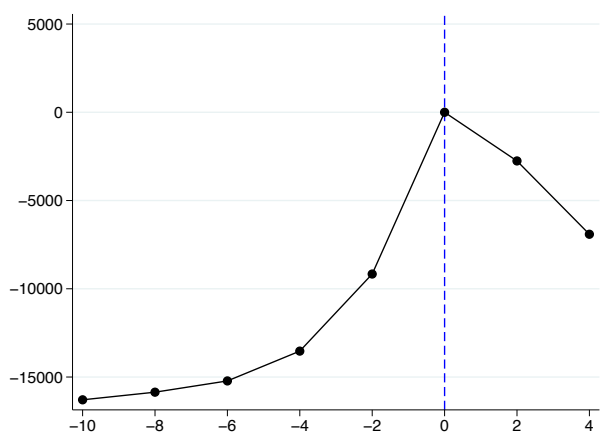

Notes: The graph shows regressions of the house value on leads and lags of the extraction dummy. Zero is the period of extraction. Even years were discarded from the dataset to avoid a change in frequency, just as for the local projections in Section 4.4. We focus on households that stay in their home upon extraction. The regressions include year and household fixed effects. 


\section{A.9 Life cycle debt patterns in PSID data}

Figure A.19 shows life-cycle loan-to-value profiles obtained by regressing individual loanto-value ratios on six age group dummies (25-34, 35-44, 45-54, 55-64, 65-74, and 75-85 years). The left panel repeats the results from the SCF+ data from Section 3.4 for comparison. The middle panel shows PSID data treated analogously to the SCF+ data, and the right panel shows results that exploit the panel dimension of the PSID by including household fixed effects. Note that the SCF + data start in 1950, whereas the PSID data only begin in $1969 .^{34}$

Figure A.19: Comparison of life-cycle loan-to-value ratios
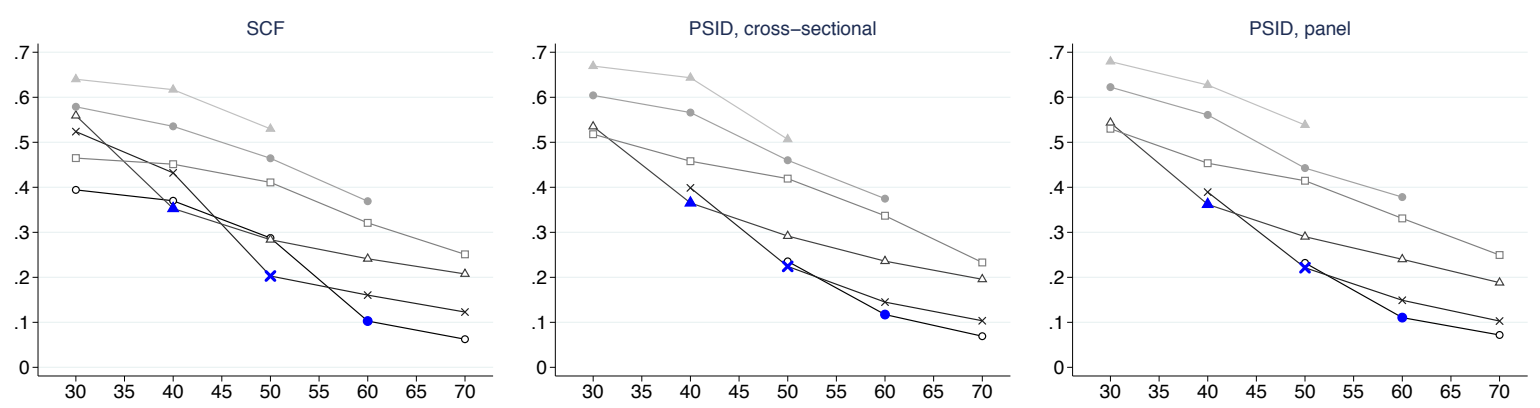

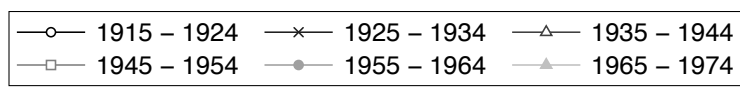

Notes: The graph shows life-cycle loan-to-value profiles for different cohorts. The left panel shows the $\mathrm{SCF}+$ data, the middle panel shows PSID data when treating the data as cross-sectional, and the right panel shows PSID data when exploiting the panel dimension by including household fixed effects.

Figure A.20 shows analogous results for the housing debt-to-income ratio. It also includes a fourth panel, in which we exploited the PSID's panel dimension to replace income by its three-year moving average (MA) within each household. This step helps to avoid extreme values due to temporary income fluctuations. The results are quantitatively and qualitatively similar across both datasets and all specifications. Housing debt-to-income ratios and leverage (loan-to-value) have both shifted and turned upward conspicuously. We see a shift in slopes around 1980 for all cohorts, no matter whether they were 40, 50, or 60 years at this point (see blue markers). The shift is most pronounced for households around age 40 in 1980. The results are very similar when controlling for household fixed effects in the PSID, which confirms that the results obtained with the SCF + are not artifacts of working with synthetic cohorts.

${ }^{34}$ The first PSID wave from 1968 was excluded, as many important variables are still missing in this year. 
Figure A.20: Comparison of life-cycle housing debt-to-income profiles
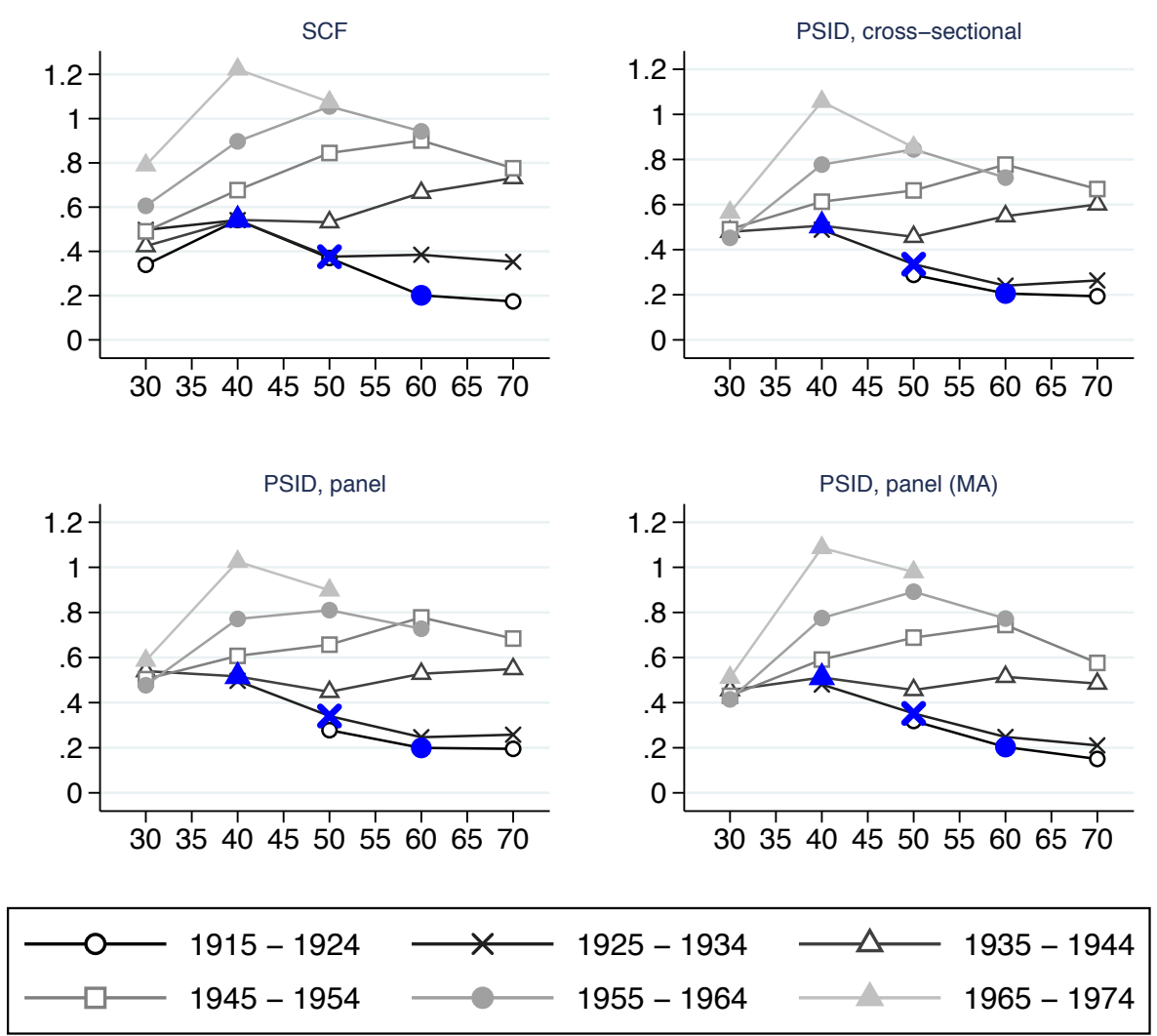

Notes: The graph shows life-cycle housing debt-to-income profiles for different cohorts. The upper left panel shows the SCF + data, the upper right panel shows PSID data when treating the data as crosssectional, and the lower left panel shows PSID data when exploiting the panel dimension by including household fixed effects. The lower right panel uses a three-year moving average of total household income in the denominator.

\section{B Comparison of PSID and SCF + housing data}

In this section, we compare the data on the two main variables of interest, housing and housing debt, from the PSID and the SCF +. The SCF + collects data at the household level, whereas the PSID collects data at the family level. To make the data comparable, we aggregate PSID families living together into one household (cf. Pfeffer et al. 2016). ${ }^{35}$ All variables are taken from the two surveys as they are, without further harmonization of income, asset, and debt concepts (cf. Pfeffer et al. 2016 for a comparison of the survey instruments with respect to wealth). Nominal variables were converted to 2016 dollars

\footnotetext{
${ }^{35}$ To identify the person among families sharing a household who would most likely have been identified as the head in the $\mathrm{SCF}+$, we create scores based on (a) being male, (b) being the oldest person in the household below retirement age (set to 65), (c) having the highest income within the household, and (d) owning the house. Within each household, the person with the highest score is defined to be the head, and his or her demographics are kept. If there is a tie, we choose the homeowner as the head. If there is still a tie, we choose the senior person, and if there is still a tie, we choose the person with the higher income. Income and wealth variables are summed across all families in the household.
} 
using the CPI from the Macrohistory Database (Jordà, Schularick, and Taylor 2017).

Figure B.1: Comparison of average house value and housing debt: PSID vs. SCF+

(a) Housing: intensive margin

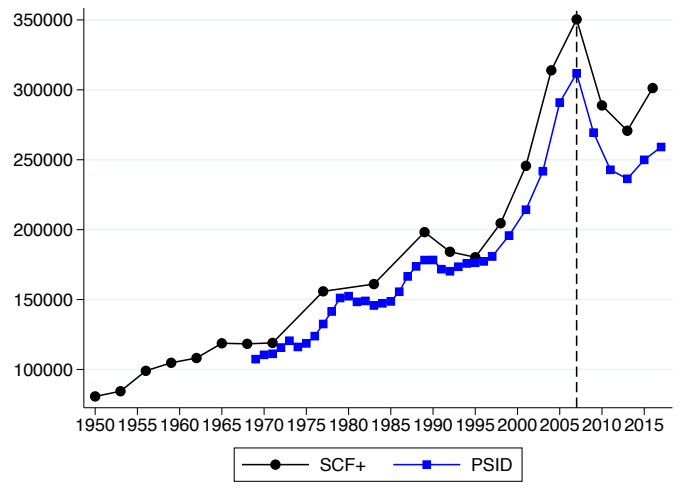

(c) Housing: extensive margin

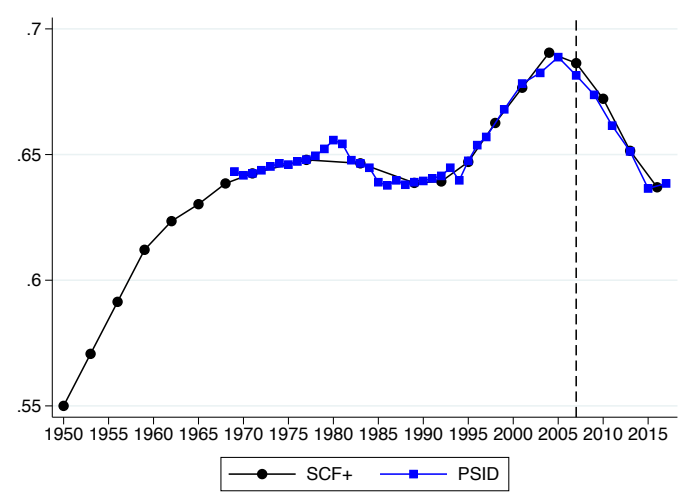

(e) Housing debt: homeowners

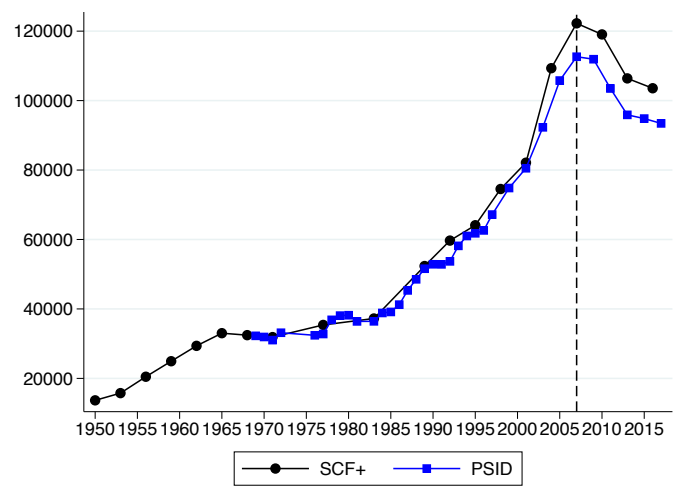

(b) Housing debt: intensive margin

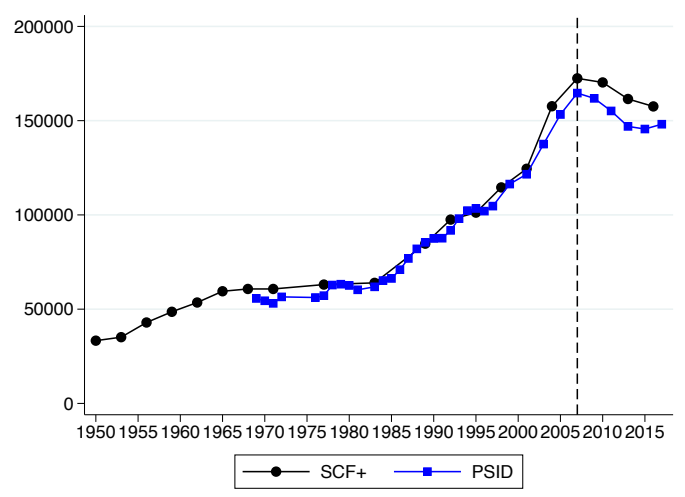

(d) Housing debt: extensive margin

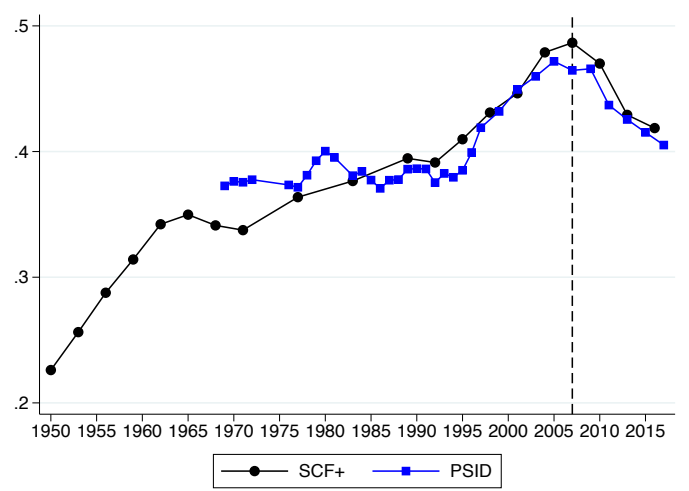

(f) Total income

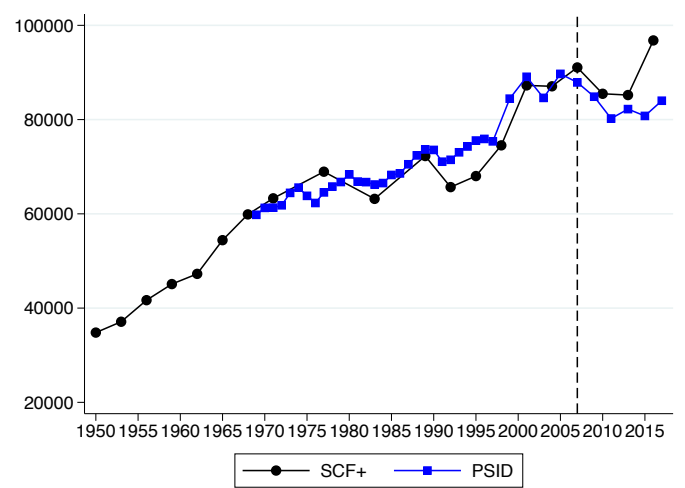

Notes: Panel (a) shows the average value of a house, conditional on being a homeowner. Panel (b) shows the average value of housing debt, conditional on having any housing debt. Panel (c) shows the homeownership rate. Panel (d) shows the share of households with positive housing debt. Panel (e) shows average housing debt in the subsample of homeowners. Panel (f) shows total household income. Black lines with dots show SCF+ data, gray lines with squares show PSID data.

Figure B.1 shows the intensive and extensive margins of housing and housing debt from the two data sources. We find that the two datasets yield very similar results at both margins. The intensive margin for housing is lower in the PSID, consistent with the fact that the SCF provides a better coverage of the right tail of the wealth distribution. The intensive margin of housing debt is matched very closely. There are some differences at 
the extensive margin for debt, especially during the 1970s and housing during the 2000s, consistent with the results of Pfeffer et al. (2016), who report several differences in asset ownership rates between the SCF and PSID. Overall, incomes align well between the two datasets.

Figure B.2 shows debt-to-income ratios from the PSID and the SCF+. Both datasets show the secular rise in debt-to-income ratios in the aggregate and for the middle class over time. We find the increase to be slightly more pronounced in the $\mathrm{SCF}+$ data at the aggregate and when focusing on the middle class.

Figure B.2: Housing debt-to-income ratios in the SCF+ and PSID

(a) Average

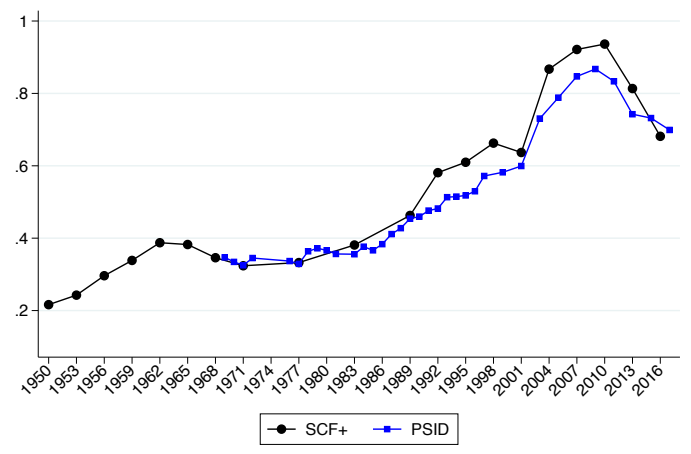

(b) $50 \%-90 \%$

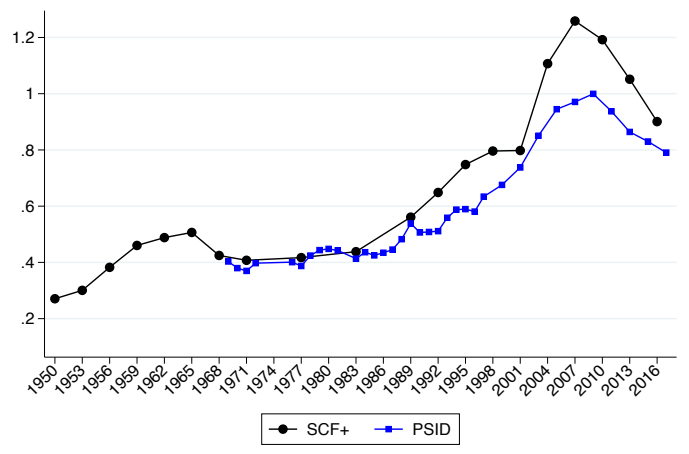

Notes: The graph shows the housing debt-to-income ratio in the SCF+ and PSID over time. The right panel shows results for households from the 50th to 90th percentiles of the income distribution only.

\section{Estimates of home equity extraction}

Several approaches have been made to quantify the importance of home equity extraction. Bhutta and Keys (2016) estimate that nearly $\$ 1$ trillion of equity was extracted between 2002 and 2005 via home equity loans, HELOCs, second mortgages, and cash-out refinancings. They exclude the use of funds to move into a more expensive home or buy a second house. According to their calculations, households on average extracted $\$ 40,000$ between 1999 and 2010. The share of extractors among households with positive mortgage debt holdings varied over time, from 8.5\% in 1999 to $18.4 \%$ at the peak in 2003. Canner, Dynan, and Passmore (2002) estimate that around $\$ 132$ billion was extracted via cash-out refinancings from 2001 to early 2002. They estimate that $16 \%-23 \%$ of households with mortgage debt were refinancing, out of which $45 \%$ extracted equity.

In the modern SCF, questions on equity extraction via cash-out refinancings and home equity loans have existed since 1995, and the amount has been elicited since 2004. Out of the households surveyed in 2004, 6.4\% had extracted equity between 2002 and 2004, which amounts to $13.4 \%$ of all households with positive housing debt. Among those households 
who extracted between the last and the current SCF wave, the average extracted amount across all available years was $\$ 41,200$ (cf. Table C.1). Extraction information in the SCF refers only to the first mortgage according to the SCF classification. While the PSID counts mortgages consecutively irrespective of their type, the SCF reports HELOCs in a separate variable. The year of origination is reported only for non-HELOC mortgages. Moreover, some households reported having a third mortgage without having a first or second mortgage. Therefore, a comparison of the extensive margin of extraction with the PSID is not straightforward. However, the extracted amount conditional on extracting is of a broadly similar magnitude in both surveys.

Table C.1: Average amount extracted

\begin{tabular}{ccc}
\hline year & PSID & SCF + \\
\hline & & \\
1999 & 32724.29 & $\cdot$ \\
2001 & 29245.52 & $\cdot$ \\
2003 & 32835.51 & $\cdot$ \\
2004 & $\cdot$ & 35185.82 \\
2005 & 38884.87 & $\cdot$ \\
2007 & 37185.00 & 47736.85 \\
2009 & 39974.38 & $\cdot$ \\
2010 & $\cdot$ & 34786.23 \\
2011 & 26629.27 & $\cdot$ \\
2013 & 29090.20 & 41825.63 \\
2015 & 34378.86 & $\cdot$ \\
2016 & $\cdot$ & 46413.52 \\
2017 & 40473.45 & $\cdot$ \\
\hline
\end{tabular}

Notes: The table reports the average amount extracted, conditional upon extracting, from the SCF and PSID in 2016 dollars. The SCF measure is based on first mortgages only and refers to households who extracted over the current and previous two years.

Greenspan and Kennedy (2008) take a broader perspective, taking into account existing home sales as well. They estimate that on average, HEW generated around $\$ 590$ billion of free cash per year between 1991 and 2006, out of which two-thirds were accounted for by existing home sales. However, their estimates are based on a so-called mortgage system, which was discontinued after 2008, as it did not adequately capture features of the housing market as experienced in the financial crisis of 2007 and 2008. Klyuev and Mills (2007) obtain slightly lower but similar estimates with a more simple method. They use the difference between all borrowing secured by dwellings $\left(T_{H}\right)$ and the net acquisition of residential assets $\left(T_{D^{H}}\right)$ from the FA as a proxy. The FA mortgage transaction series $T_{D^{H}}$ includes all kinds of mortgages, except construction loans. The housing transaction series $T_{H}$ includes gross fixed investment in residential structures, net of depreciation, as well as land sales from other sectors to the household sector. However, this "broad" HEW 
proxy is a somewhat coarse measure of equity extraction. For instance, if a household buys a new home for $\$ 100$, and takes out a mortgage for $\$ 80$, this measure would count it as negative equity extraction (equity injection) of $\$ 20$. We compare this measure to our PSID-based equity extraction measure in Figure C.1.

Figure C.1: Comparison to FA measure of Klyuev and Mills (2007)

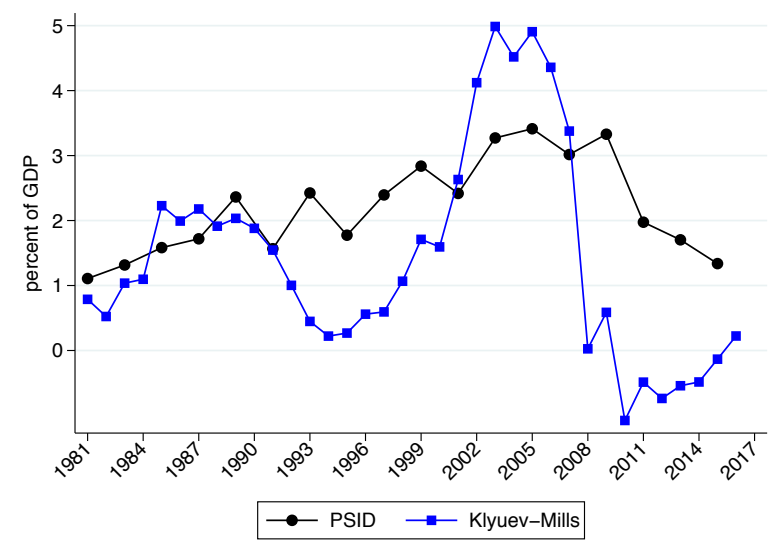

Notes: The figure shows the HEW measure proposed by Klyuev and Mills (2007) and the total amount extracted based on our computations with the PSID, both normalized by NIPA GDP.

\section{Details for life-cycle model}

\section{D.1 Derivations}

Here, we derive the optimal policies and law of motion for the Modigliani life-cycle model from Section 5 in the main part of the paper. The agent's problem reads

$$
\begin{aligned}
\max _{\left\{c_{j}, h_{j}, d_{j+1}\right\}_{j=0}^{J}} & \sum_{j=0}^{J} \beta^{j}\left(\rho \log \left(c_{j}\right)+(1-\rho) \log \left(h_{j}\right)\right) \\
\text { s.t. } & c_{j}+p_{h} h_{j}-d_{j+1}=y_{j}-(1+r) d_{j}+(1-\delta) h_{j-1} p_{h} \\
& h_{-1}, d_{0} \quad \text { given }
\end{aligned}
$$

First-order conditions deliver

$$
\begin{aligned}
\frac{1}{c_{j}} \rho p_{h} & =(1-\rho) \frac{1}{h_{j}}+\beta \rho(1-\delta) p_{h} \frac{1}{c_{j+1}} \\
\frac{1}{c_{j}} & =\beta(1+r) \frac{1}{c_{j+1}} .
\end{aligned}
$$

From equation (D.3), we get the optimal path of consumption growth,

$$
c_{j}=(\beta(1+r))^{j} c_{0} .
$$


Using the Euler equation (D.3) in equation (D.2) delivers

$$
\begin{aligned}
\rho p_{h} & =(1-\rho) \frac{c_{j}}{h_{j}}+\beta \rho(1-\delta) p_{h} \frac{c_{j}}{c_{j+1}} \\
1 & =\frac{1-\rho}{\rho} \frac{c_{j}}{p_{h} h_{j}}+\beta(1-\delta)(\beta(1+r))^{-1} \\
p_{h} h_{j} & =\frac{1-\rho}{\rho} c_{j}+\frac{1-\delta}{1+r} p_{h} h_{j} \\
p_{h} h_{j} & =\frac{1+r}{r+\delta} \frac{1-\rho}{\rho} c_{j}
\end{aligned}
$$

with the standard constant expenditure share result. Note that expenditures for housing are the user costs $\frac{r+\delta}{1+r} p_{h} h_{j}$. Combining equation (D.5) with the Euler equation delivers

$$
p_{h} h_{j}=\frac{1+r}{r+\delta} \frac{1-\rho}{\rho}(\beta(1+r))^{j} c_{0} .
$$

The law of motion for the debt level is

$$
d_{j+1}=c_{j}-y_{j}+p_{h} h_{j}+(1+r) d_{j}-(1-\delta) h_{j-1} p_{h} .
$$

Using this law of motion and plugging in recursively delivers

$d_{j+1}=\sum_{s=0}^{j}\left(c_{s}-y_{s}\right)(1+r)^{j-s}+p_{h} h_{j}+\sum_{s=0}^{j-1} p_{h} h_{s}(r+\delta)(1+r)^{j-1-s}-(1+r)^{j}\left((1-\delta) h_{-1} p_{h}-(1+r) d_{0}\right)$.

For $j=J$, we get

$d_{J+1}=\sum_{s=0}^{J}\left(c_{s}-y_{s}\right)(1+r)^{J-s}+p_{h} h_{J}+\sum_{s=0}^{J-1} p_{h} h_{s}(r+\delta)(1+r)^{J-1-s}-(1+r)^{J}\left((1-\delta) h_{-1} p_{h}-(1+r) d_{0}\right)$.

Now we multiply both sides by $(1+r)$ and subtract $(1-\delta) p_{h} h_{J}$ :

$$
\begin{aligned}
& d_{J+1}(1+r)-(1-\delta) p_{h} h_{J}=(1+r)^{J+1}\left(\sum_{s=0}^{J} \frac{c_{j}-y_{j}}{(1+r)^{s}}+\frac{(1+r) p_{h} h_{J}-(1-\delta) p_{h} h_{J}}{(1+r)^{J+1}}\right. \\
& \left.+\frac{1}{1+r} \sum_{s=0}^{J-1} \frac{p_{h} h_{s}}{(1+r)^{s}}(r+\delta)-\left((1-\delta) h_{-1} p_{h}-(1+r) d_{0}\right)\right) \\
& \frac{d_{J+1}(1+r)-(1-\delta) p_{h} h_{J}}{(1+r)^{J+1}}=\sum_{s=0}^{J} \frac{c_{j}-y_{j}}{(1+r)^{s}}+\frac{(r+\delta) p_{h} h_{J}}{(1+r)^{J+1}} \\
& +\frac{r+\delta}{1+r} \sum_{s=0}^{J-1} \frac{p_{h} h_{s}}{(1+r)^{s}}-\left((1-\delta) h_{-1} p_{h}-(1+r) d_{0}\right) \\
& \frac{d_{J+1}(1+r)-(1-\delta) p_{h} h_{J}}{(1+r)^{J+1}}=\sum_{s=0}^{J} \frac{c_{j}}{(1+r)^{s}}-\overbrace{\sum_{s=0}^{J} \frac{y_{j}}{(1+r)^{s}}}^{=Y} \\
& +\frac{r+\delta}{1+r} \sum_{s=0}^{J} \frac{p_{h} h_{s}}{(1+r)^{s}}-\underbrace{\left((1-\delta) h_{-1} p_{h}-(1+r) d_{0}\right)}_{=E} \\
& \frac{d_{J+1}(1+r)-(1-\delta) p_{h} h_{J}}{(1+r)^{J+1}}=\sum_{s=0}^{J} \frac{c_{j}}{(1+r)^{s}}+\frac{r+\delta}{1+r} \sum_{s=0}^{J} \frac{p_{h} h_{s}}{(1+r)^{s}}-(E+Y) .
\end{aligned}
$$

Under the optimal policy, it is always optimal that all resources are consumed in the last period, so that equity at the end of the life cycle is zero: $E^{\prime}=(1-\delta) p_{h} h_{J}-d_{J+1}(1+r)=0$. 
This implies that the left-hand side of equation (D.10) must be zero for the solution to be optimal, and we obtain

$$
E+Y=\sum_{s=0}^{J} \frac{c_{j}}{(1+r)^{s}}+\frac{r+\delta}{1+r} \sum_{s=0}^{J} \frac{p_{h} h_{s}}{(1+r)^{s}} .
$$

Now we plug in equations (D.4) and (D.6) and obtain

$$
\begin{aligned}
\underbrace{E+Y}_{=W} & =\sum_{s=0}^{J} \frac{c_{0}(\beta(1+r))^{s}}{(1+r)^{s}}+\frac{r+\delta}{1+r} \sum_{s=0}^{J} \frac{\frac{1+r}{r+\delta} \frac{1-\rho}{\rho}(\beta(1+r))^{s} c_{0}}{(1+r)^{s}} \\
W & =c_{0} \sum_{s=0}^{J} \beta^{s}+\frac{1-\rho}{\rho} c_{0} \sum_{s=0}^{J} \beta^{s} \\
W & =c_{0} \frac{1-\beta^{J+1}}{1-\beta}+\frac{1-\rho}{\rho} c_{0} \frac{1-\beta^{J+1}}{1-\beta} \\
\underbrace{\frac{1-\beta}{1-\beta^{J+1}} W}_{=\alpha} & =\frac{1}{\rho} c_{0} \\
\rho \alpha W & =c_{0}^{*} .
\end{aligned}
$$

The law of motion from equation (8) follows directly from iterating equation (D.7):

$$
d_{j+1}=\sum_{s=0}^{j}\left(c_{s}-y_{s}\right)(1+r)^{j-s}+\sum_{s=0}^{j}\left(p_{h} h_{s}-(1-\delta) p_{h} h_{s-1}\right)(1+r)^{j-s}+(1+r)^{j+1} d_{0} .
$$

Rearranging terms, we get the expression from equation (D.8) and plug in the result for the constant expenditure shares to obtain

$$
\begin{aligned}
& d_{j+1}=\underbrace{\sum_{s=0}^{j} c_{s}(1+r)^{j-s}}_{\text {consumption costs }}-\underbrace{\sum_{s=0}^{j} y_{s}(1+r)^{j-s}}_{\text {income }}+\underbrace{p_{h} h_{j}}_{\text {current housing }} \\
& +\underbrace{\sum_{s=0}^{j-1} p_{h} h_{s} \frac{r+\delta}{1+r}(1+r)^{j-s}}_{\text {user costs }}-(1+r)^{j} \underbrace{\left((1-\delta) h_{-1} p_{h}-(1+r) d_{0}\right)}_{\text {initial endowment }} \\
& d_{j+1}=\sum_{s=0}^{j} c_{s}(1+r)^{j-s}-\sum_{s=0}^{j} y_{s}(1+r)^{j-s}+p_{h} h_{j}-(1+r)^{j}(1-\delta) h_{-1} p_{h} \\
& +\sum_{s=0}^{j-1} \frac{1-\rho}{\rho} c_{s}(1+r)^{j-s}+(1+r)^{j+1} d_{0} \\
& \underbrace{\frac{d_{j+1}}{(1+r)^{j}}}_{\begin{array}{c}
\text { present value } \\
\text { of debt }
\end{array}}=\overbrace{\sum_{s=0}^{j} \frac{c_{s}}{(1+r)^{s}}+\sum_{s=0}^{j-1} \frac{1-\rho}{\rho} \frac{c_{s}}{(1+r)^{s}}}^{\begin{array}{c}
\text { present value of } \\
\text { total expenditures }
\end{array}}-\overbrace{\sum_{s=0}^{j} \frac{y_{s}}{(1+r)^{s}}}^{\begin{array}{c}
\text { present value } \\
\text { of income }
\end{array}} \\
& +\underbrace{\left(\frac{p_{h} h_{j}}{(1+r)^{j}}-(1-\delta) h_{-1} p_{h}\right)}_{\begin{array}{c}
\text { present value of } \\
\text { housing adjustments }
\end{array}}+\underbrace{(1+r) d_{0}}_{\begin{array}{c}
\text { (present value }) \\
\text { initial debt }
\end{array}} .
\end{aligned}
$$




\section{D.2 Discussion}

In the model, households will reduce housing consumption after a positive house price shock, but housing wealth $(1-\delta) p_{h} h$ will increase nonetheless. ${ }^{36}$ This result implies that our stylized model predicts that households will not upgrade to larger/better houses after a positive house price shock. A key reason is that the stylized model abstracts from borrowing constraints and adjustment costs. ${ }^{37}$

In turn, the model predicts too much downgrading: households buy less/worse housing after a positive house price shock. Introducing trading and adjustment costs would allow us to more closely match the empirically observed patterns. Moreover, the model abstracts from renters. Current renters constitute the pool of potential new homeowners who are affected by rising house prices.

When house prices rise, households who switch from renting to owning have to pay more for a home of a given size. Hence, new homeowners will have to rely on additional debt to finance their home, buy a smaller house, or postpone homeownership. The data suggest that during the housing boom, many new homeowners relied on additional debt to finance their new home (Figure A.11).

In our stylized environment, we do not consider ways in which extracted equity could be used other than for non-durable consumption. Empirical studies have found that home equity is also used for home improvements, the repayment of personal debt, or the foundation of a business (see Mian and Sufi 2011, Cloyne et al. 2017, Greenspan and Kennedy 2008).

Finally, it should be noted that we abstract from other factors beyond house prices that have likely contributed to an increase in debt financing since the 1980s, such as lower mortgage interest rates and higher inflation, which raised the attractiveness of debt financing, falling mortgage transaction costs, the disappearing of mortgage prepayment penalties, or the rising costs of financing children's education (see, e.g., Bhutta and Keys 2016, Canner, Dynan, and Passmore 2002, Greenspan and Kennedy 2008, Cooper 2010).

\section{E Financial fragility}

Figure E.1 shows the entire time series for the estimates for the loan value at risk as a share of aggregate household income and as a share of bank equity from 1950 to 2016.

\footnotetext{
${ }^{36}$ The elasticity of housing with respect to prices is $\frac{\partial h}{\partial p_{h}} \frac{p_{h}}{h}=\theta_{h}-1$, so $\frac{\partial\left(p_{h} h\right)}{\partial p_{h}} \frac{p_{h}}{p_{h} h}=\theta_{h}$.

${ }^{37}$ Without borrowing constraints and adjustment costs, households react immediately to a positive shock to house prices and substitute away from housing. If, however, households are borrowing constrained, then a shock that increases home equity slackens the constraint and allows them to upgrade. The idea that upgrading households use (part of) their equity gain for the down payment of a new home has been discussed, for example, in Genesove and Mayer (1997).
} 
Figure E.2 compares the amount of the value at risk from our baseline stress test scenario in Section 6 between the SCF + and PSID data. We find that the value at risk differs slightly between datasets because the income distribution also differs slightly between the SCF + and PSID data. While income and debt service are similar on average, the share of households with a debt-service-to-income ratio above 0.4 is somewhat lower in the PSID. The general patterns in the PSID data are, however, consistent with the SCF+ data.

Figure E.1: Value at risk as share of income and bank equity

(a) Aggregate (share of income)

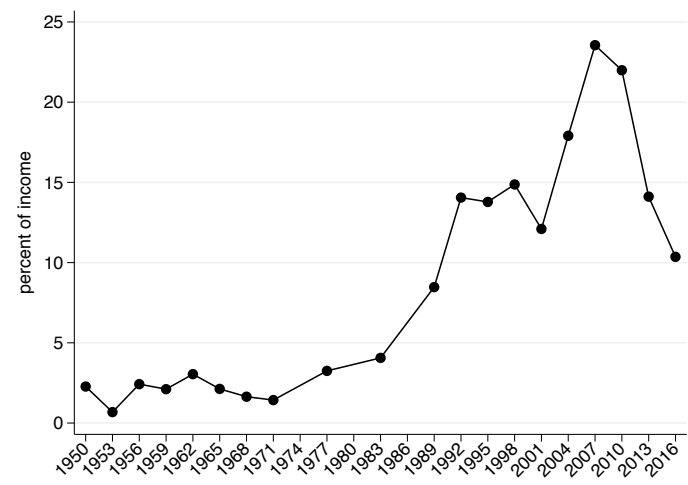

(c) Aggregate (share of bank equity)

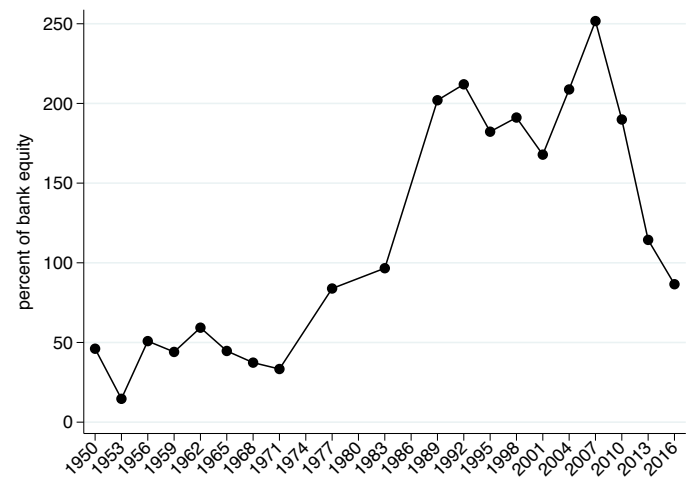

(b) By income group (share of income)

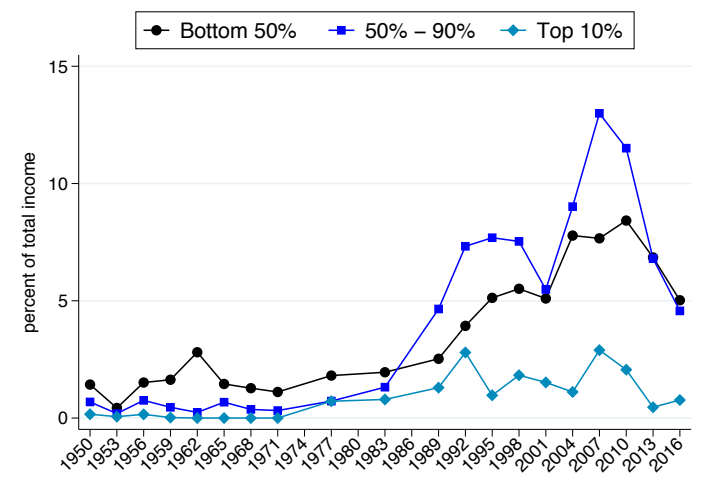

(d) By income group (share of bank equity)

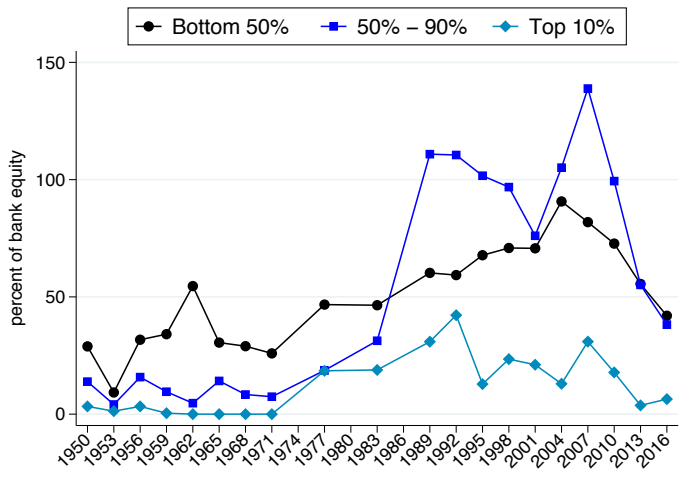

Notes: The figure shows the value at risk relative to total income and bank equity for the baseline stress test scenario. In the baseline scenario, the main earner of the household receives a $39 \%$ income shock. Households are assumed to be at risk if they have a debt-service-to-income ratio $>40 \%$. The top left panel shows the aggregate value at risk relative to aggregate household income and the top right panel stratifies the same data by income groups. The bottom left panel shows the aggregate value at risk relative to bank equity, and the bottom right panel stratifies the same data by income groups. See text for more details. The graph is based on $\mathrm{SCF}+$ data. 
Figure E.2: Value at risk relative to income by group

(a) $\mathrm{SCF}+$

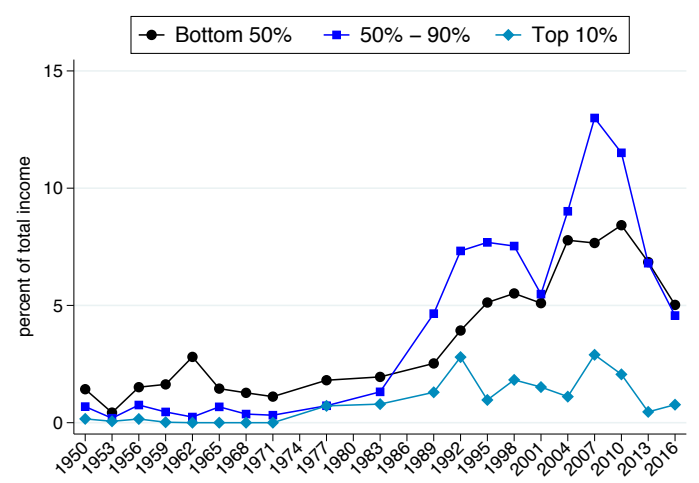

(b) PSID

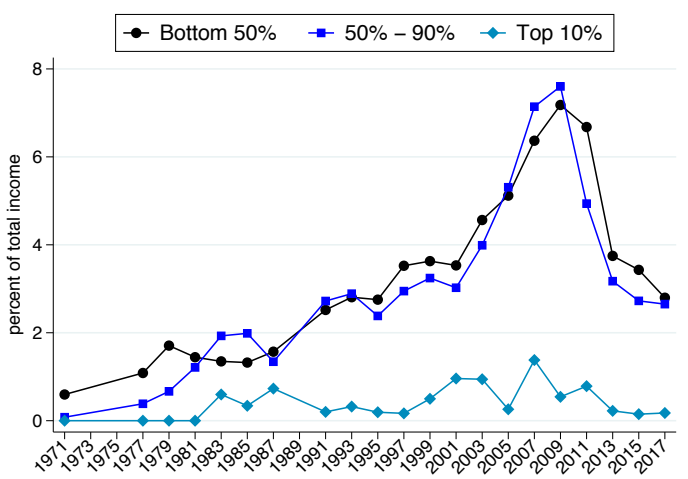

Notes: The figure shows the value at risk relative to total income in the SCF+ (left panel) and PSID (right panel) after a 39\% drop in the main earner's income. Households are assumed to be at risk if they have a debt-service-to-income ratio $>40 \%$.

Figure E.3 shows the time series for the estimates of the value at risk as a share of aggregate household income for the "double trigger" scenario. Under this scenario, the income of the main earner drops by $39 \%$, and house prices drop by $20 \%$. The $20 \%$ drop in house prices is similar to the drop in average national constant-quality house prices between 2007 and 2012. Under this scenario, we consider households to be at risk if they have negative home equity and a debt-service-to-income ratio greater than $40 \%$.

The double trigger scenario is more conservative than the baseline scenario as households have to jointly satisfy two conditions to be considered at risk. This reduces the value at risk under this scenario. However, it is important to note that financially, these households are in a much worse position than in our baseline scenario and therefore are also more likely to end in delinquency or default. This is important when thinking about the impact of the shock on the macroeconomy. We also observe under the double trigger scenario a strong secular rise in financial fragility stemming from the household sector. When scaling by aggregate income, we find an equally strong increase in the value at risk over time relative to the baseline scenario. Looking across income groups, we again find that the middle class saw the strongest increase in its value at risk. The top $10 \%$ of the income distribution hardly make any contribution to the aggregate value at risk. When we scale the value at risk by bank equity instead of aggregate household income, we corroborate the result of strongly rising financial risk from the household sector for the financial sector over time. The increase is only slightly less pronounced than in our baseline scenario. When breaking the value at risk down by income groups, we find as in the baseline case that the middle class has turned into the epicenter of financial risk for the U.S. banking sector. 
Figure E.3: Value at risk as share of income and bank equity (double trigger scenario)

(a) Aggregate (share of income)

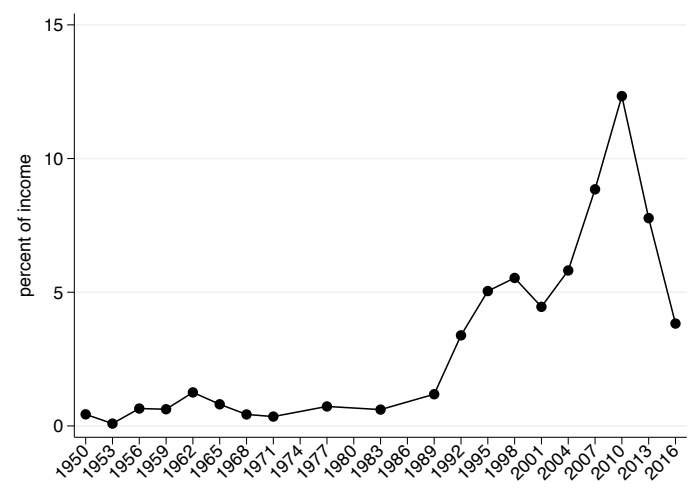

(c) Aggregate (share of bank equity)

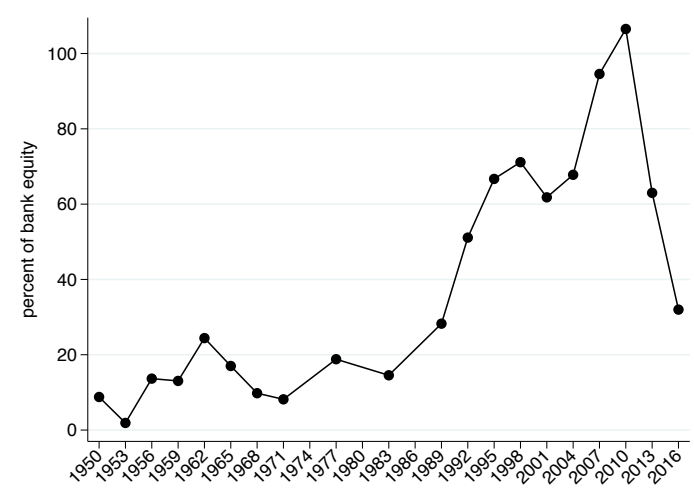

(b) By income group (share of income)

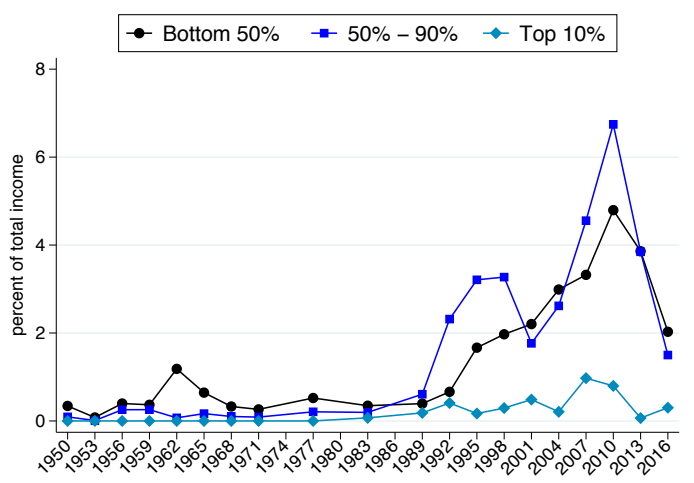

(d) By income group (share of bank equity)

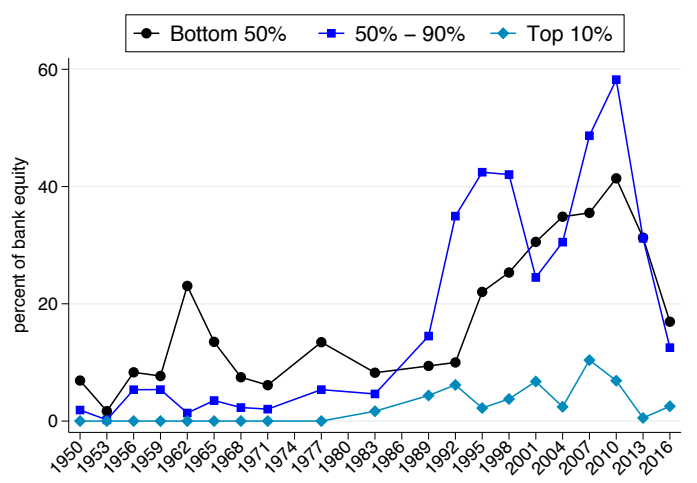

Notes: The figure shows the value at risk relative to total income and bank equity for the double trigger stress test scenario. Under this scenario, the income of the main earner drops by $39 \%$, and house prices drop by $20 \%$. Households are assumed to be at risk if they have negative home equity and a debtservice-to-income ratio $>40 \%$. The top left panel shows the aggregate value at risk relative to aggregate household income, and the top right panel stratifies the same data by income groups. The bottom left panel shows the aggregate value at risk relative to bank equity, and the bottom right panel stratifies the same data by income groups. See text for more details. The graph is based on SCF+ data. 